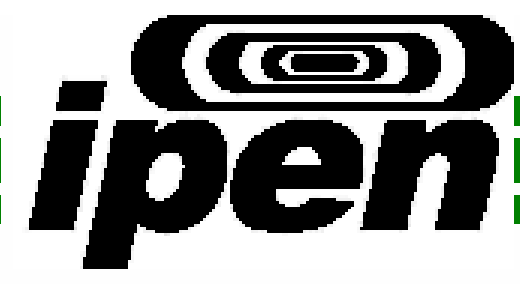

AUTARQUIA ASSOCIAD A A UIIVERSIDADE DE SÄO PAULO

\title{
IMPLANTAÇÃO DE UM PROGRAMA DE CONTROLE DE QUALIDADE EM EQUIPAMENTOS DE RAIOS X POR MEIO DE MEDIDORES NÃO INVASIVOS
}

RODRIGO FERREIRA DE LUCENA

Dissertação apresentada como parte dos requisitos para obtenção do Grau de Mestre em Ciências na Área de Tecnologia Nuclear - Aplicações.

Orientadora:

Dra. Maria da Penha Albuquerque Potiens 


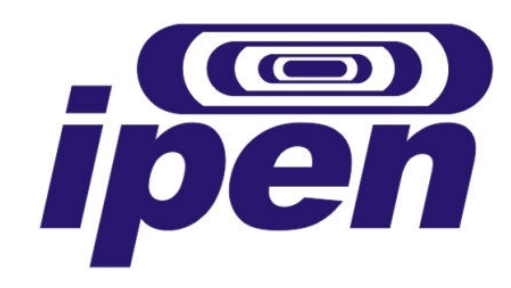

AUTARQUIA ASSOCIADA À UNIVERSIDADE DE SÃO PAULO

IMPLANTAÇÃO DE UM PROGRAMA DE CONTROLE DE QUALIDADE EM
EQUIPAMENTOS DE RAIOS X POR MEIO DE MEDIDORES NÃO INVASIVOS

Rodrigo Ferreira de Lucena

Dissertação apresentada como parte dos requisitos para obtenção do Grau de Mestre em Ciências na Área de Tecnologia Nuclear - Aplicações

Orientadora:

Profa. Dra Maria da Penha Albuquerque Potiens

São Paulo

2010 
Aos meus pais,

Manoel e Glória. 


\section{Agradecimentos}

À Dra. Maria da Penha A. Potiens pela paciência e dedicação em sua orientação e pela amizade.

Ao Dr. Vitor Vívolo pela ajuda permanente na manipulação dos equipamentos do laboratório de raios $X$, por todos os esclarecimentos técnicos e pela amizade.

Ao amigo Eduardo Correa pelas discussões que renderam vários esclarecimentos, pela ajuda na realização das medidas e pelos momentos de descontração.

À amiga Priscila Franciscatto por se mostrar solícita em esclarecer dúvidas a respeito de sua Dissertação de Mestrado, utilizada como importante referência para a realização deste trabalho.

Ao Conselho Nacional de Desenvolvimento Científico e Tecnológico (CNPq) pelo auxílio financeiro fornecido.

Ao Instituto de Pesquisas Energéticas e Nucleares (IPEN) por contribuir para a minha formação acadêmica e fornecer toda a infra-estrutura necessária para as realizações experimentais.

Aos meus pais, irmãos e demais familiares que sempre me apoiaram de diversas maneiras nesta extensa e intensa caminhada.

À minha namorada por compartilhar comigo os bons e maus momentos, pelo carinho e incentivo.

Enfim, a todos que contribuíram de maneira direta e indireta para o "processo de confecção" desta Dissertação de Mestrado. 


\title{
IMPLANTAÇÃO DE UM PROGRAMA DE CONTROLE DE QUALIDADE EM EQUIPAMENTOS DE RAIOS X POR MEIO DE MEDIDORES NÃO INVASIVOS
}

\author{
Rodrigo Ferreira de Lucena
}

\begin{abstract}
RESUMO
O objetivo desse trabalho foi estudar o comportamento do principal equipamento de raios $X$ utilizado nos procedimentos do laboratório de calibração do IPEN, LCl, operado nos intervalos de tensão de 25 a $150 \mathrm{kV}$ utilizando os medidores de tensão não invasivos Diavolt ${ }^{\mathrm{TM}}$ da PTW e do sistema de espectrometria ORTEC, modelo NOMAD-PLUS 92X para o estabelecimento de um programa de controle de qualidade. O medidor Diavolt foi utilizado para as medições de kerma no ar, tensão de pico e tensão de pico prático. As medições foram feitas variando parâmetros como, corrente elétrica, Qualidade de Radiação $X$ para Radiodiag-nóstico, angulação do medidor e sua distância em relação ao ponto focal do aparelho de raios $X$. Os resultados encontrados foram comparados com dados encontrados na literatura. Com o sistema de espectrometria, foram gerados os espectros com a finalidade de determinar as tensões de pico relativas às tensões nominais escolhidas e caracterizar as Qualidades em Radiodiagnóstico determinadas anteriormente.

O programa de controle de qualidade estabelecido possibilita o controle do funcionamento tanto dos instrumentos de medição (câmaras de ionização, medidor de tensão e corrente e espectrômetro), bem como do sistema de radiação $X$. Neste trabalho também foi sugerida a periodicidade de realização de cada um dos testes.
\end{abstract}




\title{
ESTABLISHMENT OF AN X RADIATION EQUIPMENT QUALITY CONTROL PROGRAMME USING NON INVASIVE METERS
}

\author{
Rodrigo Ferreira de Lucena
}

\begin{abstract}
The objective of this work was to study the behavior of the mainly $X$ ray equipment calibration laboratory of IPEN, operated in the range from $25 \mathrm{kV}$ to $150 \mathrm{kV}$ using a PTW non invasive meter, model Diavolt ${ }^{\mathrm{TM}}$, and an ORTEC spectrometry system, model NOMAD-PLUS 92X, for the establishment of a quality control programme. The Diavolt meter was used for measurements of air kerma, peak voltage and practical peak voltage. The measurements were made varying parameters such as electrical current, $\mathrm{X}$ radiation quality for radiation diagnostic, angulations of the meter and its distance in relation to the focal spot of the $X$ ray tube. The results were compared with data found in the literature. Several spectra were generated with the spectrometer system with the purpose of determine the peak voltage in function of the nominal voltage and to characterize the radiation qualities for radiation diagnostic previously determined.

The established quality control programme enables the management of the appropriate functioning of the measurement instruments (ionization chambers, voltage and current meter and spectrometer) as well as of the $\mathrm{X}$ radiation system. This work also has proposed a time interval to run each one of the tests.
\end{abstract}




\section{SUMÁRIO}

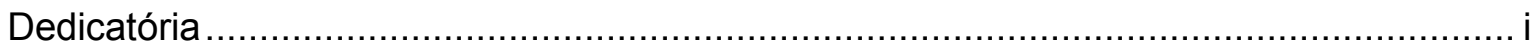

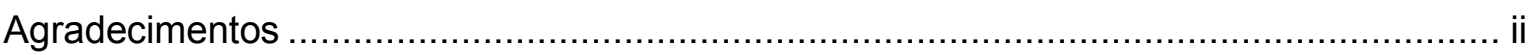

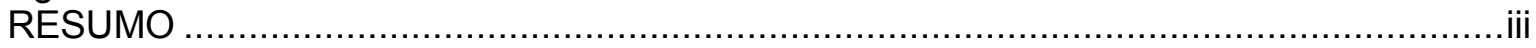

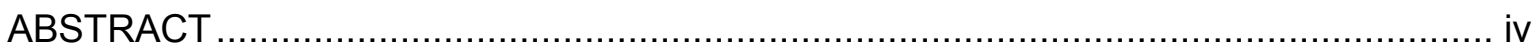

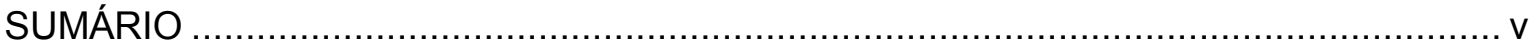

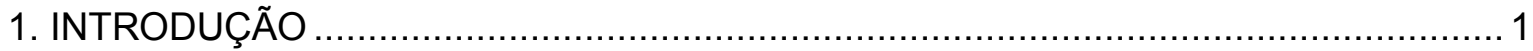

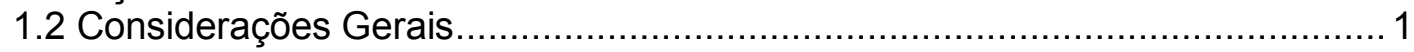

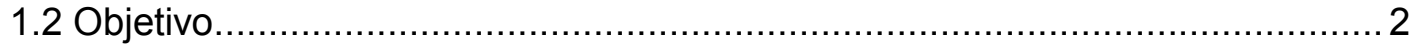

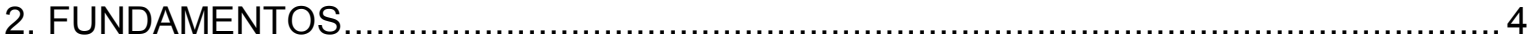

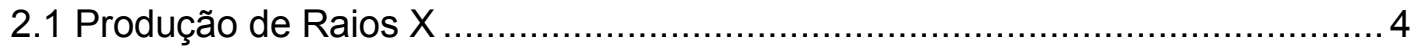

2.1.1 Radiação Característica.......................................................... 4

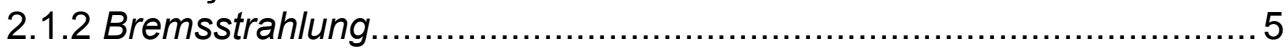

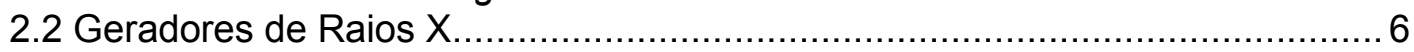

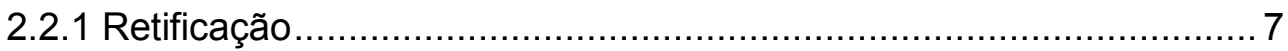

2.2.2 Geradores Monofásicos ........................................................ 8

2.2.3 Geradores Trifásicos .......................................................... 9

2.2.4 Geradores de Potencial Constante .......................................... 10

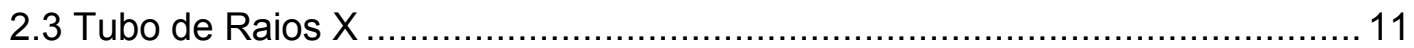

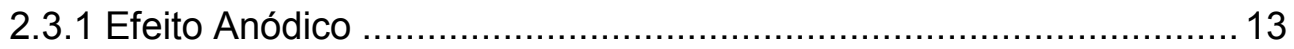

2.3.2 Filtração Inerente............................................................... 14

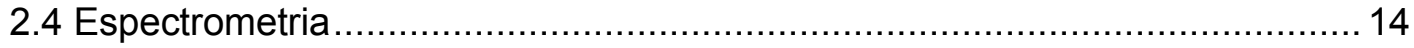

2.4.1 Fatores que Influenciam o Espectro de Raios X ......................... 15

2.4.1.1 Corrente Elétrica (mA) ............................................... 16

2.4.1.2 Distância entre Detetor e Fonte de Raios X..................... 16

2.4.1.3 Tensão Aplicada ao Tubo................................................ 17

2.4.1.4 Filtração Adicional ..................................................... 17

2.4.1.5 Material Alvo....................................................... 19

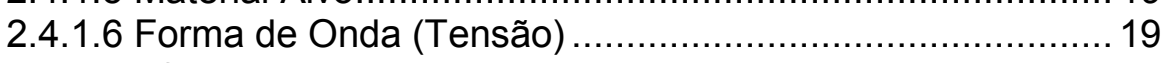

2.4.1.7 Efeito Borda K (K-edge) ............................................ 20

2.5 Detetores de Radiação ................................................................... 23

2.5.1 Câmaras de lonização........................................................... 23

2.5.1.1 Câmara de Ionização Cilíndrica (Tipo Dedal) .................... 24

2.5.2 Semicondutores.................................................................... 25

2.5.2.1 Detetor Semicondutor............................................ 27

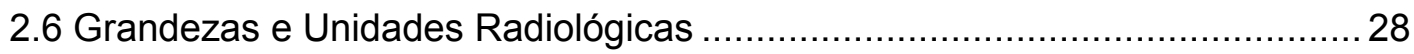

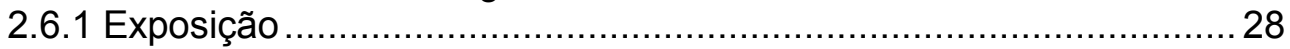

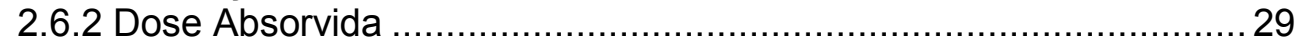

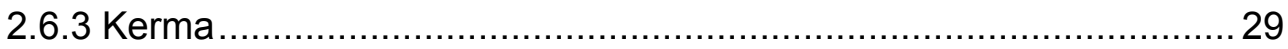

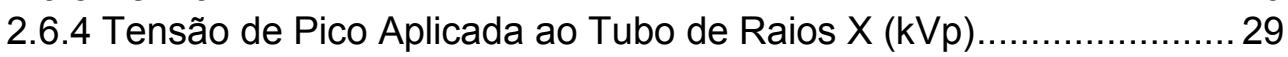

2.6.5 Tensão de Pico Prático (PPV) ................................................. 30

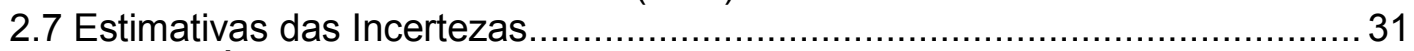

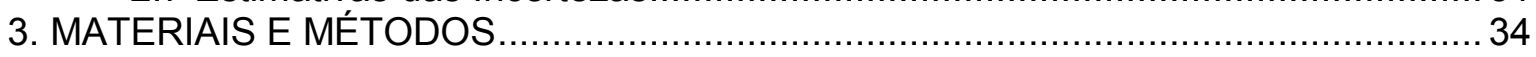

3.1 Instalação

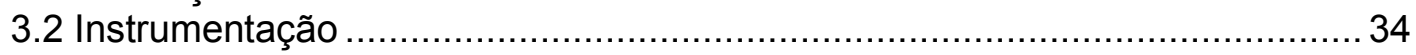

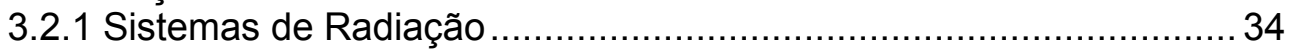

3.2.2 Detetores de Radiação ............................................................ 35

3.2.2.1 Câmara de Ionização Cilíndrica do Tipo Dedal e

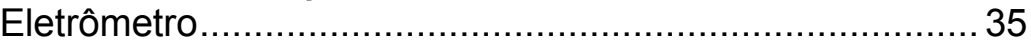

3.2.2.2 Medidor não Invasivo Diavolt Universal ............................. 37

3.2.2.3 Sistema de Espectrometria.............................................. 38

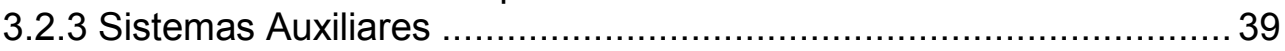

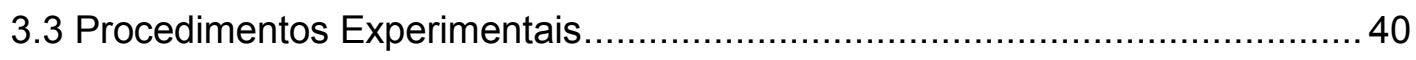


3.3.1 Testes Realizados Com a Câmara de Ionização do Tipo Dedal ......41

3.3.1.1 Teste de Repetibilidade, Estabilidade a Longo Prazo e de Fuga Corrente

3.3.1.2 Teste de Homogeneidade do Campo de Radiação ............43 43

3.3.2 Medidas Com o Medidor de Tensão não Invasivo Diavolt................ 44

3.3.2.1 Corrente Elétrica ...................................................... 45

3.3.2.2 Qualidades de Radiação para Radiodiagnóstico ...............46 46

3.3.2.3 Distância ............................................................... 46

3.3.2.4 Variação Angular .......................................................... 46

3.3.3 Sistema de Espectrometria ................................................. 47

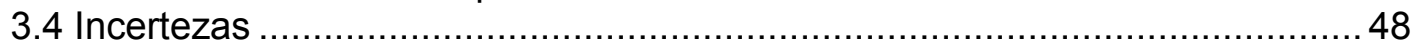

3.5 Critérios Para o Uso da Grandeza PPV (Norma IEC 61676, 2002) ................50

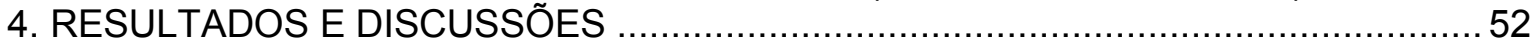

4.1 Homogeneidade do Campo de Radiação X ............................................ 52

4.1.1 Testes de Estabilidade da Câmara de Ionização .............................52

4.1.2 Teste de Homogeneidade do Campo de Radiação.......................... 52

4.2 Medidor não invasivo Diavolt ................................................................. 55

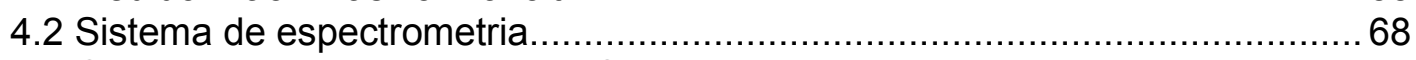

4.4 Comparação entre os Valores Obtidos para a Tensão de Pico (Diavolt e

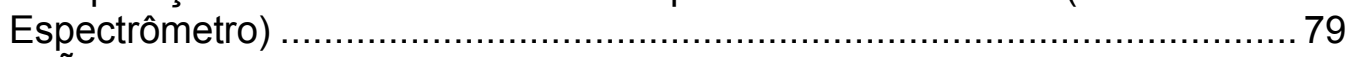

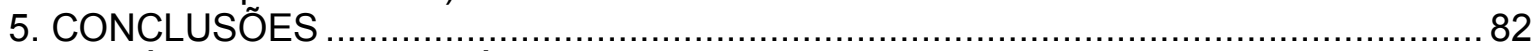

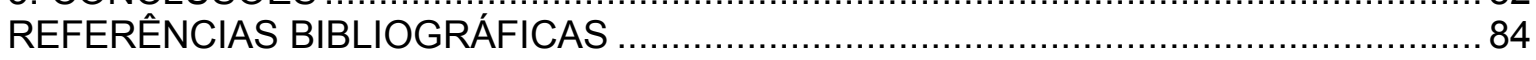

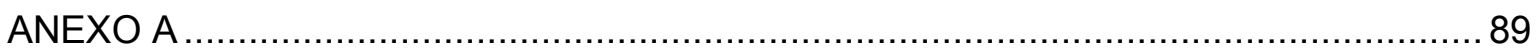

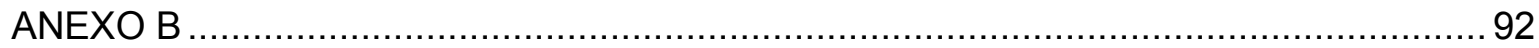

ANEXO C

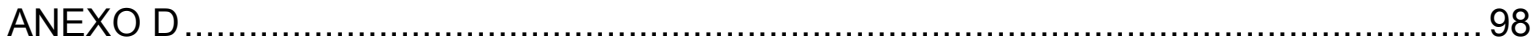




\section{INTRODUÇÃO}

\subsection{Considerações Gerais}

As atividades relacionadas à utilização de radiação ionizante são baseadas em três princípios essenciais de proteção radiológica: justificação apropriada à utilização da radiação, limites de dose, onde os riscos decorrentes da exposição à radiação são considerados aceitáveis e otimização dos níveis de radiação sempre que for possível (ICRP, 1987, 1991). Esses princípios devem ser respeitados, já que toda exposição a qualquer radiação ionizante pode provocar danos à saúde do ser humano por meio dos efeitos biológicos provocados por essa radiação. Esses efeitos podem ser classificados como estocásticos e determinísticos, onde no primeiro o efeito é probabilístico, ou seja, a probabilidade do evento ocorrer aumenta com o aumento da dose e no segundo o efeito ocorre a partir de um limiar de dose, onde a gravidade do efeito aumenta com o aumento da dose.

A otimização dos níveis de radiação estimulou o estudo mais aprofundado das características dos feixes de radiação a serem utilizados em clínicas de radioterapia, radiodiagnóstico e em laboratórios de calibração de detetores de radiação. Isso fez com que, com o passar do tempo, a precisão e exatidão fossem melhoradas para a determinação de doses, ou seja, passou a existir uma tendência em se enfatizar a necessidade por uma alta precisão e exatidão.

Visando impedir exposições desnecessárias às radiações, algumas instituições vêm publicando, ao longo dos anos, diversos documentos com recomendações e procedimentos para o uso adequado de fontes de radiação. A International Atomic Energy Agency (1979, 1987, 1992, 1994, 1997, 2000) publica freqüentemente diversas recomendações e procedimentos que envolvem tanto a calibração de feixes de radiação e de instrumentos detetores de radiação como a determinação de grandezas de referência. Foram também publicadas recomendações sobre a calibração de instrumentos com radiação eletromagnética, pela International Organization for Standardization (1997), mostrando a preocupação atual com os efeitos da radiação e seus danos ao ser 
humano e ao meio ambiente. Recentemente, o Center for Devices and Radiological Health (2010) elaborou um documento com o intuito de eliminar a exposição de radiação desnecessária na formação de imagens médicas com o objetivo de reduzir a exposição no paciente.

No Brasil, a Anvisa (Agência Nacional de Vigilância Sanitária) publicou a portaria número 453 (Ministério da Saúde, 1998), uma componente básica da política nacional de proteção radiológica e segurança na área de radiodiagnóstico, onde o objetivo é reduzir, em escala nacional, os riscos e maximizar os benefícios na utilização dos raios $X$ diagnósticos. Este documento estabelece requisitos básicos de proteção radiológica para os serviços de radiodiagnóstico, incluindo todos os testes de controle de qualidade e sua periodicidade.

Ainda na área de radiação $X$, vários trabalhos foram desenvolvidos visando um controle de qualidade dos equipamentos envolvidos na emissão e medição deste tipo de radiação. Potiens (1999), Ros (2000), Betti (2007), Ramos (2009), dentre outros (Costa, 2003; Oliveira, 2005; Vivolo, 2006), focaram seus trabalhos no controle de qualidade dos sistemas e equipamentos de Laboratórios de Calibração e Dosimetria. Esses trabalhos são de grande importância, já que esses laboratórios atendem um grande número de instituições externas. No IPEN, por exemplo, no ano de 2009 foram calibrados, em feixes de radiação $X$, gama, beta e alfa, cerca de 1500 aparelhos medidores de radiação. Dessa maneira, esses laboratórios possuem grande responsabilidade no uso final desses medidores calibrados e a otimização dos processos de calibração se faz necessária para o uso devido da radiação nas diversas instituições externas habilitadas pelas autoridades governamentais de seus países.

\subsection{Objetivo}

O objetivo do presente trabalho é o estabelecimento e a implantação de um programa de controle da qualidade para os equipamentos de radiação $X$ do Laboratório de Calibração de Instrumentos do IPEN, que são utilizados tanto para atividades de calibração como para o desenvolvimento de projetos de pesquisa. Estes equipamentos devem ser mantidos em condições adequadas de funcionamento para se garantir a qualidade metrológica do serviço de calibração e para implementar uma metodologia de verificação periódica dos parâmetros que 
podem influenciar os feixes de raios X. Para esse controle de qualidade, foram utilizados essencialmente três detetores de radiação (medidor de tensão não invasivo Diavolt, câmara de ionização do tipo cilíndrica e um sistema de espectrometria). 


\section{FUNDAMENTOS}

\subsection{Produção de Raios X}

Os raios $\mathrm{X}$ são ondas eletromagnéticas compreendidas no intervalo energético entre $10^{3}$ e $10^{5} \mathrm{eV}$ e sua produção se dá pelo bombardeamento de elétrons livres a grandes velocidades em um determinado material alvo (Johns, 1974).

Durante o bombardeamento, os elétrons interagem com o material alvo transformando sua energia cinética em outras formas de energia, como em calor e em fótons de raios $X$. A interação dos elétrons com o material alvo possibilita a geração de raios $X$ a partir dos processos de transição eletrônica (Radiação característica) e de freamento dos elétrons (Bremsstrahlung).

\subsubsection{Radiação Característica}

A radiação característica no intervalo de frequência dos raios $X$ é produzida na eletrosfera de um átomo quando um de seus elétrons transita de um estado mais energético para um estado menos energético liberando a energia excedente em forma de um fóton na frequência dos raios $X$. Essa geração pode ocorrer a partir de choques entre elétrons livres e orbitais, onde os elétrons livres incidentes devem possuir energia maior que a energia de ligação dos elétrons orbitais fazendo com que esses se ejetem de seus respectivos átomos deixando vacâncias nas camadas em que esses elétrons se encontravam inicialmente. Essas vacâncias são preenchidas por elétrons que estão nas camadas mais energéticas e durante a transição dos elétrons entre as camadas são liberados fótons com energia característica dessas transições (FIG. 1). 


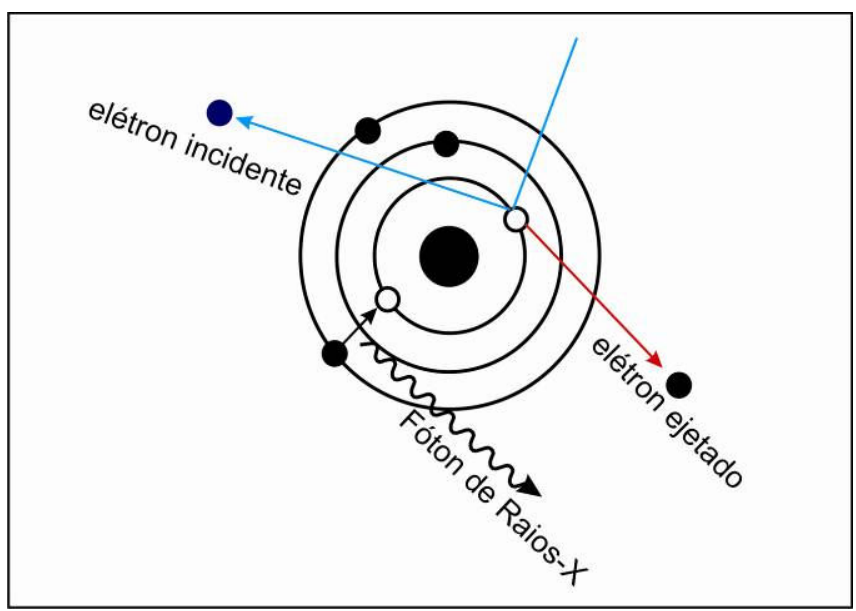

FIGURA 1 - Esquematização do processo de produção de raios X por meio da radiação característica.

Em um determinado material alvo, o processo de transição dos elétrons pode ocorrer entre diversas camadas orbitais gerando uma série de energias características de um mesmo elemento (Johns, 1974). Essas energias podem ser identificadas em um espectro de raios $X$ através de picos de contagens nas referentes energias características $\left(\mathrm{k}_{\alpha}, \mathrm{k}_{\beta}, ..\right)$ que são associadas diretamente ao elemento que as originaram.

\subsubsection{Bremsstrahlung}

Um elétron em repouso submetido a uma diferença de potencial (ddp) tende a aumentar sua velocidade e consequentemente sua energia cinética até que agentes externos influenciem em seu movimento. Se o elétron é totalmente barrado por um obstáculo (material alvo), ele perde toda sua energia cinética que se transforma em outros tipos de energia, como em calor ou em um fóton de raios X. Quanto maior a ddp aplicada, maior será a energia cinética do elétron e, consequentemente, maior será a energia do fóton de raios $X$ gerado. Contudo, nem todos os elétrons incidentes em um determinado material alvo são totalmente barrados por esse material, onde as desacelerações dos elétrons se converterão em feixes de raios $X$ com energias distintas. Portanto, a energia do feixe de raios $X$ variará entre os fótons menos energéticos derivados dos elétrons que perderam o mínimo possível de energia cinética durante o processo de freamento e os fótons mais energéticos relativos aos elétrons que foram totalmente barrados 
durante o processo de freamento. Dessa forma, o feixe de raios $\mathrm{X}$ apresentará um espectro contínuo entre a energia mínima e a energia máxima de seus fótons sendo facilmente observados através de um espectro de raios $X$ (FIG. 2).

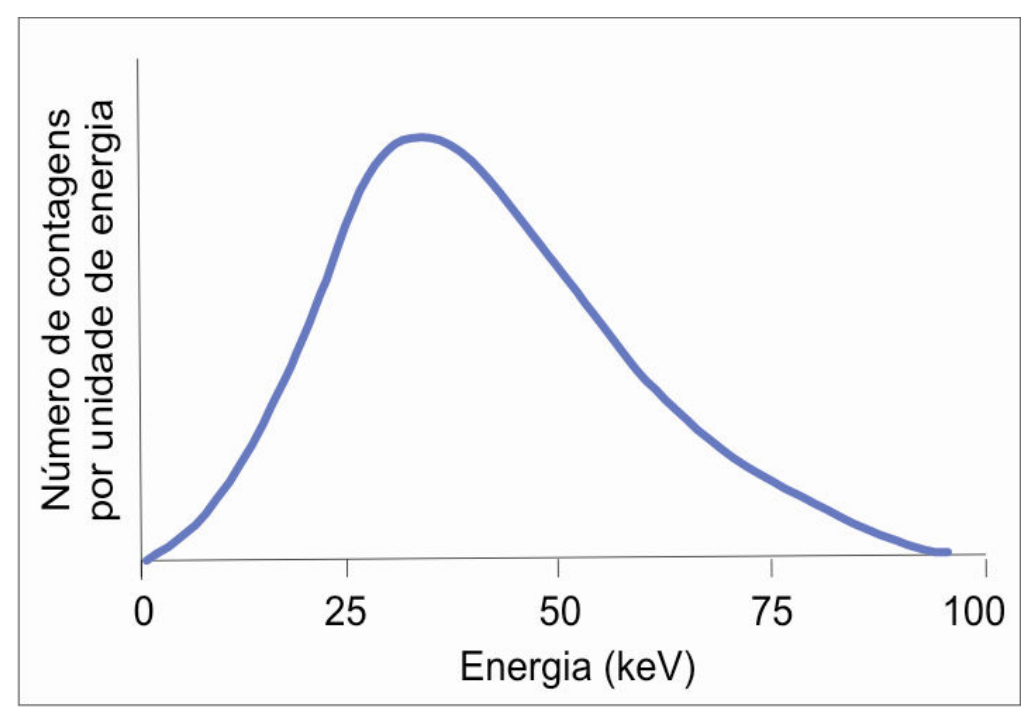

FIGURA 2 - Espectro hipotético referente a produção de raios $X$ apenas por freamento.

\subsection{Geradores de Raios X}

Os geradores de raios $X$ são dispositivos que tem por finalidade produzir raios $X$ por meio de transformações energéticas. A energia inicial do sistema advém da rede elétrica por onde os processos de transformação energética resultarão, em menor proporção, em radiação $\mathrm{X}$ e, em maior proporção, em calor, que provocará um aquecimento de todo o equipamento.

Um gerador é constituído essencialmente por um gerador de energia elétrica que faz o papel de fonte energética e de um tubo de raios $X$ que produzirá, de fato, a radiação $X$. Além disso, os geradores possuem painéis com comando eletro-eletrônico possibilitando configurar alguns parâmetros, como tensão nominal, corrente elétrica e tempo de exposição que alteram o resultado final das medições efetuadas.

Os elétrons acelerados no tubo de raios $X$ são resultados de uma alta tensão aplicada ao tubo. Como, geralmente, a rede elétrica que abastece o gerador de raios $X$ é de baixa tensão há a necessidade de um transformador de 
tensão no equipamento que transformará a baixa tensão da rede elétrica em uma alta tensão a ser aplicada ao tubo.

\subsubsection{Retificação}

Os transformadores de tensão presentes nos geradores de raios $X$ fornecem em sua saída uma alta tensão alternada com respectiva corrente elétrica alternada (FIG. 3). Essa variação da tensão provoca inversões da corrente elétrica com o decorrer do tempo, ou seja, se essa tensão fosse aplicada ao tubo de raios $X$, em um instante os elétrons seriam acelerados no sentido do alvo produzindo raios $X$ e em um outro instante seriam acelerados no sentido do catodo podendo danificar o filamento ali presente (Wolbarst, 1993).

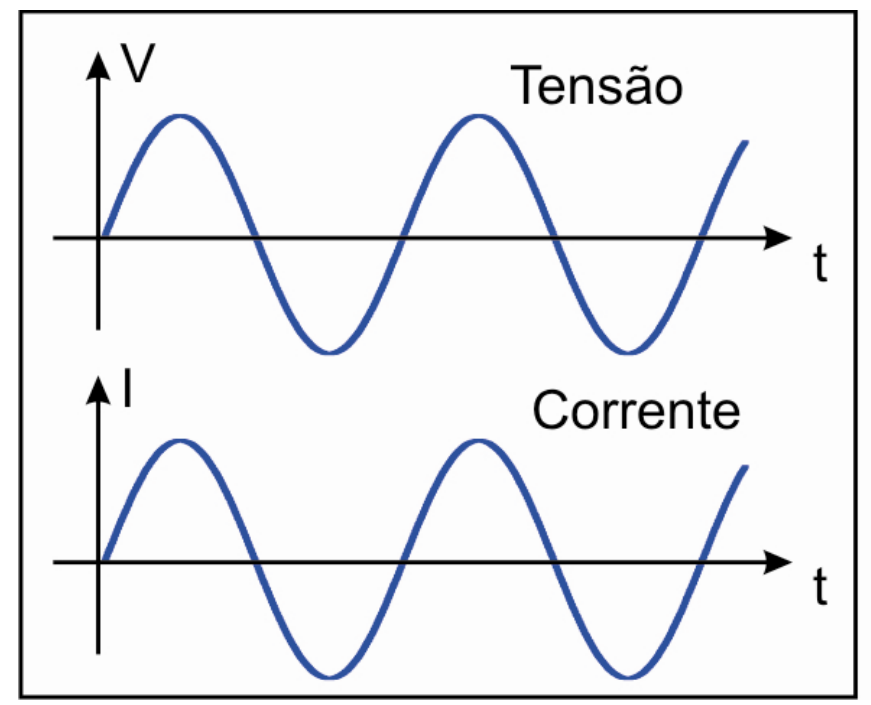

FIGURA 3 - Exemplo de tensão e corrente elétrica alternadas (monofásicas) na saída de um transformador.

Para evitar os efeitos provocados pelas inversões nos sentidos das trajetórias dos elétrons dentro do tubo de raios $X$, são utilizados retificadores (de diodo a gás ou de estado sólido) que possuem a finalidade de "permitir" o fluxo de elétrons em apenas um sentido. Quando utilizado um sistema de um elemento retificador tem-se um circuito de retificação de meia-onda (FIG. 4a), onde a corrente elétrica é zero na metade do período da onda. Já nos sistemas de quatro elementos retificadores tem-se os circuitos de retificação de onda completa (FIG. $4 b)$, onde a corrente elétrica é zero apenas nos pontos referentes a cada meio 
período de onda (Sprawls, 1990). Dessa forma, os circuitos de retificação de onda completa são mais eficientes que os de meia onda.

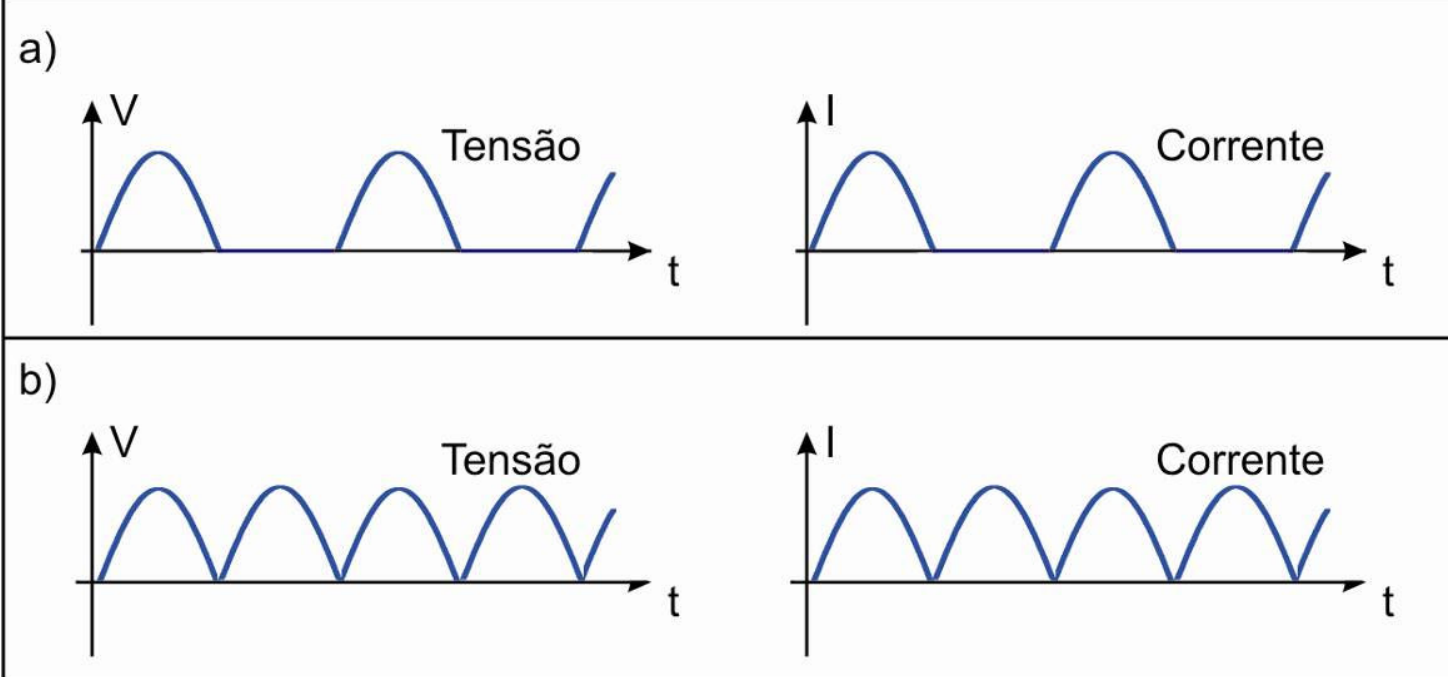

FIGURA 4 - Exemplos de a) retificação de meia-onda e b) retificação de onda completa para as correntes elétricas.

\subsubsection{Geradores Monofásicos}

Os geradores monofásicos são os geradores que possuem na saída de seu transformador de tensão uma forma de onda monofásica (FIG. 3). Essa forma de onda quando passa pelo retificador apresenta o comportamento observado na FIG. 4a (retificação de meia-onda) ou na FIG. 4b (retificação de onda completa), dependendo do gerador.

O valor nominal escolhido no painel de um gerador monofásico corresponde ao valor máximo atingido pela tensão em sua variação periódica que é denominado tensão de pico $(k \bigvee p)$. Para se ter uma idéia mais geral da tensão aplicada ao tubo, utiliza-se a grandeza tensão efetiva $\left(V_{e}\right)$ que é a tensão que fornece o mesmo contraste de imagem entre um gerador de tensão variável e um gerador de potencial constante. No caso de um gerador monofásico com retificação de onda completa, a tensão efetiva equivale a $70,7 \%$ do valor da tensão de pico (FIG. 5). 


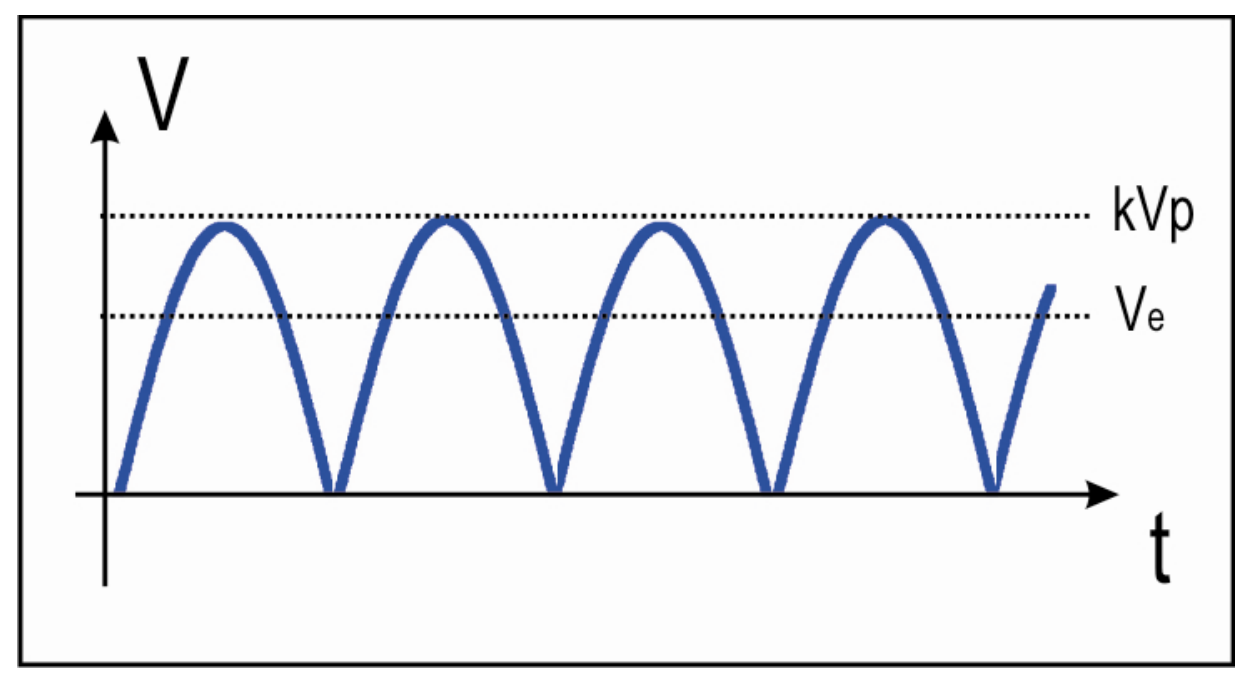

FIGURA 5 - Tensões efetiva e de pico em um gerador monofásico com retificação de onda completa.

Em um gerador monofásico, a tensão aplicada ao tubo de raios $\mathrm{X}$ varia com o tempo provocando acelerações distintas no fluxo de elétrons no interior do tubo, o que acaba interferindo na eficiência da produção de raios $X$ (Hendee, et al., 2002), já que a mesma diminui quando a tensão se aproxima de zero.

\subsubsection{Geradores Trifásicos}

Assim como nos geradores monofásicos, os geradores trifásicos apresentam uma tensão variável com o tempo na saída de seu transformador, porém com uma forma de onda diferenciada denominada trifásica (Hendee, et al., 2002). Essa forma de onda é derivada de um sistema de 3 circuitos monofásicos com $120^{\circ}$ de defasagem que faz com que haja o triplo de picos da forma de onda monofásica por período (FIG. 6). 


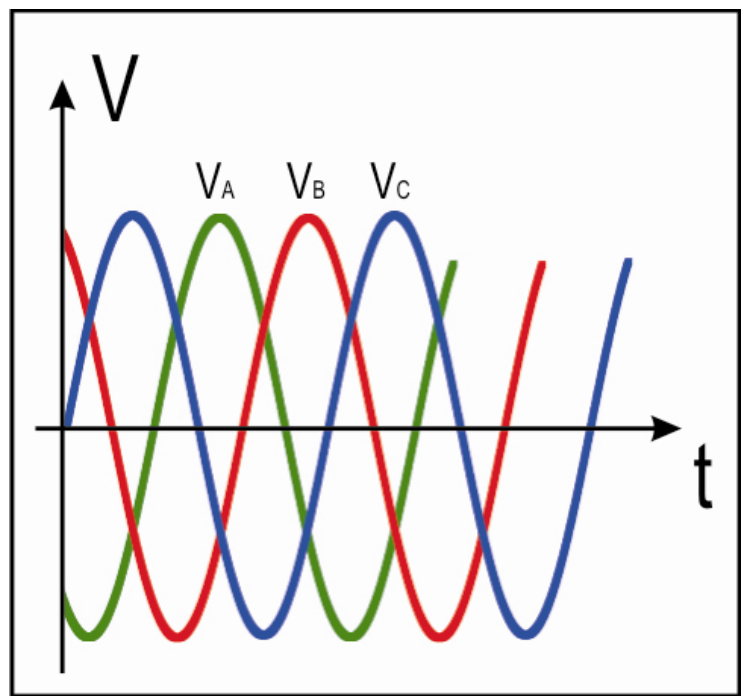

FIGURA 6 - Tensão alternada trifásica derivada de 3 circuitos monofásicos $\left(V_{A}\right.$, $V_{B}$ e $V_{C}$ ) com $120^{\circ}$ de defasagem.

$\mathrm{Na}$ forma de onda trifásica, o intervalo de variação da tensão (ripple) diminui, em relação à monofásica, devido a presença das 3 ondas defasadas em $120^{\circ}$. Isso faz com que a tensão esteja sempre próxima da tensão de pico elevando, assim, a tensão efetiva que se aproxima da tensão de pico, havendo uma maior eficiência energética na produção de raios X (Hendee, et al., 2002).

\subsubsection{Geradores de Potencial Constante}

Nos geradores de potencial constante, a tensão aplicada ao tubo de raios $\mathrm{X}$ não varia com o tempo, logo a tensão de pico e a tensão efetiva são a própria tensão constante no decorrer do tempo (FIG. 7).

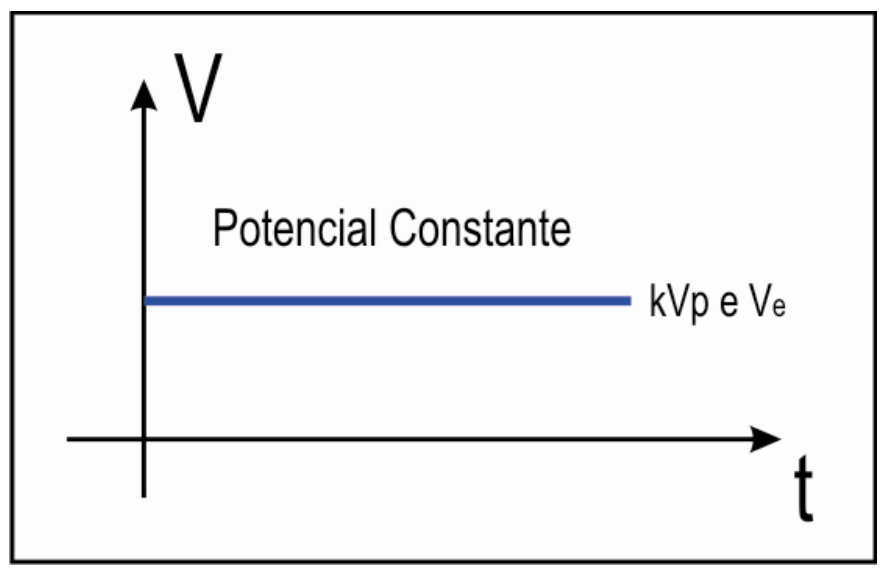

FIGURA 7 - Tensões efetiva e de Pico em um gerador de potencial constante. 
Nesse tipo de gerador, a eficiência energética é maior do que nos monofásicos e trifásicos, já que nele é muito pequena a oscilação da tensão e, portanto, a tensão de pico é praticamente igual a tensão efetiva. Além disso, o fluxo de elétrons no tubo de raios $X$ dos geradores de potencial constante é aproximadamente constante, o que permite a produção de um número maior de fótons de raios $\mathrm{X}$ em um menor intervalo de tempo quando comparado aos geradores monofásicos e trifásicos (Ros, 2000).

\subsection{Tubo de Raios X}

O tubo de raios $X$ é o componente essencial do aparelho de raios $X$, onde ocorre a conversão da energia cinética dos elétrons em fótons de raios $X$. Ele é constituído basicamente de uma ampola de vidro selada com vácuo em seu interior juntamente com dois eletrodos, o catodo e o anodo. No catodo encontrase um filamento constituído de tungstênio que quando aquecido devido ao estabelecimento de uma corrente elétrica forma uma nuvem de elétrons ao seu redor (emissão termoiônica). Esses elétrons são acelerados através de uma tensão ou ddp aplicada ao tubo e são incididos no anodo, onde serão observados os fenômenos de Bremsstrahlung e de radiação característica, ou seja, produção de raios $\mathrm{X}$, cujos fótons sairão do tubo por uma área da ampola denominada janela (um dos componentes responsáveis pela filtração inerente no aparelho de raios $\mathrm{X}$ ). No entanto somente $1 \%$ da energia inicial dos elétrons é convertida em raios X, o restante da energia (99\%) é "perdida" em forma de calor (Curry III et al., 1990). A FIG. 8 mostra, em detalhes, os principais componentes de um tubo de raios $\mathrm{X}$ com anodo giratório. 


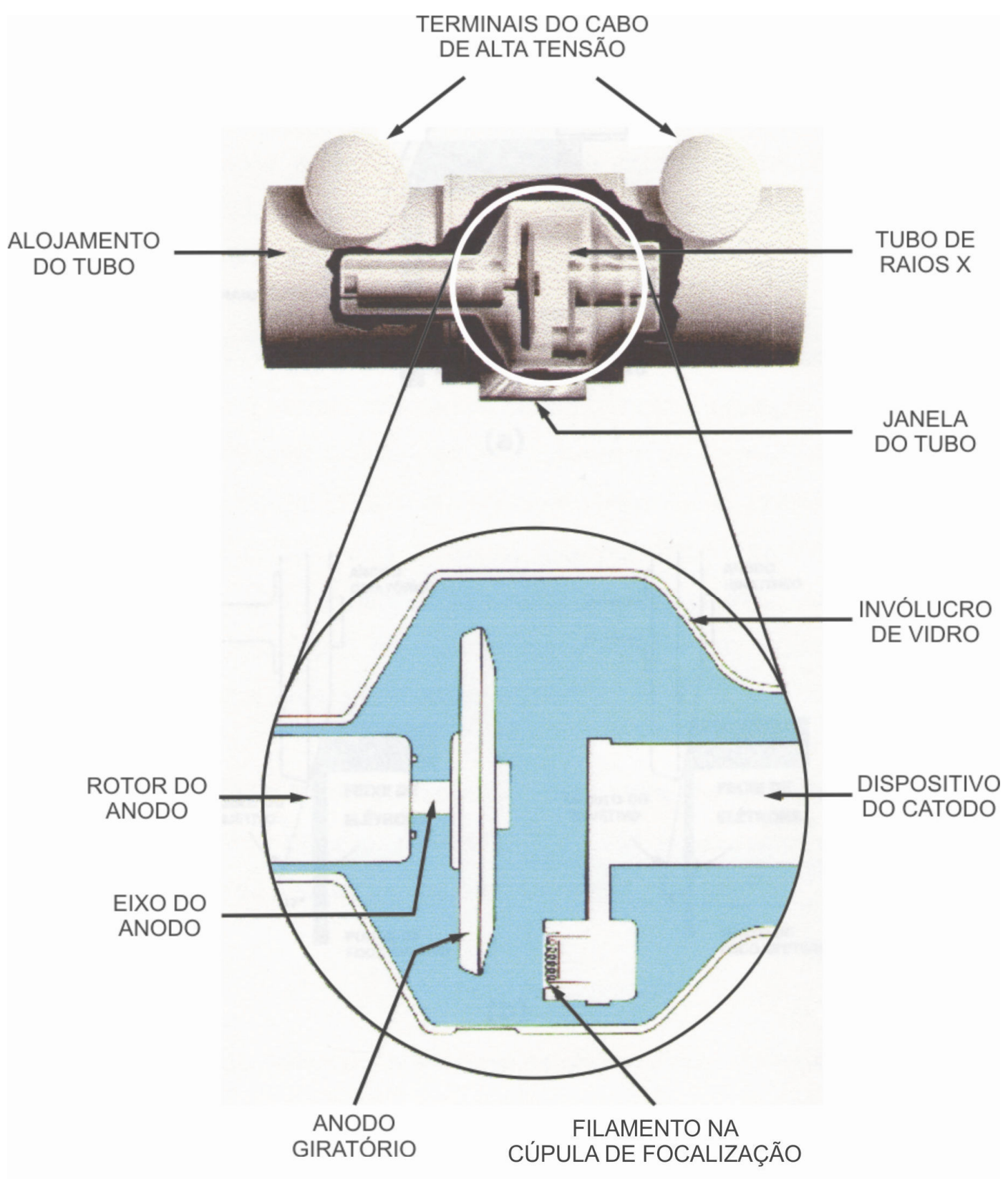

FIGURA 8 - Tubo de raios X de anodo giratório (Kodak, 1980).

Devido ao grande aquecimento provocado pelo feixe de elétrons incidente em uma determinada área do alvo do anodo (ponto focal) é comum encontrarmos nos tubos de raios $X$ anodos giratórios, onde o calor gerado pelos elétrons é distribuído por uma área maior do alvo diminuindo o aquecimento nos pontos focais, aumentando, dessa maneira, a eficiência do aparelho, o que não ocorre com os anodos estacionários que sofrem um bombardeio constante de elétrons em uma mesma área provocando um aquecimento maior da região. 
O alvo no anodo possui uma leve inclinação entre 6 e $20^{\circ}$ em relação ao plano perpendicular do feixe incidente dos elétrons. De acordo com essas inclinações, o feixe de raios $X$ é direcionado para a janela do tubo com tamanhos aparentes distintos do ponto de foco efetivo (Curry III et al., 1990). Na FIG. 9 são mostrados 2 exemplos de inclinação do anodo e seus respectivos efeitos nos pontos de foco efetivo.
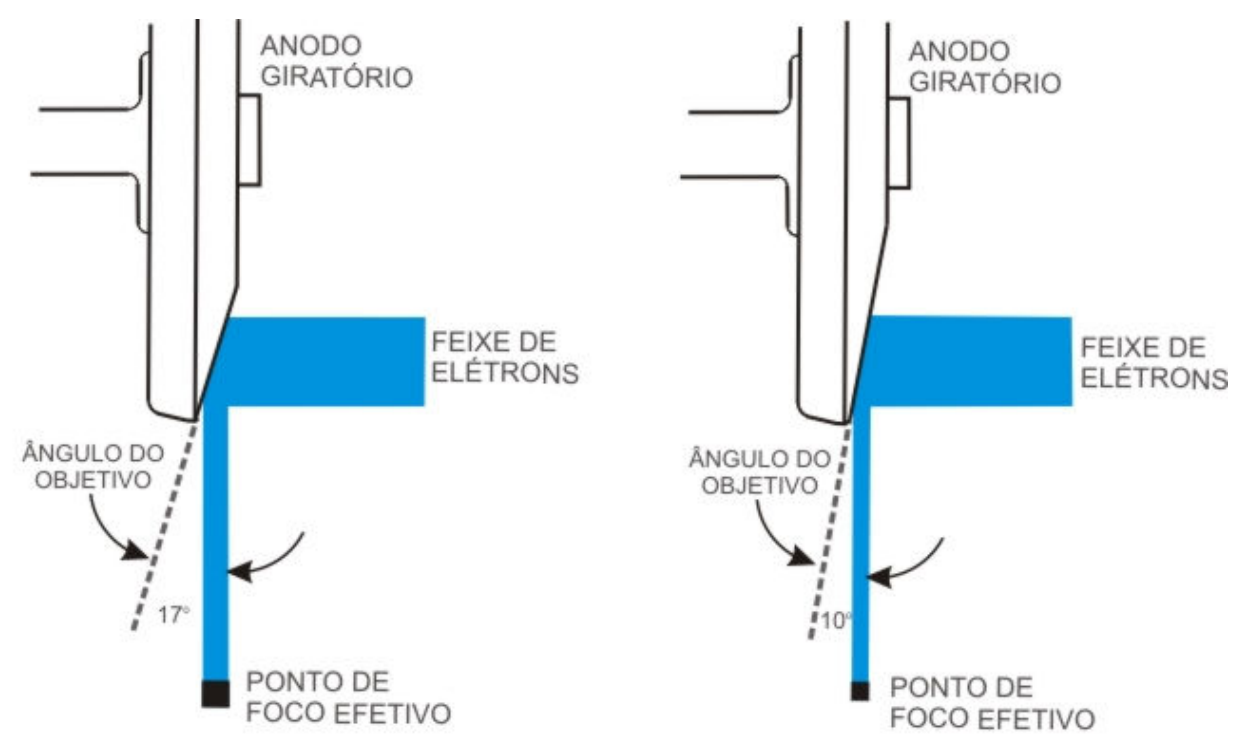

FIGURA 9 - Efeito do ângulo do alvo no foco projetado. Adaptado de Kodak (1980).

\subsubsection{Efeito Anódico}

Os elétrons incidentes no interior do tubo de raios $X$ atingem o material alvo presente no anodo em diversas profundidades gerando um feixe de raios $\mathrm{X}$ em forma de cone que atravessará todo o material alvo e sairá pela janela do tubo de raios $X$. Devido à inclinação do alvo, parte dos fótons de raios $X$ terá que percorrer um caminho maior dentro do material alvo para sair pela janela (FIG. 10), isso fará com que esses fótons sejam atenuados dentro de uma direção preferencial que sempre será o lado do anodo (Bushong, 1997). Portanto na saída da janela do tubo de raios $X$ tem-se um feixe assimétrico, onde um lado é mais intenso (catodo) que o outro (anodo). A esse fenômeno dá-se o nome de Efeito Anódico. 


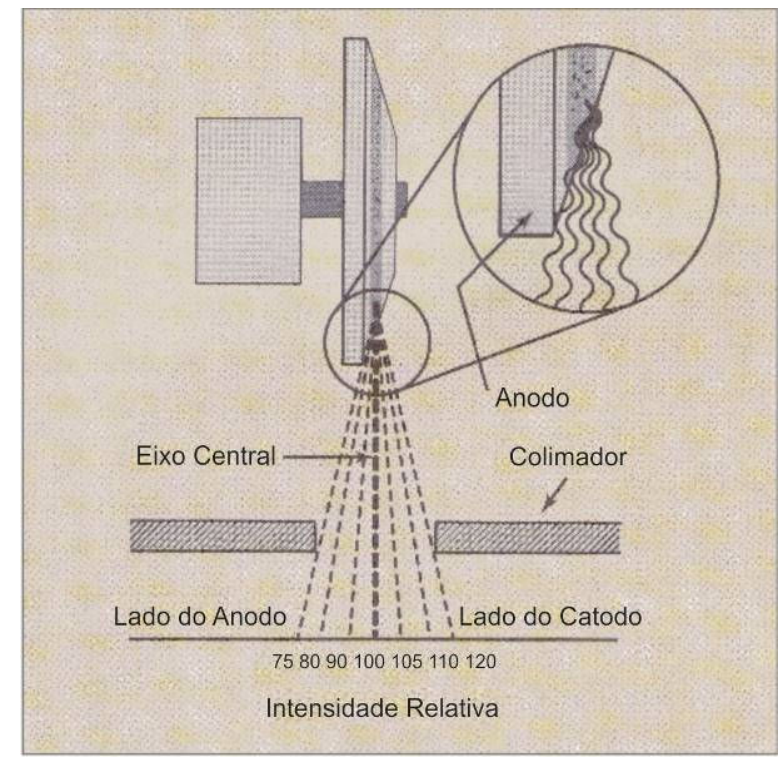

FIGURA 10 - Esquematização do fenômeno Efeito Anódico (Bushong, 1997).

O efeito anódico pode ser corrigido por meio da rotação do tubo de raios $X$ em um sentido de modo que o lado do catodo seja afastado e o lado do anodo seja aproximado do medidor de radiação ou do paciente exposto à radiação.

\subsubsection{Filtração Inerente}

A filtração inerente é a filtração intrínseca do sistema de radiação $X$, ou seja, não pode ser removida para a realização das medições. Ela é composta pela janela do tubo de raios $\mathrm{X}$, o óleo que refrigera todo o sistema de radiação $\mathrm{e}$ uma placa de Berílio posicionada de modo a possibilitar o freamento dos elétrons secundários. O Berílio é escolhido por apresentar baixo número atômico $(Z=4)$ e dessa forma, interferir o mínimo possível no feixe de raios $X$, já que possui baixa densidade. Pelo mesmo motivo, a janela do tubo de raios $\mathrm{X}$, confeccionada de vidro, possui pequenas espessuras, no geral, de cerca de décimos de mm (Johns, 1974).

\subsection{Espectrometria}

O conhecimento do espectro de raios $\mathrm{X}$ é de grande importância para entender os vários estágios na produção de uma imagem diagnóstica com o intuito de reduzir ao máximo a dose no paciente e ao mesmo tempo otimizar a 
qualidade de imagem (Birch et al., 1979). Os espectros de raios $X$ são obtidos a partir de dispositivos que possibilitam não só a contagem de fótons de raios $X$ no volume sensível, mas também o registro e a distinção da energia desses fótons. A disponibilização da energia dos fótons em função do número de contagens resulta no espectro de raios $X$. Esse espectro é essencialmente dividido em uma curva contínua, resultado dos fótons gerados por freamento, com picos no decorrer da curva, resultado dos fótons gerados por radiação característica (FIG. 11). Além disso, o espectro de raios $X$, na prática, é "contaminado" pela radiação de fundo presente no ambiente e de possíveis retroespalhamentos provocados pela geometria do laboratório e posicionamento dos equipamentos no local de trabalho.

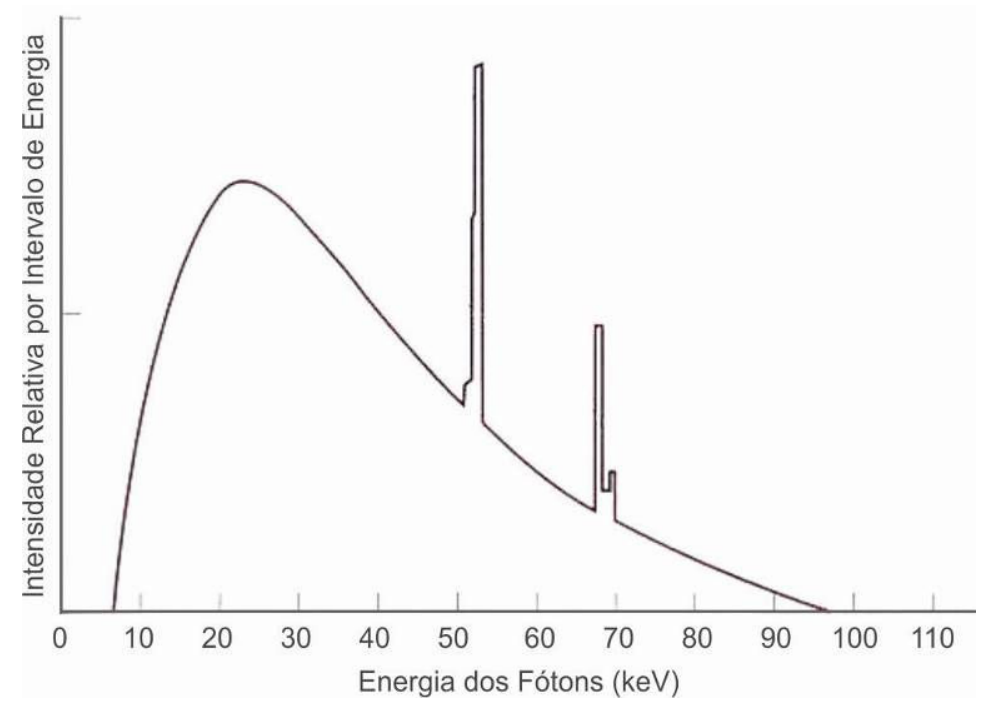

FIGURA 11 - Espectro de emissão com filtração adicional para um tubo de raios $X$ com alvo de tungstênio operado a $100 \mathrm{kV}$. A curva contínua se deve a produção de raios $\mathrm{X}$ por Bremsstrahlung e os picos se deve a produção por radiação característica devido ao alvo de tungstênio. Adaptado de Hendee, et al., 2002.

\subsubsection{Fatores que Influenciam o Espectro de Raios $X$}

Para gerar um determinado espectro de raios $X$ é necessário levar em consideração diversos parâmetros que modificam algumas características do espectro. Dependendo de como esses parâmetros são configurados, características como amplitude, energia média, comprimento do intervalo energético do 
espectro, dentre outras, serão alteradas. A seguir são descritos esses parâmetros e suas contribuições na modificação de um espectro de raios $X$.

\subsubsection{Corrente Elétrica ( $\mathrm{mA})$}

O aumento da corrente elétrica no tubo de raios $X$ faz com que haja um maior fluxo de elétrons indo do catodo para o anodo, aumentando assim, o número de interações entre elétrons e alvo tendo como conseqüência um número maior de fótons de raios $X$ saindo pela janela do tubo. Portanto, há um aumento da intensidade de fótons, o que faz com que o espectro apresente uma amplitude maior devido ao aumento de contagens para cada energia (FIG. 12). Portanto, o aumento do número de contagens é diretamente proporcional ao aumento da corrente elétrica (Potiens, 1999).

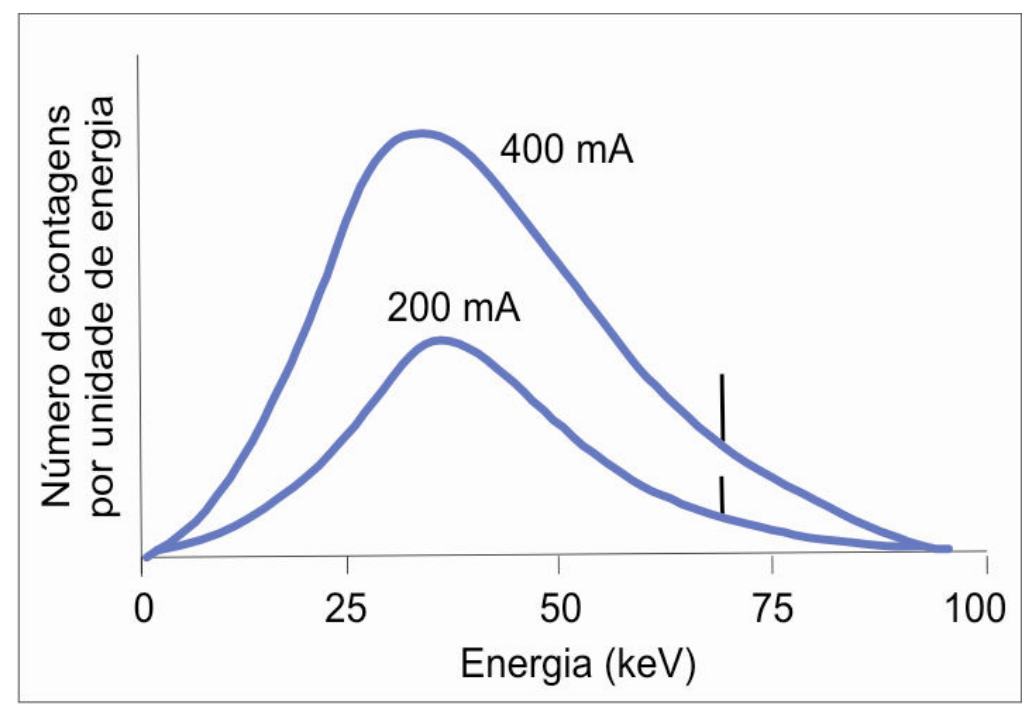

FIGURA 12 - Aumento da amplitude do espectro de raios $X$ com o aumento da corrente elétrica de 200 mA para 400 mA. Adaptado de Bushong (1997).

\subsubsection{Distância entre Detetor e Fonte de Raios X}

A intensidade de um feixe de ondas eletromagnéticas decai proporcionalmente com o inverso do quadrado da distância devido ao aumento do ângulo sólido, o que provoca a diminuição do fluxo de fótons por unidade de área. Essa lei se aplica ao feixe de raios $X$ que diminui sua intensidade com o aumento da distância entre a fonte de raios $\mathrm{X}$ e o detetor. Portanto, com o aumento da 
distância há uma diminuição das contagens dos fótons e consequentemente da amplitude do espectro de raios $X$.

\subsubsection{Tensão Aplicada ao Tubo}

O aumento da tensão aplicada ao tubo de raios $X$ aumenta a energia cinética dos elétrons incidentes no alvo do anodo fazendo com que os fótons de raios $\mathrm{X}$ gerados pelo processo de Bremsstrahlung tenham uma energia, na média, maior do que para tensões menores. Dessa maneira, com o aumento da tensão haverá o aumento da energia máxima atingida pelos fótons de raios $\mathrm{X}$. Além disso, haverá um número maior de interações dos elétrons com o alvo aumentando a quantidade de fótons de raios $X$ emitidos (Bushong, 1997). No espectro será observado um deslocamento da energia máxima para a direita (aumento da energia), bem como a sua energia média, e um aumento da amplitude devido ao aumento do número de contagens (FIG. 13).

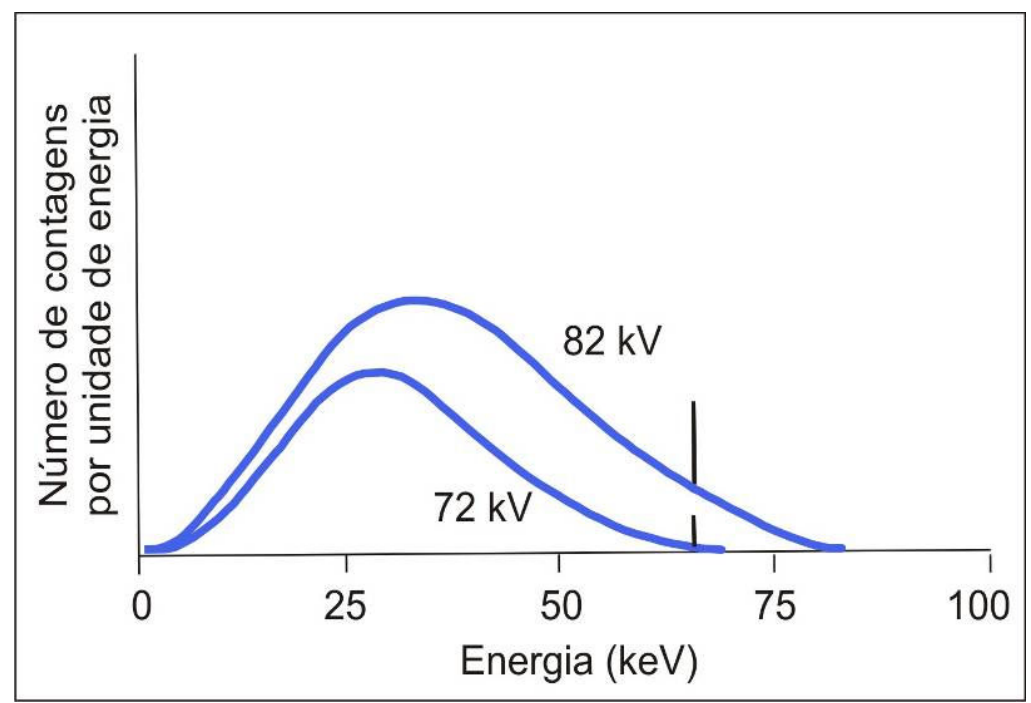

FIGURA 13 - Alteração do espectro de raios X com o aumento da tensão aplicada ao tubo de raios X. Adaptado de Bushong (1997).

\subsubsection{Filtração Adicional}

A filtração adicional produz um efeito na forma do espectro, porém sem alterar a energia máxima observada no final do espectro (Bushong, 1997). A presença da filtração induz o barramento dos fótons de baixa energia, o que 
ocorre em menor quantidade com os fótons de alta energia. Dessa maneira, diminui-se o número de contagens diferentemente para cada valor energético provocando a alteração da forma do espectro, assim como a redução da sua amplitude.

Birch e Marshall (1979) demonstraram que com o aumento da filtração adicional, a energia média dos fótons do espectro aumenta, ou seja, há um aumento na contagem dos fótons de maior energia. $O$ aumento da filtração adicional na saída do feixe de raios $X$ abranda um fenômeno denominado Empilhamento de Pulsos decorrente em medidores de contagens e energia. $O$ medidor, ao adquirir os dados para o espectro de raios $\mathrm{X}$ deixa de registrar muitos fótons de diversas energias por não possuir resolução suficiente para medir todo o fluxo de fótons que passa em seu volume sensível, portanto haverá um acúmulo de fótons que não será medido, por isso a denominação de empilhamento de pulsos (Giarratano et al., 1991). Com a presença de uma filtração adicional entre a fonte de raios $\mathrm{X}$ e o detetor, o feixe de raios $\mathrm{X}$ é atenuado, onde essa atenuação é maior para os fótons de baixa energia, o que faz com que o detetor consiga registrar um número maior de fótons mais energéticos. Portanto, o espectro passará a ter uma forma diferente, com um número maior de contagens no final da curva do espectro, ou seja, o final da curva apresentará uma queda mais acentuada (FIG. 14).

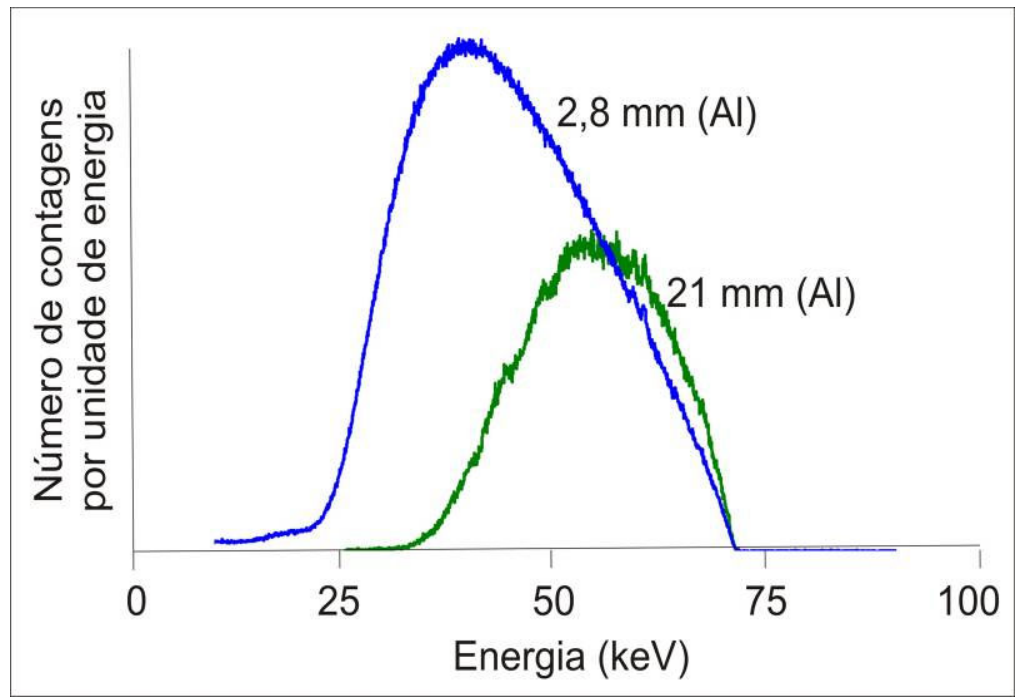

FIGURA 14 - Alteração do espectro de raios X com o aumento da filtração adicional. 


\subsubsection{Material Alvo}

O elemento do material alvo influencia tanto na quantidade de contagens no espectro de raios $X$ como em sua energia efetiva. A mudança mais pronunciada é a que se refere à radiação $X$ característica produzida no tubo. Com o aumento do número atômico do material alvo, os picos associados à radiação característica são deslocados para a direita, onde se encontram as contagens de maior energia. Isso ocorre porque nos elementos com maior número atômico os elétrons transitam entre órbitas com maiores intervalos energéticos liberando fótons de raios $X$ com maior energia (Bushong, 1997). Além disso, com o aumento do número atômico há um aumento de interações entre os elétrons acelerados no tubo de raios $\mathrm{X}$ e o alvo devido a alta densidade do material alvo. Dessa maneira, serão produzidos mais fótons de raios $X$ e a amplitude do espectro aumentará. Na FIG. 15 são mostradas as diferenças entre 3 espectros produzidos com materiais alvos distintos, mas com todos os outros parâmetros configurados igualmente.

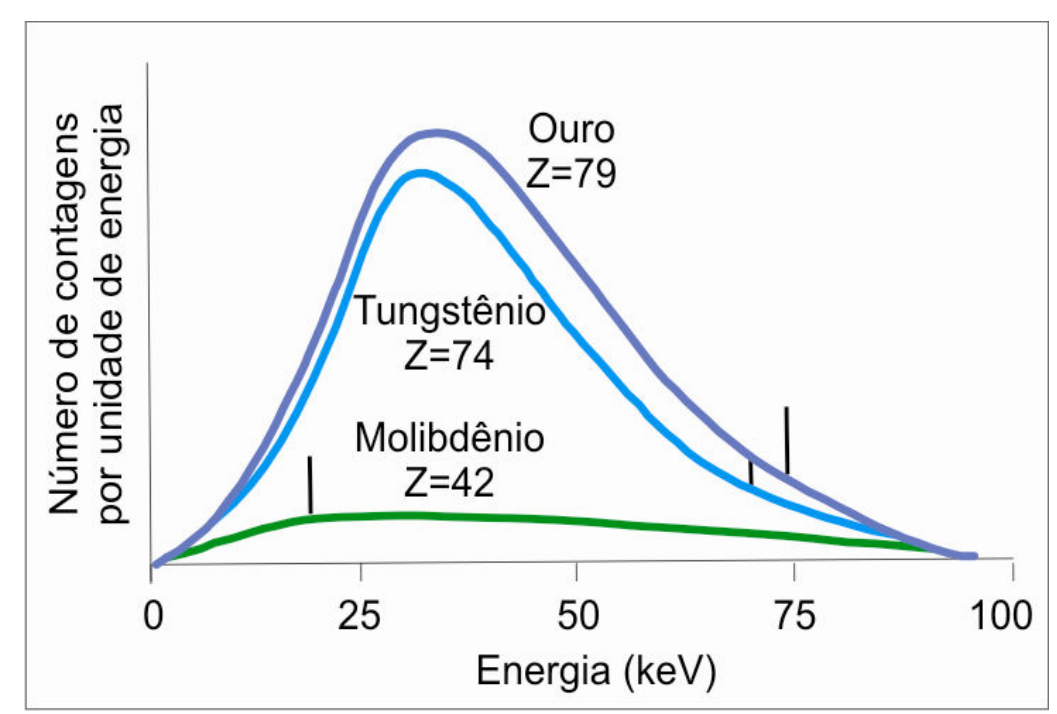

FIGURA 15 - Alteração do espectro de raios X com a mudança do material alvo. Adaptado de Bushong (1997).

\subsubsection{Forma de Onda (Tensão)}

Como visto na Seção 2.2, os geradores de potencial constante possuem uma eficiência energética maior que os geradores trifásicos que por sua vez 
possuem eficiência energética maior que os geradores monofásicos. Logo, a energia média difere de um aparelho para outro. Nos espectros de raios X (FIG. 16) nota-se a diferença dos 3 geradores observando o deslocamento horizontal dos máximos dos espectros (energias com maiores números de contagens). Isso indica que a energia média dos fótons aumenta de um gerador para outro quando usados os mesmos parâmetros de configuração. Além disso, observa-se a alteração da amplitude do espectro, ou seja, do número de contagens que, como foi visto na seção 2.2, é devido a uma maior eficiência na produção de fótons de raios $\mathrm{X}$ dos geradores de potencial constante seguidos pelos geradores trifásicos e por último pelos geradores monofásicos.

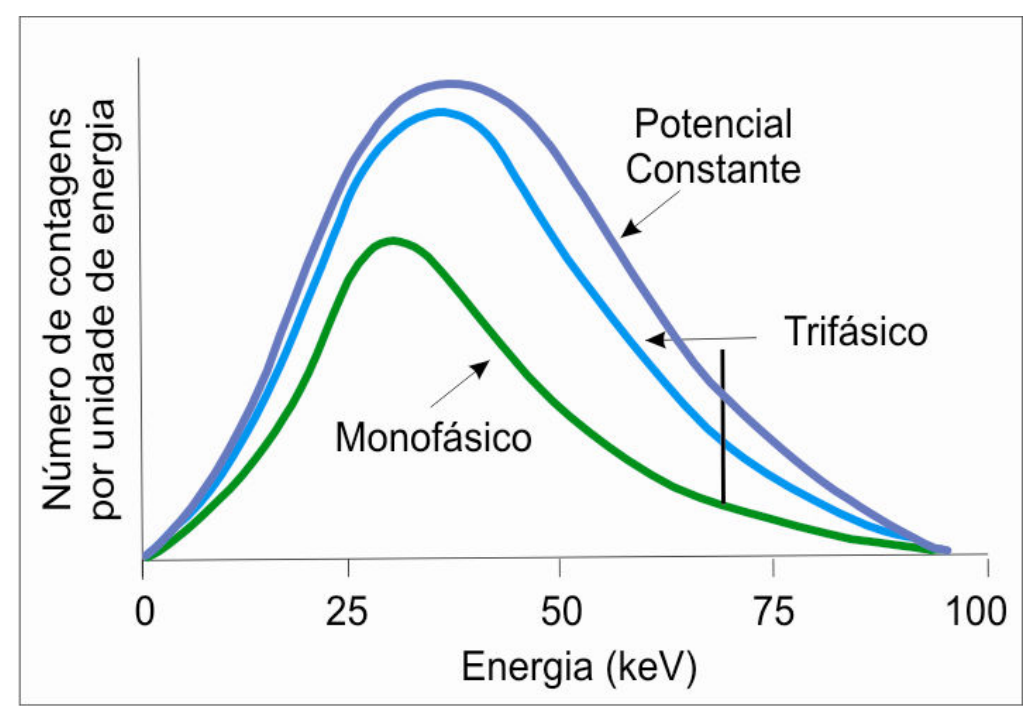

FIGURA 16 - Espectro de raios X produzidos por geradores Monofásicos, Trifásicos e de Potencial Constante. Adaptado de Bushong (1997).

\subsubsection{Efeito Borda K (K-edge)}

Os fótons de raios $X$ produzidos pelos sistemas de radiação $X$ podem ser absorvidos por um determinado material através de um fenômeno denominado efeito fotoelétrico. Nesse efeito um fóton de raios $\mathrm{X}$ é absorvido por um elétron da camada mais interna do átomo, onde o elétron é ejetado para fora desse átomo. Para ocorrer esse fenômeno o fóton deve possuir energia igual ou superior a energia de ligação do elétron ao átomo. Dessa forma, um fóton com energia superior a energia de ligação do elétron cederá parte de sua energia para "arrancar" o elétron do átomo e o restante da energia é convertida em energia 
cinética no elétron ejetado (Khan, 1994). No entanto, a probabilidade de ocorrência do efeito fotoelétrico diminui com o aumento da energia do fóton de raios $X$ a partir da energia de ligação do elétron como pode ser visto na FIG. 17. Além disso, a probabilidade de ocorrência do efeito aumenta com o aumento do número atômico $Z$, já que no caso de grandes números atômicos a quantidade de elétrons envolvidos no processo aumenta, ou seja, há uma maior probabilidade de interação (Johns, 1974).

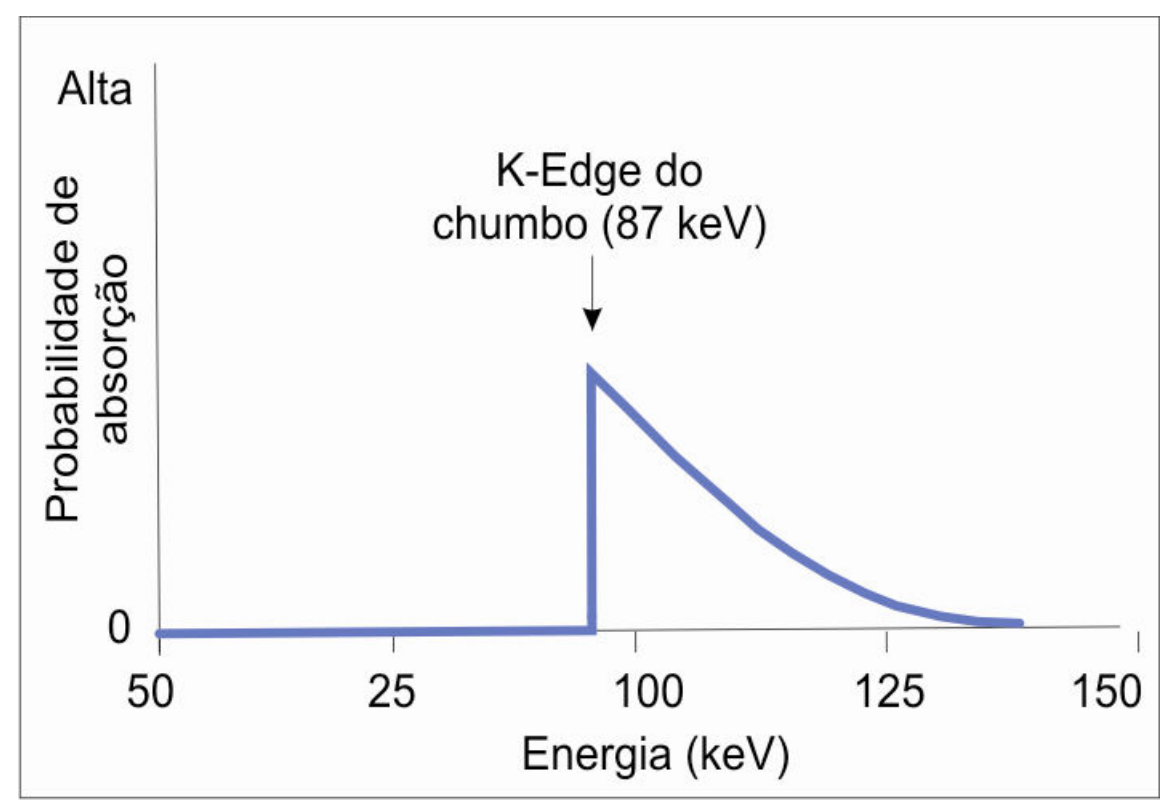

FIGURA 17 - Probabilidade de absorção de fótons de raios $\mathrm{X}$ no elemento chumbo por efeito fotoelétrico.

Se na medição do espectro de raios $\mathrm{X}$ houver um obstáculo entre o detetor $\mathrm{e}$ o feixe de raios $\mathrm{X}$ medido capaz de absorver fótons de raios $\mathrm{X}$ através do efeito fotoelétrico, ocorrerá um fenômeno denominado borda K. Nesse efeito ocorrerá uma grande absorção dos fótons de raios $\mathrm{X}$ com energias iguais ou ligeiramente superiores a energia de ligação dos elétrons do material do obstáculo. Dessa forma será observada uma queda brusca na amplitude do espectro a partir da energia de ligação referente aos elétrons dos átomos do material do obstáculo. Esse fenômeno é facilmente observado em geradores de raios $X$ com Molibdênio na filtração inerente (FIG. 18). 


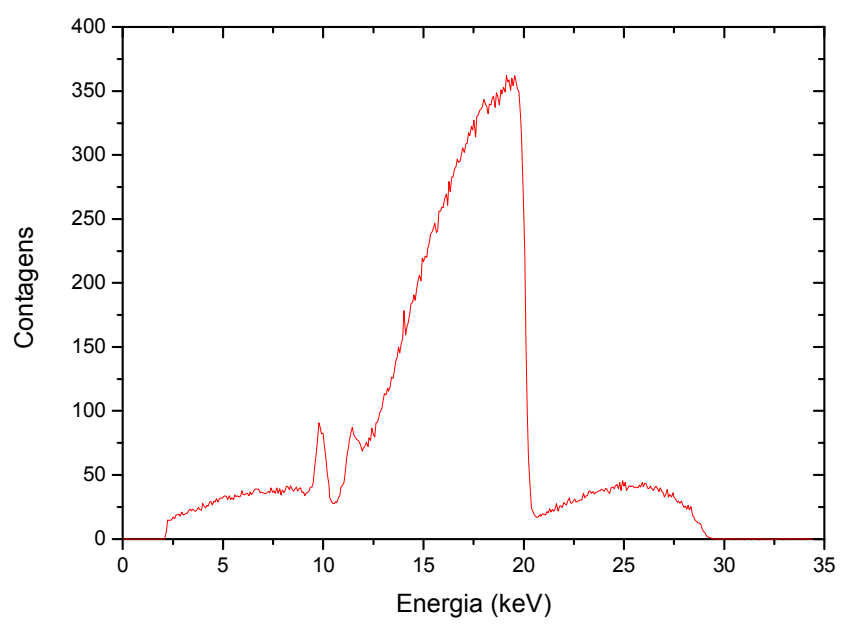

FIGURA 18 - Efeito de borda K observado a $20 \mathrm{keV}$ devido a 0,06 mm (RQRM2) de filtração adicional de Molibdênio (Corrêa, E.L. et al., 2009).

Na TAB. 1 são mostradas as energias médias da borda de absorção $K$ responsáveis pela ocorrência do efeito borda $\mathrm{K}$ em diversos elementos. Essas energias $\left(E_{K}\right)$ podem ser calculadas pela equação 1 (Eisberg et al., 1979), onde $Z$ é o número atômico do elemento.

TABELA 1 - Energia média da borda de absorção $\mathrm{K}$ de diversos elementos.

\begin{tabular}{cc}
\hline Elemento & $\begin{array}{c}\text { Energia Média } \\
\text { Da Borda de } \\
\text { Absorção K (keV) }\end{array}$ \\
\cline { 2 - 2 } Alumínio & 1,6 \\
Cobre & 9,9 \\
Molibdênio & 21,7 \\
Bário & 39,6 \\
Lantânio & 41,1 \\
Gadolínio & 52,3 \\
Tungstênio & 70,7 \\
Chumbo & 87,0 \\
\hline
\end{tabular}

$$
E_{K} \approx 13,6 \cdot 10^{-3} \cdot(Z-2)^{2}
$$




\subsection{Detetores de Radiação}

\subsubsection{Câmaras de lonização}

As câmaras de ionização foram criadas com o intuito de mensurar a intensidade das radiações ionizantes. Devido às suas boa reprodutibilidade, estabilidade e alta sensibilidade, elas são utilizadas com prioridade para a detecção de feixes de raios $X$.

Esses detetores se caracterizam por apresentarem formatos, dimensões e materiais distintos que se adequam à finalidade para o qual são destinados (grandezas distintas, tipos de radiação medida, intensidade e variação da radiação no espaço e tempo das medidas efetuadas).

Em geral, uma câmara de ionização (FIG. 19) é constituída essencialmente por dois ou mais eletrodos que envolvem um gás que faz o papel de volume sensível da câmara. A radiação ionizante que incide nesse gás produz várias ionizações que são coletadas pelos eletrodos por estarem sujeitos a uma diferença de potencial externa. Logo, cria-se um fluxo de íons (corrente elétrica da ordem de $10^{-12} \mathrm{~A}$ ) que é medido por um instrumento sensível conectado a câmara de ionização, o eletrômetro. Esse dispositivo fornece indiretamente a leitura da intensidade da radiação incidente, já que a mesma é proporcional ao fluxo de íons.

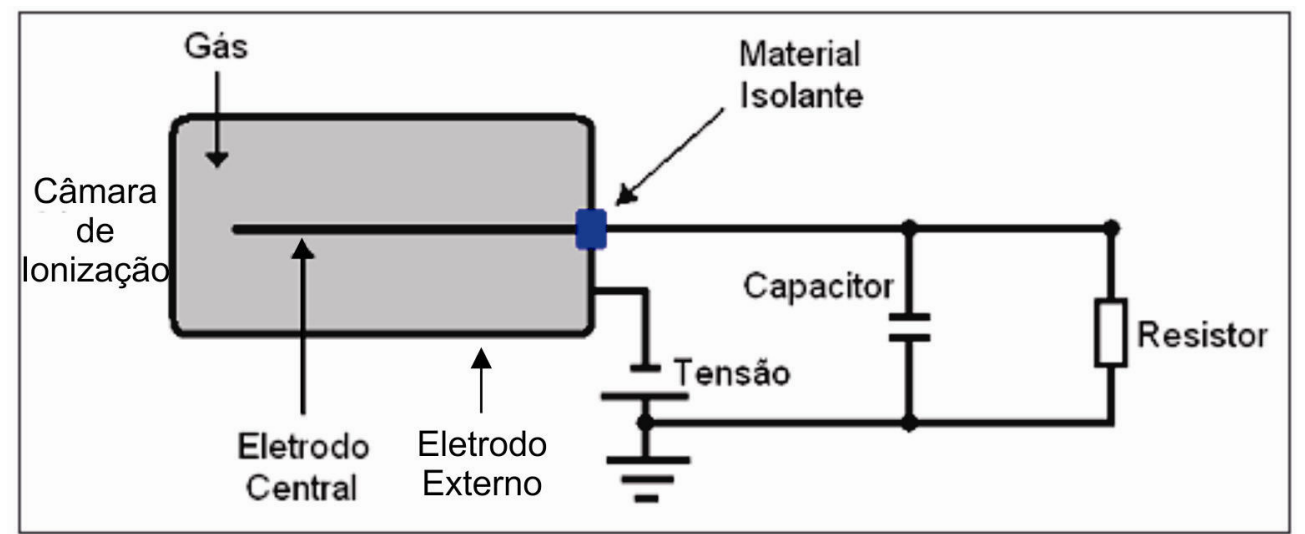

FIGURA 19 - Esquema simplificado de funcionamento de uma câmara de ionização (Oliveira, 2008). 
A câmara de ionização se restringe a medições de intensidade do fluxo de radiação, não sendo capaz de diferenciar as energias das radiações responsáveis pelas ionizações em seu volume sensível.

\subsubsection{Câmara de Ionização Cilíndrica (Tipo Dedal)}

As câmaras de ionização do tipo dedal apresentam pequenas dimensões proporcionando facilidade em seu manuseio e grande versatilidade. Como não possui a capacidade de medir diretamente a grandeza de referência (kerma no ar) é necessária a sua calibração em relação a um sistema rastreável a um padrão primário.

Uma câmara de ionização do tipo dedal (FIG. 20) é constituída por uma parede sólida cilíndrica que envolve um determinado volume de ar. No interior da parede da câmara encontra-se inserido um eletrodo responsável pela coleta dos íons formados no volume sensível (constituído de ar) entre a parede sólida e o eletrodo. Tanto a parede como o eletrodo da câmara devem ser constituídos de um material equivalente ao ar em relação às interações dos fótons e dos elétrons secundários com o meio. Isso faz com que o campo de radiação não seja perturbado no interior da câmara.

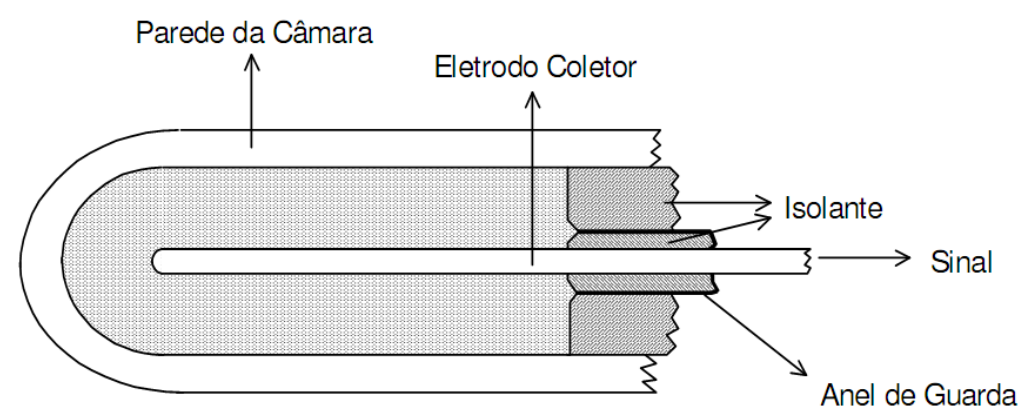

FIGURA 20 - Vista seccional de uma câmara de ionização dedal típica (Boag et al., 1987).

O ar presente no volume sensível da câmara tipo dedal está em contato com o ambiente externo através de um orifício. Portanto, correções referentes a fatores ambientais, como temperatura e pressão devem ser efetuadas por modificarem as condições no volume sensível da câmara. Esse fator de correção 
$\left(F_{T, P}\right)$ é dado pela equação 2 , onde $T_{T}$ e $P_{T}$ são, respectivamente, os valores da temperatura $\left({ }^{\circ} \mathrm{C}\right)$ e pressão $(\mathrm{kPa})$ durante as medições.

$$
F_{T, P}=\left(\frac{T_{T}+273,15}{293,15}\right) \frac{101,30}{P_{T}}
$$

O fator de correção deve ser multiplicado pelo produto do valor medido (Q) e pelo coeficiente de calibração $\left(N_{K}\right)$ para se obter o valor do kerma no ar (K) medido na posição em que se encontra a câmara de ionização, como pode ser observado na equação 3.

$$
K=F_{T, P} \cdot N_{K} \cdot Q
$$

\subsubsection{Semicondutores}

Um semicondutor é um sólido que possui ligações covalentes entre seus átomos e apresenta comportamento de isolante a baixas temperaturas. $\mathrm{Na}$ temperatura de zero absoluto, todos os elétrons presentes nesse sólido se encontram em um estado energético denominado de banda de valência (ligados aos átomos) e por isso o material apresenta comportamento de isolante. Para apresentar um comportamento condutivo, os elétrons, no semicondutor, devem "migrar" para um estado energético denominado de banda de condução e para isso devem "pular" um estado energético denominado de banda proibida, onde não são encontrados nenhum elétron (FIG. 21). Dessa maneira, os elétrons que "migram" para a banda de condução estão livres para serem conduzidos e deixam vacâncias (buracos) na banda de valência que também contribuem para a condução elétrica, já que apresentam comportamento de portador positivo. Essas transições eletrônicas podem ser estimuladas, por exemplo, por aumento de temperatura ou por fotoexcitação dos elétrons na banda de valência (Eisberg et al., 1979). 


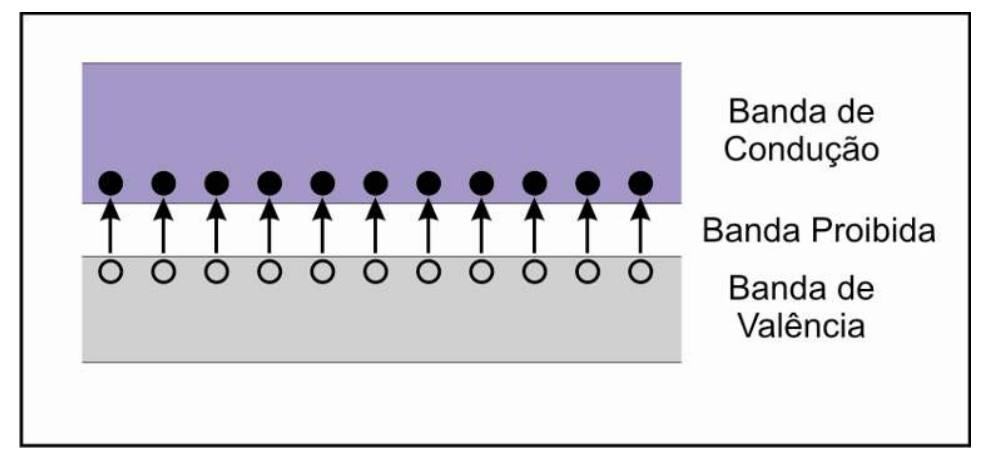

FIGURA 21 - Esquematização da "migração" dos elétrons da banda de valência para a banda de condução em um semicondutor.

Para aumentar a condutividade elétrica são inseridas (dopagem) impurezas na rede cristalina do sólido semicondutor. Essas impurezas são átomos que possuem valências diferentes em relação aos átomos que são a matriz do material semicondutor. Dopando o material semicondutor com átomos de valência maior há uma sobra de elétrons durante a realização das ligações covalentes entre os átomos. Esses elétrons que sobram estão praticamente livres por não fazerem parte das ligações covalentes e podem ser facilmente ionizáveis e irem para a banda de condução aumentando a condutividade do material. A impureza utilizada nesse processo é denominada impureza doadora e o semicondutor resultante é chamado de tipo-n (negativo). Dopando o material semicondutor com átomos de valência menor surgem vacâncias nas bandas de valência devido a falta de elétrons para completar a ligação covalente. Os elétrons dos átomos vizinhos "migram" para essas vacâncias deixando, por sua vez, vacâncias em suas bandas de valência que serão preenchidas por outros elétrons, ou seja, ocorrem deslocamentos das vacâncias (portadores positivos) permitindo que o semicondutor aumente sua condutividade. A impureza utilizada nesse processo é denominada impureza aceitadora e o semicondutor resultante é chamado de tipop (positivo).

Ao se dopar uma região de um semicondutor com impurezas aceitadoras e outra região com impurezas doadoras cria-se um fenômeno denominado junção $p$-n, onde os elétrons livres tendem a migrar da região $n$ para a $p$ e as vacâncias tendem a migrar da região $\mathrm{p}$ para a $\mathrm{n}$ estabelecendo uma diferença de potencial entre $\mathrm{n}$ e p. Essa diferença de potencial pode ser intensificada quando aplicada uma diferença de potencial externa ao semicondutor, onde o pólo positivo é ligado 
na região n e o pólo negativo na região p. Nesse processo de junção, uma região neutra resistiva denominada de região de depleção se estabelece entre n e p e pode ser utilizada como detetor de radiação ionizante (Tsoulfanidis, 1995).

\subsubsection{Detetor Semicondutor}

O detetor semicondutor é um medidor de radiações ionizantes que apresenta em seu interior um elemento semicondutor capaz de proporcionar a medição da intensidade das radiações e as energias dos fótons incidentes, diferentemente das câmaras de ionização, cujo volume sensível não permite a medição das energias. Normalmente são compostos por semicondutores de Germânio e Silício (valência 4) dopados com Gálio (tipo p com valência 3) e Lítio (tipo $n$ com valência 5), porém outros materiais vêm sendo testados visando os mesmos fins de medição. A resposta de um detetor semicondutor não depende somente do material em que ele é composto, mas também como esse material é formado e tratado. A forma e o tamanho do cristal também influenciam na performance do detetor.

O volume sensível do detetor semicondutor se encontra na região de depleção do semicondutor com junção p-n. A radiação que penetra essa região ioniza os átomos ali presentes e cria uma série de pares elétron-lacuna, cuja quantidade é proporcional a energia dessa radiação penetrante (FIG. 22). Portanto, uma corrente elétrica se estabelece devido ao movimento dos elétrons e das lacunas e essas cargas são registradas pelo dispositivo eletrônico agregado ao detetor semicondutor (Tsoulfanidis, 1995).

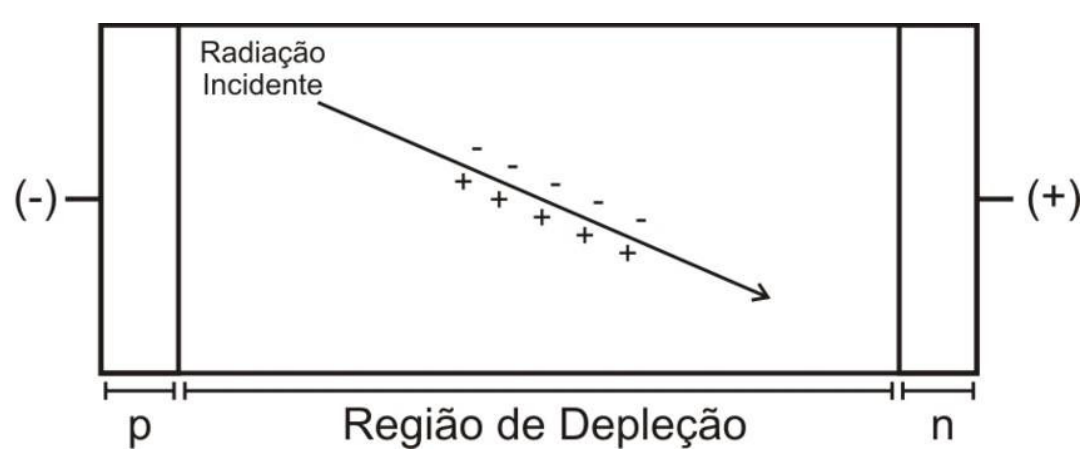

FIGURA 22 - Região de Depleção atuando como um detetor de radiação. 
Alguns detetores semicondutores necessitam operar a temperaturas muito baixas para manter seus semicondutores isolantes e possibilitar a detecção da radiação na região de depleção. É o caso dos espectrômetros com semicondutores de Germânio dopados com Lítio e Gálio. Para atingir tais temperaturas o detetor é refrigerado com nitrogênio líquido e só então podem ser utilizados. Outros detetores são constituídos de semicondutores que em condições normais de temperatura e pressão apresentam comportamento de isolante, o que elimina a necessidade da refrigeração do sistema.

\subsection{Grandezas e Unidades Radiológicas}

Para um conhecimento adequado dos conceitos físicos envolvidos nos estudos radiológicos é de vital importância o domínio dos conceitos referentes às grandezas físicas e suas respectivas unidades. Nessa seção serão apresentadas as grandezas que possuem um papel importante para uma melhor compreensão deste trabalho. As definições apresentadas foram baseadas nas definições encontradas no Technical Reports Series 457 (2007) e na International Electrotechnical Comission 61676 (2002).

\subsubsection{Exposição}

A grandeza exposição $(X)$ é a razão entre $d Q$ e dm, onde $d Q$ é o valor, em módulo, da carga total de íons de mesmo sinal produzidos no ar devido a ionizações provocadas pelo feixe de fótons eminente em um volume de ar de massa dm, volume esse em que todos os elétrons resultados das ionizações foram completamente freados.

$$
X=\frac{d Q}{d m}
$$

A grandeza exposição só pode ser utilizada para medir radiação eletromagnética em um meio composto de ar. Sua unidade é dada por C.kg ${ }^{-1}$. 


\subsubsection{Dose Absorvida}

A Dose Absorvida (D) é a razão entre a Energia Média ( $d \bar{E}$ ) cedida pela radiação ionizante e a massa $\mathrm{dm}$, onde a energia média é depositada. Essa grandeza pode ser utilizada para qualquer tipo de radiação e medida em qualquer material.

$$
D=\frac{d \bar{E}}{d m}
$$

A unidade da dose absorvida é ${\mathrm{J} . \mathrm{kg}^{-1}}^{\text {ou }} \mathrm{Gy}$, onde 1 Gy equivale a $1{\mathrm{~J} . \mathrm{kg}^{-1}}^{-}$.

\subsubsection{Kerma}

A grandeza Kerma (kinetic energy in material) é a razão entre $d E_{t r}$ e dm, onde $d E_{t r}$ é a soma de todas as energias cinéticas iniciais referentes as partículas carregadas liberadas por fótons ou partículas neutras incidentes em uma massa $\mathrm{dm}$.

$$
k=\frac{d E_{t r}}{d m}
$$

A unidade da grandeza Kerma é a mesma da grandeza dose absorvida, ou seja, J.kg-1 ou Gy.

\subsubsection{Tensão de Pico Aplicada ao Tubo de Raios X (kVp)}

É a tensão nominal selecionada no painel do aparelho de raios $\mathrm{X}$. Em um gerador com tensão variável (monofásica ou trifásica), a tensão de pico é o valor máximo (crista da onda) da tensão em função do tempo, já em um gerador com potencial constante, a tensão de pico é o valor da tensão em qualquer tempo $t$. Essa tensão de pico é responsável pelos fótons de raios $X$ mais energéticos produzidos no tubo de raios $X$. Portanto, o valor numérico da energia máxima (em eletrovolt) encontrada no espectro de raios $X$ equivale ao valor numérico da tensão de pico (em Volts) aplicada ao tubo de raios $\mathrm{X}$. 
A unidade da grandeza da Tensão de Pico $(k \bigvee p)$ é o $V($ Volt $)$.

\subsubsection{Tensão de Pico Prático (PPV)}

Foi visto na seção 2.2 que um gerador de potencial constante gera um espectro de raios $X$ diferente dos geradores de tensão variável. Dessa forma, as intensidades e energias médias dos feixes de raios $X$ produzidos são diferentes entre si, mesmo possuindo a mesma tensão de pico e outros parâmetros configurados da mesma maneira. Isso acaba sendo um problema, já que utilizando geradores de raios $X$ distintos com a mesma configuração, o paciente pode estar recebendo energia e intensidade abaixo ou acima do pretendido, produzindo diferentes contrastes radiográficos. Para evitar esse tipo de problema criou-se a grandeza Tensão de Pico Prático (PPV), onde um mesmo valor dessa grandeza resulta em um mesmo contraste radiológico para geradores de potencial constante e de tensão variável (Kramer, et al., 1998).

O PPV (U) é calculado através de uma média ponderada das tensões instantâneas $\left(U_{i}\right)$ aplicadas ao tubo de raios $X$ com fator de ponderação $\omega(U i)$.

$$
U=\frac{\sum_{i=1}^{n} p\left(U_{i}\right) \omega\left(U_{i}\right) U_{i}}{\sum_{i=1}^{n} p\left(U_{i}\right) \omega\left(U_{i}\right)}
$$

O fator de ponderação $\omega\left(U_{i}\right)$ depende dos valores das tensões instantâneas $\left(U_{i}\right)$ e é calculado de acordo com o intervalo em que se encontram essas tensões. Para o intervalo de $20 \mathrm{kV} \leq \mathrm{U}_{\mathrm{i}}<36 \mathrm{kV}$ é utilizada a expressão 8 e para o intervalo $36 \mathrm{kV} \leq \mathrm{U}_{\mathrm{i}}<150 \mathrm{kV}$ é utilizada a expressão 9.

$$
\omega\left(U_{i}\right)=\exp \left(a U_{i}^{2}+b U_{i}+c\right)
$$

Onde,

$a=-8,646855 \cdot 10^{-3}$

$b=0,817036$

$c=-23,27793$ 


$$
\omega\left(U_{i}\right)=d U_{i}^{4}+e U_{i}^{3}+f U_{i}^{2}+g U_{i}^{2}+h
$$

Onde,

$d=4,310644 \cdot 10^{-10}$

$\mathrm{e}=-1,662009 \cdot 10^{-7}$

$f=2,30819 \cdot 10^{-5}$

$g=1,030820.10^{-5}$

$\mathrm{h}=-1,747153 \cdot 10^{-2}$

Para mamografia ou tensões menores ou iguais a $50 \mathrm{kV}$, o fator de ponderação $\omega\left(\cup_{\mathrm{i}}\right)$ é dado pela equação 10.

$$
\omega\left(U_{i}\right)=\exp \left(k U_{i}^{4}+I U_{i}^{3}+m U_{i}^{2}+n U_{i}+p\right)
$$

Onde,

$k=-2,142352.10^{-6}$

$\mathrm{I}=2,566291.10^{-4}$

$\mathrm{m}=-1,968138 \cdot 10^{-2}$

$\mathrm{n}=0,8506836$

$p=-15,14362$

\subsection{Estimativas das Incertezas}

As estimativas das incertezas nas medições realizadas em laboratório são baseadas em dois tipos de avaliação: incertezas de tipo A e tipo B. As incertezas de tipo A são estimadas a partir da análise estatística de uma série de medições efetuadas. O desvio padrão e o desvio padrão da média são bons exemplos desse tipo de avaliação. Já as incertezas de tipo B são estimadas por outros métodos que não os estatísticos, como por exemplo, a resolução dos instrumentos utilizados nas medições fornecidas pelos fabricantes dos aparelhos.

As incertezas de tipo A e B fazem parte de distribuições de probabilidades que indicam a probabilidade de um determinado evento medido se encontrar nesse intervalo de incerteza. Quando a incerteza e o nível de confiança 
(probabilidade do evento medido se encontrar dentro da incerteza) é conhecido, deve-se se tratar a distribuição de probabilidade como uma distribuição normal e a incerteza conhecida deve ser dividida por $\sqrt{n}$, onde $\mathrm{n}$ é o número de medições efetuadas. No caso em que se conhece apenas os intervalos das incertezas, a distribuição de probabilidade pode ser tratada como uma distribuição retangular e a incerteza deve ser dividida por $\sqrt{3}$. Essas incertezas resultantes são utilizadas para o cálculo das incertezas combinadas e expandidas discutidas nos próximos parágrafos.

O procedimento para a estimativa e correlação das incertezas de tipo $\mathrm{A} e$ tipo B é apresentado pelo Guia Para a Expressão da Incerteza de Medição (2003). Inicialmente, é necessário fazer um levantamento de todas as fontes de incertezas que contribuem para a realização de uma determinada medição ou conjunto de medições. Essas fontes podem originar incertezas de tipo A e tipo B que são correlacionadas por uma incerteza denominada incerteza combinada $\left(u_{c}\right)$, dada pela equação 11 :

$$
u_{c}=\left[\left(u_{1}\right)^{2}+\left(u_{2}\right)^{2}+\ldots+\left(u_{n}\right)^{2}\right]^{1 / 2}
$$

As incertezas $u_{1}, u_{2}, \ldots, u_{n}$ são as fontes de incertezas de tipo $\mathrm{A}$ e tipo $\mathrm{B}$ referentes as medições efetuadas. No caso das incertezas de tipo $A$, é utilizado o desvio padrão, $u_{1}$ (equação 12 ), da série de medições como uma das componentes para estimar a incerteza combinada.

$$
u_{1}=\sqrt{\frac{1}{n} \sum_{i=1}^{m}\left(y_{i}-\bar{y}\right)^{2}}
$$

Onde: $\mathrm{n}=$ número amostral

$y_{i}=$ valores medidos

$\bar{y}=$ média dos valores medidos

Já as demais incertezas, pertencentes ao tipo B, são obtidas através das resoluções dos instrumentos envolvidos durante a medição, como réguas, 
termômetros, câmaras de ionização, barômetros, dentre outros, e também da calibração do sistema padrão cuja incerteza é obtida diretamente do certificado de calibração do instrumento de medição. Todas essas incertezas $\left(u_{i}\right)$ entram como componentes para a estimativa da incerteza combinada.

Deve-se, ainda, a partir da incerteza combinada estimar a incerteza expandida $\left(U_{e}\right)$ que fornecerá um intervalo de confiança para os valores encontrados até aqui. A expressão da incerteza expandida é dada pela equação 13 , onde o fator $k$ é denominado de fator de abrangência e de acordo com o seu valor é determinado um nível de confiança nas incertezas avaliadas. Para um nível de confiança de $95 \%$ (probabilidade de que o valor verdadeiro se encontre dentro do intervalo da incerteza calculada) o valor de $\mathrm{k}$ deve ser 2,26 (para um grau de liberdade igual a 9). Com o aumento do fator $\mathrm{k}$ há um aumento do nível de confiança, porém aumenta-se também o valor da incerteza, por isso é necessário fazer a escolha de um fator $\mathrm{k}$ que não aumente muito o valor da incerteza, mas que também não ofereça um baixo nível de confiança. Neste trabalho foi escolhido o fator de abrangência referente a um grau de liberdade igual a 9 e nível de confiança igual a $95 \%(k=2,26)$.

$$
U_{e}=k u_{c}
$$




\section{MATERIAIS E MÉTODOS}

\subsection{Instalação}

Todos os dados utilizados para a realização deste trabalho foram adquiridos no Laboratório de Calibração de Instrumentos (LCl) pertencente à Gerência de Metrologia das Radiações localizada nas instalações do Instituto de Pesquisas Energéticas e Nucleares (IPEN/CNEN - SP).

\subsection{Instrumentação}

\subsubsection{Sistemas de Radiação}

Durante a aquisição dos dados foram utilizados 3 sistemas de irradiação: um sistema de radiação $X$ e 2 fontes radioativas $\left({ }^{90} \mathrm{Sr}\right.$ e $\left.{ }^{241} \mathrm{Am}\right)$.

O sistema de radiação X (FIG. 23) de energias intermediárias é formado por um gerador de potencial constante Agfa NDT Pantak/Seifert GmbH \& Co. KG., Alemanha, modelo ISOVOLT $160 \mathrm{HS}$, ligado a um tubo de raios $X$ da Comet, modelo MRX 160/22 com anodo estacionário (alvo de Tungstênio) e janela de Berílio com $1 \mathrm{~mm}$ de espessura. O tubo está posicionado dentro de uma blindagem de chumbo, onde sua janela vai de encontro a um obturador (shutter), também de chumbo, que é aberto ou fechado por um dispositivo eletrônico presente fora da sala de irradiação. $O$ aparelho permite uma operação da tensão no intervalo de 5 a $160 \mathrm{kV}$ com a corrente elétrica podendo variar entre 0,1 e 45 mA. Com essa configuração, o sistema proporciona uma potência máxima de $3 \mathrm{~kW}$. 


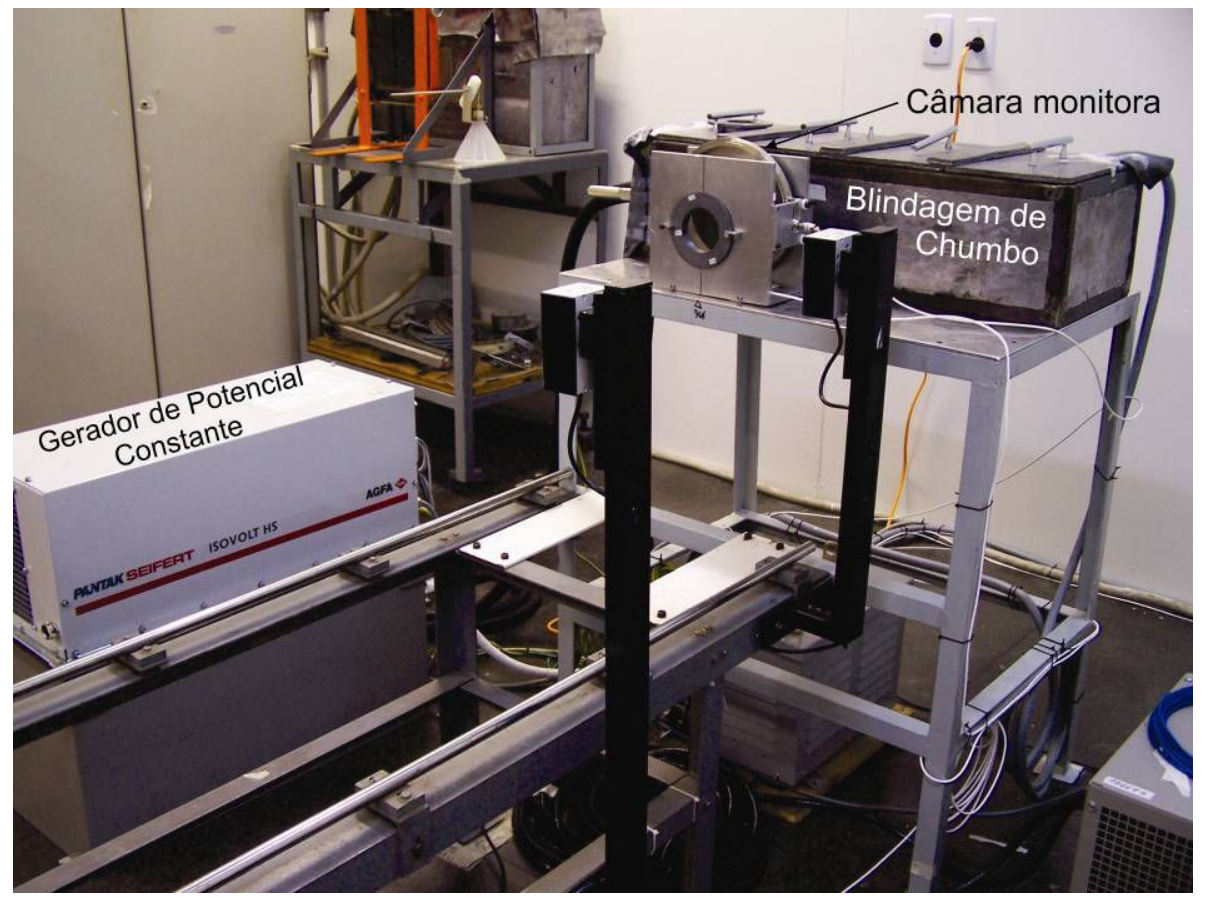

FIGURA 23 - Sistema de radiação X composto pelo gerador de potencial constante Pantak e o tubo de raios X Comet blindado com chumbo.

A fonte radioativa de ${ }^{90} \mathrm{Sr}$ da PTW, série 1253, foi utilizada para controle de estabilidade da câmara de ionização, onde sua atividade nominal era de 11,1 MBq em 1976.

A fonte de ${ }^{241} \mathrm{Am}$, com atividade nominal de 286,5 kBq (01/01/1981) foi fornecida pela Agência Internacional de Energia Atômica (IAEA) ao Laboratório de Metrologia Nuclear do Centro de Reatores de Pesquisa (CRPq) do IPEN que cedeu-a gentilmente para a calibração do sistema de espectrometria presente no laboratório LCl.

\subsubsection{Detetores de Radiação}

\subsubsection{Câmara de Ionização Cilíndrica do Tipo Dedal e Eletrômetro}

A câmara utilizada foi fabricada pela empresa PTW, modelo 31002, série 0389 com volume sensível de $0,125 \mathrm{~cm}^{3}$ (FIG. 24). Sua incerteza $( \pm 2 \%$ ) e seu fator de calibração $\left(3,047.10^{10} \mathrm{R} / \mathrm{C}\right)$ foi fornecido pelo seu certificado de calibração realizada pela empresa PTW FREIBURG. Nesse trabalho, a finalidade da câmara foi medir a intensidade dos feixes de raios $X$ para verificar $a$ 
uniformidade do campo de radiação. As pequenas dimensões foram determinantes para a escolha dessa câmara.

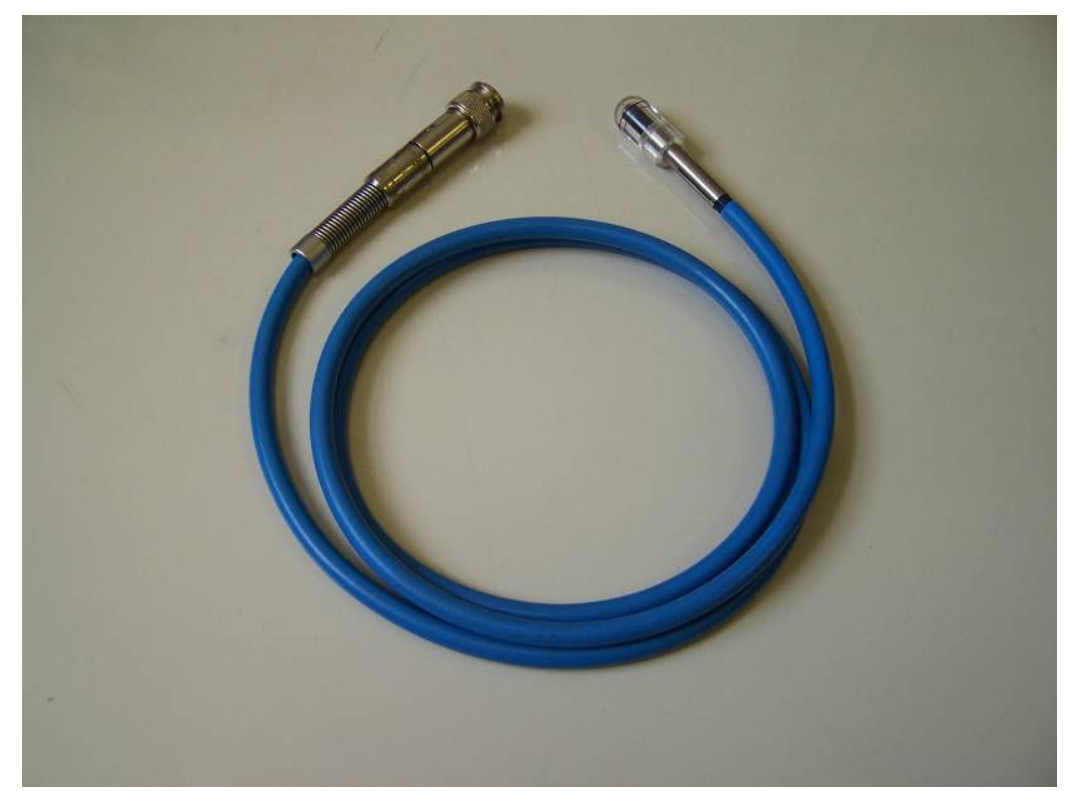

FIGURA 24 - Câmara cilíndrica do tipo dedal, modelo 31002, da PTW.

A câmara de ionização foi acoplada ao eletrômetro da PTW (FIG. 25), modelo Unidos E, tipo 10010, série 00212.

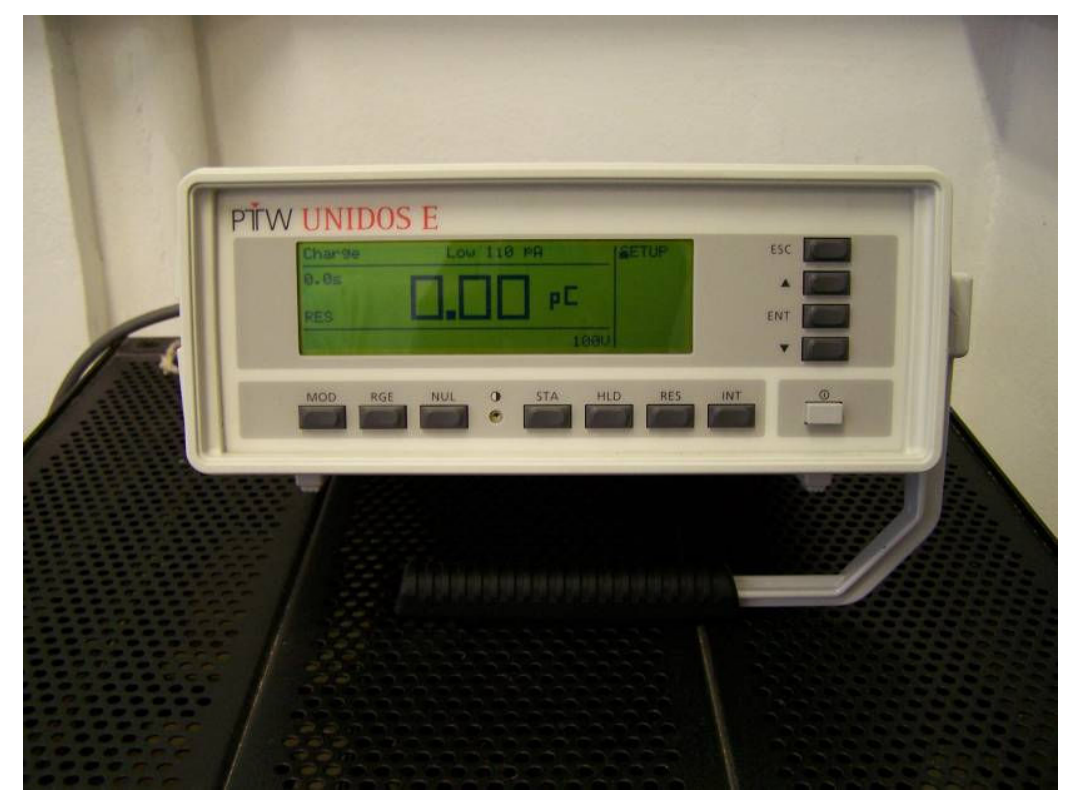

FIGURA 25 - Eletrômetro da PTW, modelo Unidos E, utilizado em conjunto com a câmara cilíndrica do tipo dedal. 


\subsubsection{Medidor não Invasivo Diavolt Universal}

O medidor não invasivo Diavolt Universal (FIG. 26), da fabricante PTW, proporciona as medições das grandezas tensão de pico $(k \bigvee p)$, tensão de pico prático (PPV), kerma no ar e tempo de exposição no intervalo de 40 a 150 kV, no modo radiodiagnóstico. $\mathrm{O}$ aparelho utilizado possui rastreabilidade ao PTB (Physikalisch-Technische Bundesanstalt) e seu certificado é apresentado no ANEXO A contendo as informações das incertezas de calibração utilizadas para estimar as incertezas no tratamento dos dados adquiridos.

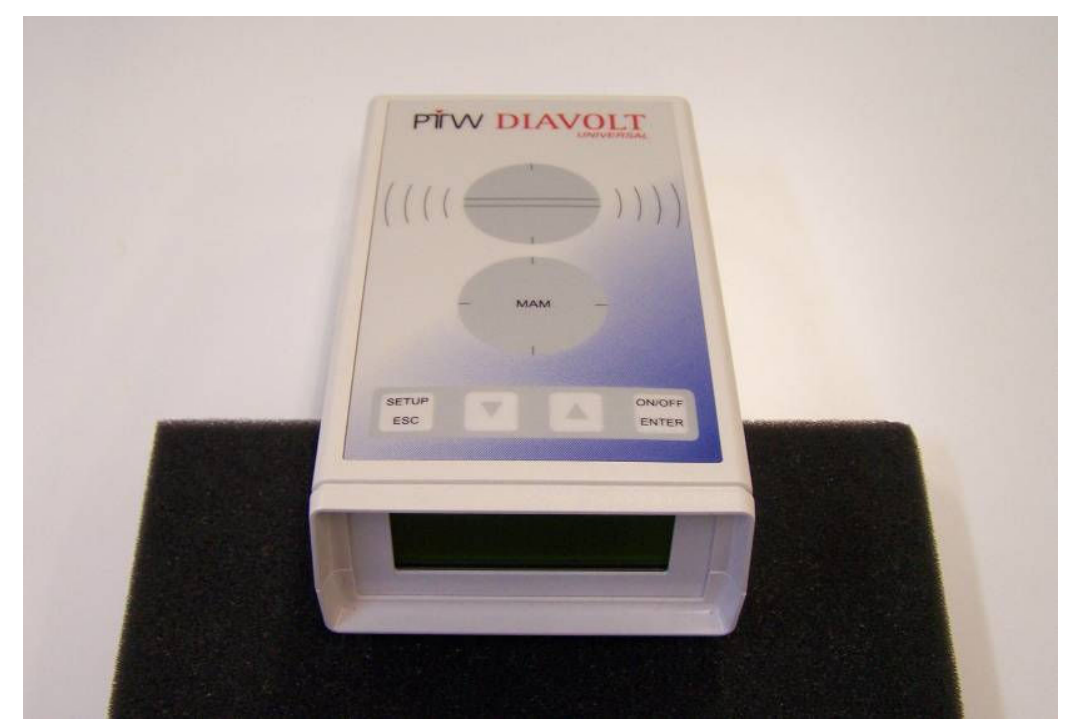

FIGURA 26 - Medidor não invasivo Diavolt Universal da PTW.

A grandeza kerma no ar foi obtida por meio da calibração no Laboratório de Calibração de Instrumentos (LCI) nas Qualidades RQR 3, 5 e 8 e seu certificado está apresentado no ANEXO B. Para as demais qualidades (RQR 2, 4, 6, 7 e 10), os fatores de calibração foram obtidos através da interpolação e extrapolação a partir de um polinômio de grau 3 dos fatores de correção das qualidades conhecidas (FIG. 27). Esses fatores interpolados e extrapolados foram utilizados para a determinação de todos os valores de kerma no ar medidos pelo Diavolt. 


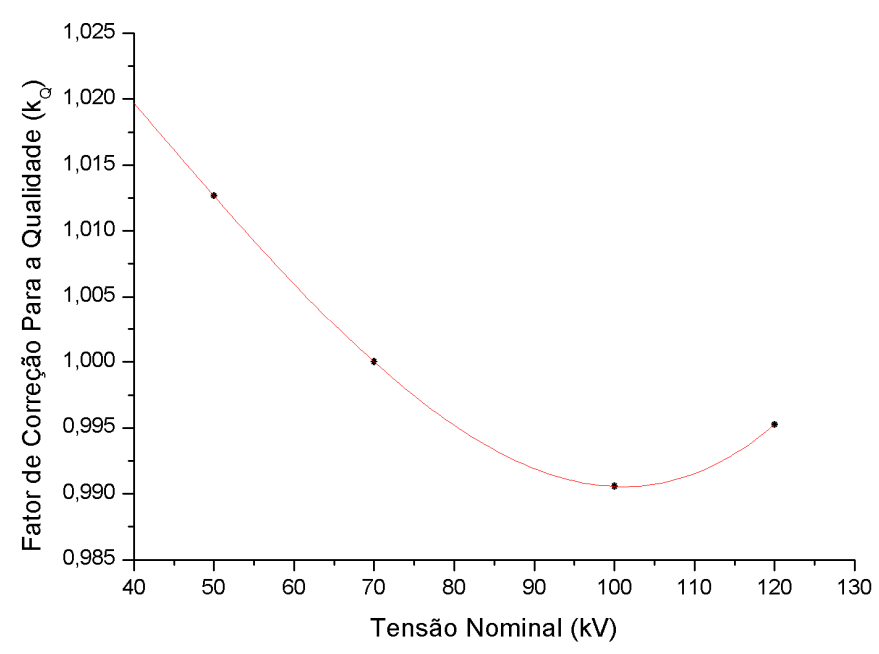

FIGURA 27 - Curva de Interpolação e extrapolação utilizada para a determinação dos fatores de correção $\left(k_{Q}\right)$ para as qualidades não fornecidas pelo certificado de calibração da PTB.

\subsubsection{Sistema de Espectrometria}

O sistema espectrométrico utilizado foi fabricado pela empresa EG\&G Ortec, modelo NOMAD-PLUS 92X (FIG. 28), que possui um detetor de estado sólido (semicondutor) HPGe (Germânio de alta pureza), modelo GLP-16195/10P. Para a refrigeração do detetor semicondutor, o aparelho precisa ser abastecido com nitrogênio líquido. Sua janela de incidência de radiação possui um diâmetro de $3 \mathrm{~cm}$ com uma espessura de 0,5 mm, cuja composição é de Berílio.

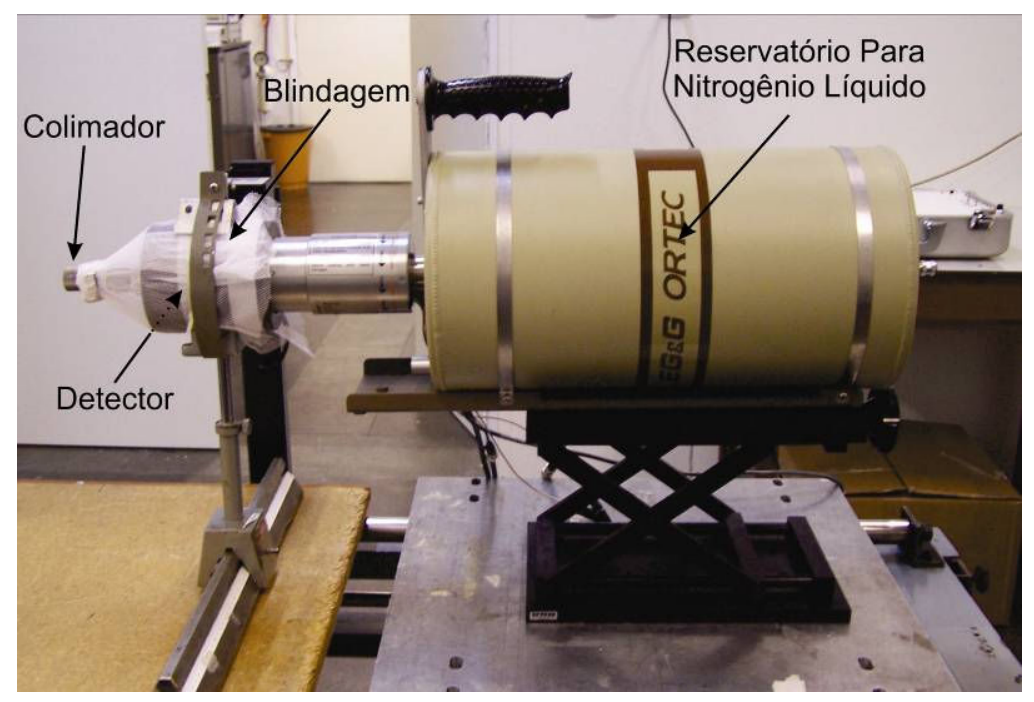

FIGURA 28 - Sistema espectrométrico da Ortec utilizado para a realização da espectrometria. 
Todos os dados obtidos pelo espectrômetro foram registrados por um computador (FIG. 29) acoplado ao sistema de aquisição, e o software utilizado foi o Maestro ${ }^{1}$, da própria empresa fabricante do sistema espectrométrico.

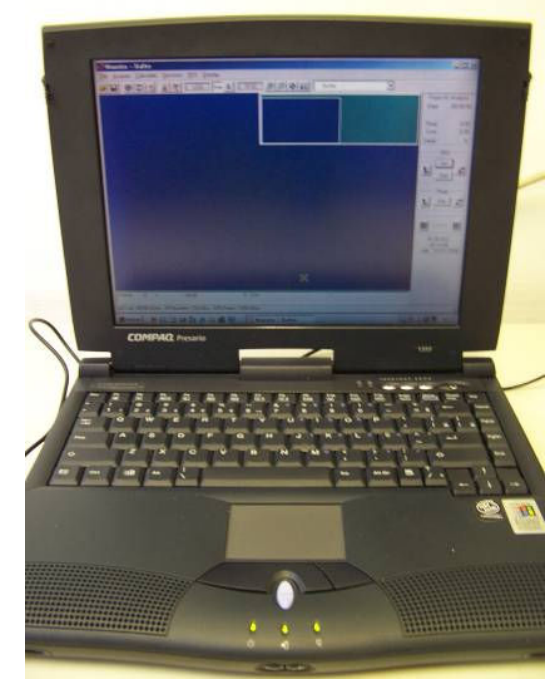

FIGURA 29 - Computador acoplado ao sistema de espectrometria com o software Maestro instalado.

\subsubsection{Sistemas Auxiliares}

A seguir são listados e descritos os demais sistemas utilizados para auxiliar na realização das medições:

- Colimadores para delimitar o feixe de raios X durante a espectrometria. Foram utilizados alternadamente 2 colimadores posicionados próximos a janela do espectrômetro. O primeiro (FIG. 30a), com $1 \mathrm{~mm}$ de diâmetro e $8 \mathrm{~mm}$ de espessura, é composto de chumbo e foi fabricado no IPEN. O segundo (FIG. 30b), fabricado pela empresa Amptek, modelo EXVC, é constituído internamente por um disco colimador de $0,1 \mathrm{~mm}$ de diâmetro de uma liga de Tungstênio (90\%), Níquel (6\%) e Cobre (4\%), posicionado em um cilindro de latão, onde ambos são revestidos por um extensor cilindrico de aço inoxidável.

\footnotetext{
${ }^{1}$ Maestro $^{\mathrm{TM}} 32$ (modelo A65-B32) vinculado ao espectrômetro da empresa Ortec.
} 


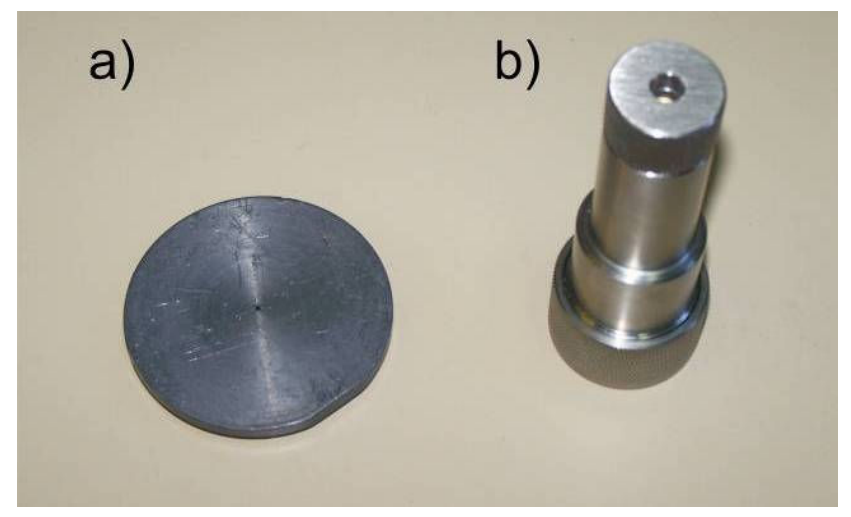

FIGURA 30 - Colimadores utilizados durante as aquisições de espectrometria. a) Colimador confeccionado no Ipen. b) Colimador Amptek.

- Régua de aço KDS de $100 \mathrm{~cm}$ com precisão de \pm 0,05 cm.

- Termômetro Hart Scientific, modelo 1529, com precisão de $\pm 0,0025^{\circ} \mathrm{C}$.

- Barômetro GE Druck, modelo DPI 142, calibrado em 13/02/2006 com resolução de 0,01\%.

- Higrômetro Präzision-Faden (Alemanha) com intervalo de medida entre 0 e $100 \%$ e precisão de $1 \%$ de umidade relativa do ar .

- Cronômetro Nuclear Enterprises, USA, modelo Laboratory Timer no 2546, com intervalo de medida de 0,001 a 9999,99 s. Precisão de $\pm 0,001 \mathrm{~s}$.

- Filtros adicionais de Alumínio e Cobre com pureza maior que 99,9\%.

- Transferidor Maped com precisão de 0,50.

- Micrômetro Mitutoyo com precisão de \pm 0,01 mm.

\subsection{Procedimentos Experimentais}

Os procedimentos experimentais serão descritos de acordo com o detetor utilizado e o tipo de medição realizada. As filtrações adicionais (TAB. 2) utilizadas nos procedimentos experimentais foram baseadas nos estudos de Franciscatto (2009) para a caracterização das Qualidades de Radiação $X$ para Radiodiagnóstico (RQR) a partir da norma International Eletrotechnical Commission, IEC 61267 (2005). As filtrações utilizadas para a determinação da tensão de pico com o sistema de espectrometria foram baseadas nas formas dos espectros gerados. 
TABELA 2 - Filtração adicional utilizada para cada qualidade de radiação em radiodiagnóstico (Franciscatto, 2000).

\begin{tabular}{ccc}
\hline $\begin{array}{c}\text { Qualidade } \\
\text { de Radiação }\end{array}$ & $\begin{array}{c}\text { Tensão } \\
\text { Nominal (kV) }\end{array}$ & $\begin{array}{c}\text { Filtração } \\
\text { Adicional (mmAl) }\end{array}$ \\
\hline RQR 2 & 40 & 2,3 \\
RQR 3 & 50 & 2,4 \\
RQR 4 & 60 & 2,7 \\
RQR 5 & 70 & 2,8 \\
RQR 6 & 80 & 3,0 \\
RQR 7 & 90 & 3,1 \\
RQR 8 & 100 & 3,2 \\
RQR 9 & 120 & 3,5 \\
RQR 10 & 150 & 4,2 \\
\hline
\end{tabular}

\subsubsection{Testes Realizados Com a Câmara de Ionização do Tipo Dedal}

\subsubsection{Teste de Repetibilidade, Estabilidade a Longo Prazo e de Fuga}

\section{Corrente}

Antes, durante e depois da utilização da câmara tipo dedal no feixe de raios $X$ foram realizados testes de repetibilidade, estabilidade a longo prazo e teste de fuga de corrente com a fonte radioativa de ${ }^{90} \mathrm{Sr}$. O arranjo desses testes pode ser observado na FIG. 31. 


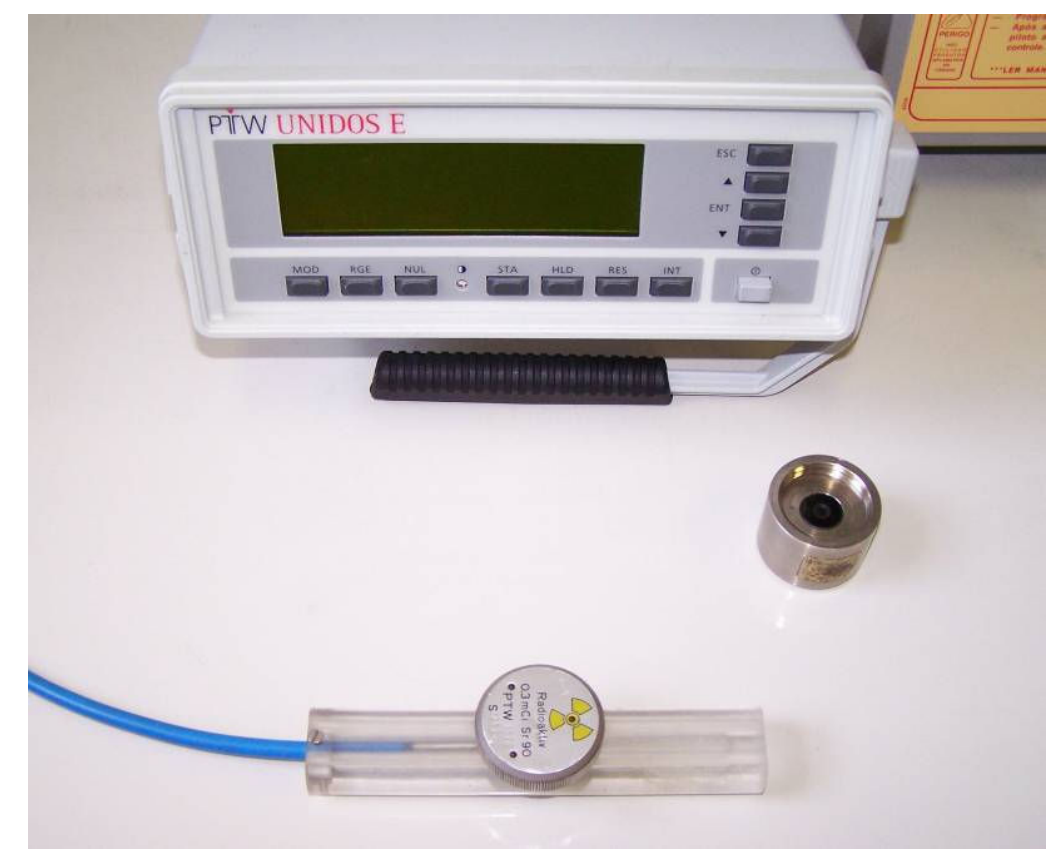

FIGURA 31 - Arranjo experimental para a realização dos testes de repetibilidade, estabilidade a longo prazo e de fuga.

O teste de repetibilidade consistiu na realização de 10 medições de $60 \mathrm{~s}$, cada, da câmara com a fonte posicionada próximo ao seu volume sensível. Em seguida foi calculado o desvio padrão percentual e comparado com as normas internacionais vigentes. Já o teste de estabilidade a longo prazo consistiu em realizar o teste de repetibilidade semanalmente ao longo do período de desenvolvimento deste trabalho levando em consideração o decaimento radioativo da fonte utilizada. Os valores médios dos testes de repetibilidade foram comparados com um valor de referência encontrado no certificado de calibração da câmara.

O teste de fuga de corrente foi realizado para verificar se o eletrômetro não estava registrando um sinal que não advém de uma ionização ocorrida no volume sensível da câmara ou que não estava perdendo sinal coletado ao longo das medições. Para a realização desse teste a câmara foi irradiada por uma fonte radioativa de ${ }^{90} \mathrm{Sr}$ por $60 \mathrm{~s}$, em seguida a fonte foi retirada e o valor registrado pelo eletrômetro foi anotado. Passados 600 s e 1200 s, os valores registrados pelo eletrômetro novamente foram anotados visando observar algum tipo de variação. A variação percentual calculada foi comparada com a norma IEC 60731 (1997) que estabele limite para esta variação. Os testes de fuga foram realizados juntamente com os de repetibilidade, ou seja, semanalmente. 
Em todos os testes foram anotados os valores da temperatura e pressão em cada medição para a determinação do fator de correção possibilitando a correção do valor medido. Além disso, todas as medições foram realizadas com a umidade relativa do ar entre 50 e 55\%. Para garantir a confiabilidade nas medições efetuadas o mesmo arranjo experimental foi mantido durante a realização de todos os testes.

\subsubsection{Teste de Homogeneidade do Campo de Radiação}

O teste para verificar a uniformidade do campo de radiação $X$ foi realizado em 2 distâncias distintas da câmara de ionização em relação ao ponto focal do aparelho de raios $X: 1$ e 2,5 m. Essas distâncias foram escolhidas por serem as utilizadas para a calibração de diversos detetores de radiação (1,0 m e 2,5 m). As medições da primeira distância foram realizadas com 0 aparelho de raios $X$ configurado com corrente elétrica de $10 \mathrm{~mA}$, tensão nominal de $70 \mathrm{kV}$ com filtração adicional de 2,5 mm de alumínio e colimador de 50,8 mm de diâmetro na saída do feixe de raios $X$. Os mesmos valores foram utilizados na segunda distância, com exceção da corrente que foi configurada em 20 mA e do colimador, que foi trocado por um de 70,5 mm de diâmetro.

A câmara foi posicionada com seu volume sensível posicionado no centro do campo de raios $X$, como pode ser observado na FIG. 32, e foram feitas medições de kerma no ar varrendo o campo nas direções horizontal e vertical com intervalos de $1 \mathrm{~cm}$ (FIG. 33). Os posicionadores à laser presentes no sistema de radiação $X$ foram utilizados como referência para a varredura do campo de radiação pela câmara na vertical e na horizontal. Em cada posição foram realizadas 5 medições, onde cada uma durou $60 \mathrm{~s}$. 


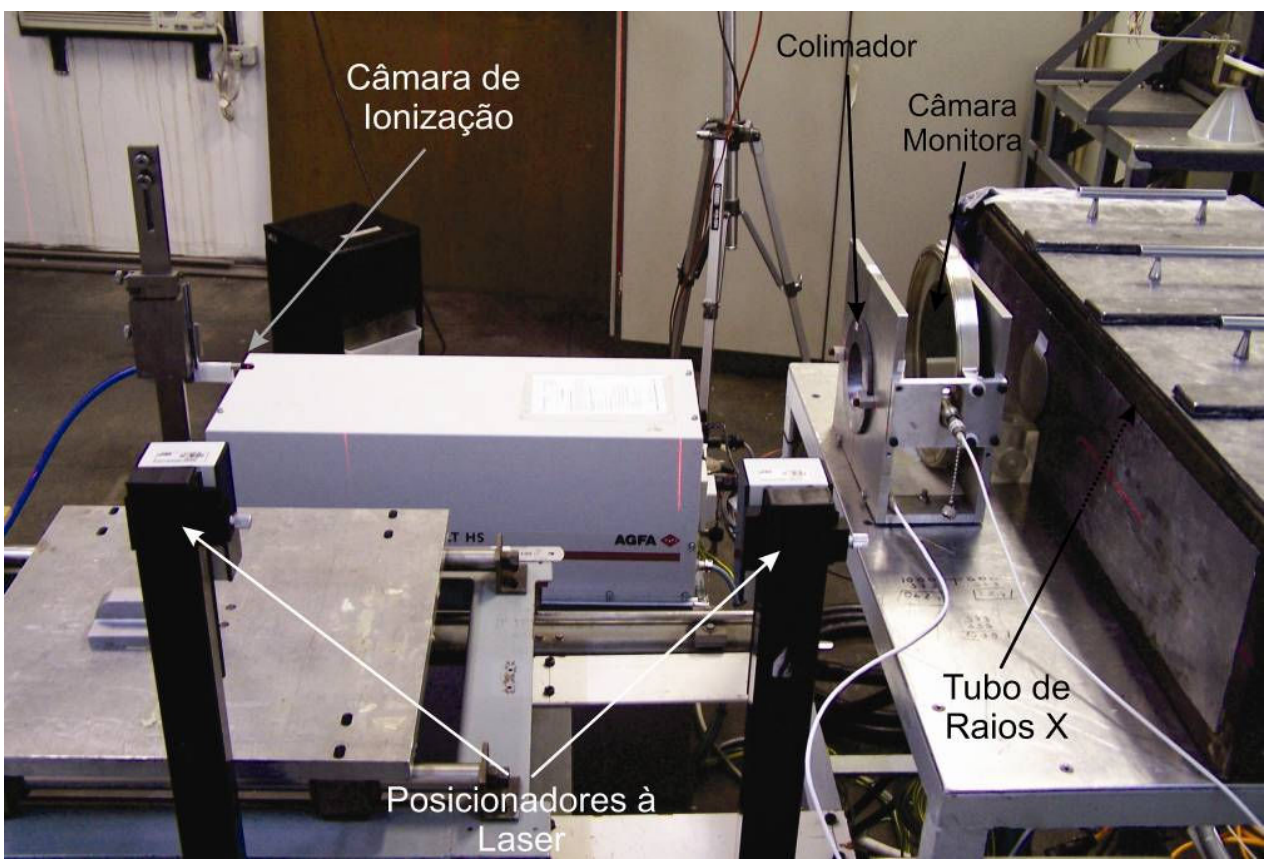

FIGURA 32 - Posicionamento da câmara, em relação ao aparelho de raios X, durante o teste de homogeneidade do feixe.

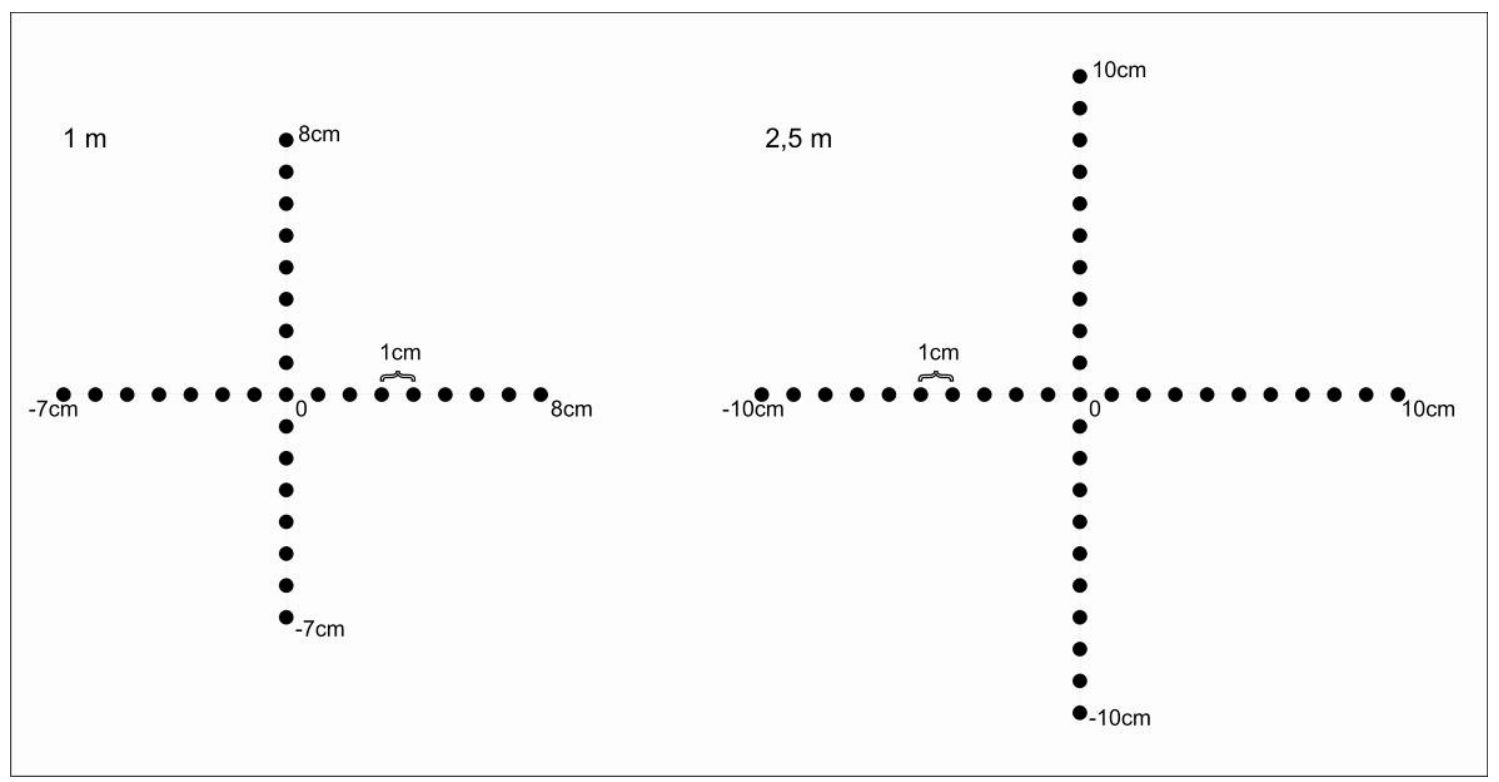

FIGURA 33 - Varredura do campo de radiação X pela câmara de ionização a 1 e $2 \mathrm{~m}$ de distância do ponto focal do aparelho de raios $X$.

\subsubsection{Medidas Com o Medidor de Tensão não Invasivo Diavolt}

Com o medidor Diavolt, foram feitos diversos testes variando alguns parâmetros e fixando outros visando um controle de qualidade do medidor, bem 
como do aparelho de raios X. Em todas as medições, o medidor (Diavolt) foi posicionado na vertical com a tela de leitura voltada para cima (FIG. 34) e centralizado de acordo com os feixes de laser instalados servindo de sistema de referência para o posicionamento dos detetores. Em todos os casos, foram medidos a tensão de pico média (média calculada pelo Diavolt de todas as tensões de pico adquiridas no intervalo de 60s), a tensão de pico prático e o kerma no ar com cada medição tendo duração de $60 \mathrm{~s}$, sendo repetidas 10 vezes em cada configuração. A temperatura e a umidade ambientais foram controladas permitindo a realização das medições sem nenhum tipo de problema. Para a escolha dos parâmetros, foram feitas uma série de medições com diversas configurações para verificar o comportamento do aparelho Diavolt e suas limitações e dessa maneira escolher os melhores parâmetros para os testes realizados.

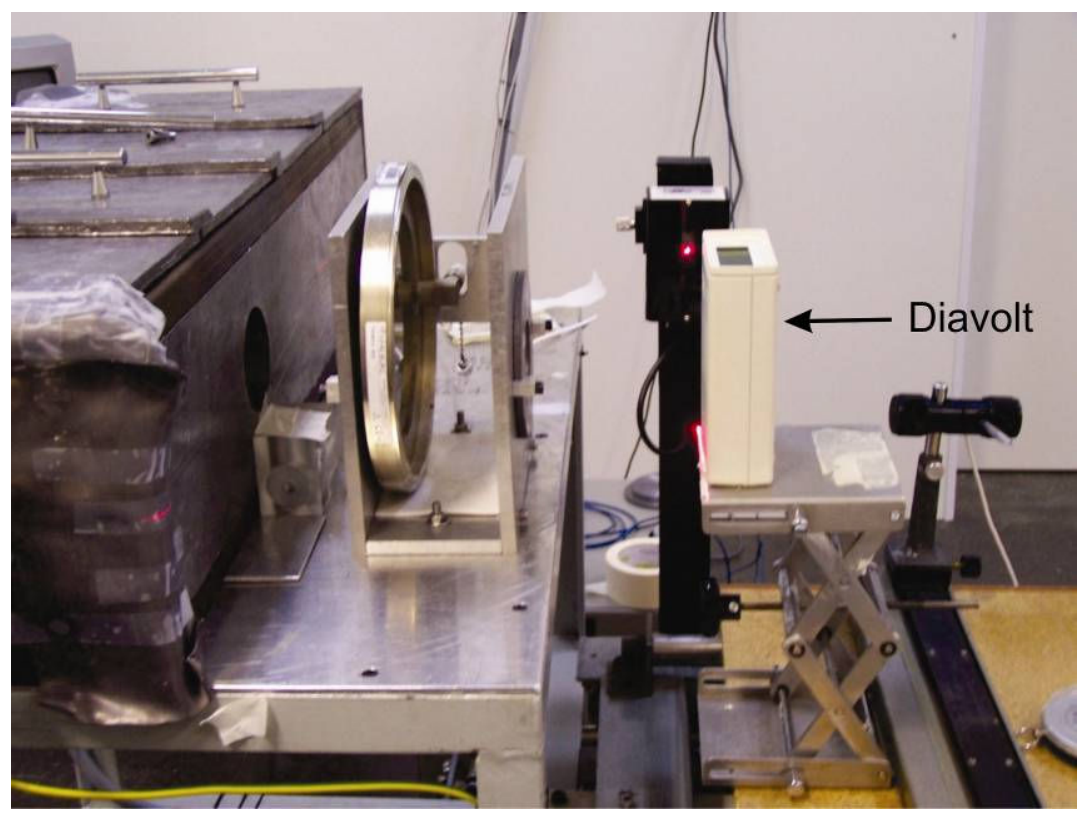

FIGURA 34 - Posicionamento do medidor Diavolt em relação ao sistema de radiação $X$.

\subsubsection{Corrente Elétrica}

O medidor foi posicionado a $1 \mathrm{~m}$ do ponto focal do aparelho de raios $\mathrm{X}$ com todo o sistema configurado nas Qualidades RQR 5 e RQR 9. Foram efetuadas medições com a corrente elétrica em 3, 5, 8, 10, 15, 20 e 25 mA. 


\subsubsection{Qualidades de Radiação para Radiodiagnóstico}

O medidor foi posicionado a $1 \mathrm{~m}$ (distância de calibração) do ponto focal do aparelho de raios $X$ com a corrente elétrica fixada em $25 \mathrm{~mA}$. Foram efetuadas medições nas Qualidades RQR 2, 3, 4, 5, 6, 7, 8, 9 e 10, onde o medidor não conseguiu fazer as leituras na RQR 10 por limitações técnicas.

\subsubsection{Distância}

Todo o sistema foi configurado nas Qualidades RQR 5 e RQR 9 com a corrente elétrica fixada em $20 \mathrm{~mA}$ e as distâncias entre medidor e ponto focal do aparelho de raios $X$ foram variadas de $0,5 \mathrm{~m}$ a $3 \mathrm{~m}$ com intervalos de $0,5 \mathrm{~m}$.

\subsubsection{Variação Angular}

O medidor foi posicionado a $1 \mathrm{~m}$ do ponto focal do aparelho de raios $\mathrm{X}$ com todo o sistema configurado na Qualidade RQR 5 e a corrente elétrica fixada em $20 \mathrm{~mA}$. A área sensível do medidor foi rotacionada entre $-60^{\circ}$ e $60^{\circ}$ (FIG. 35) e medições em ângulos diferentes foram efetuadas.

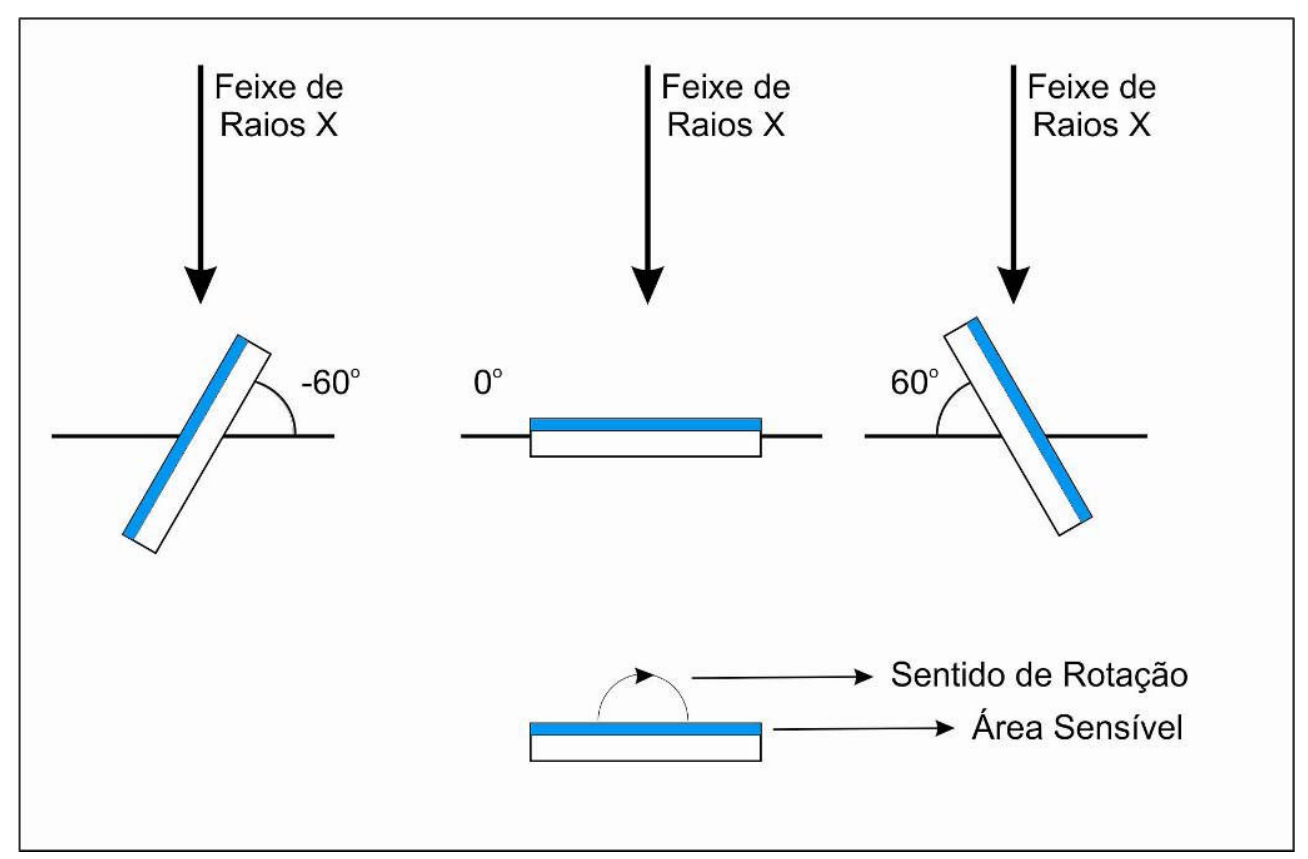

FIGURA 35 - Exemplos de posicionamento do medidor com a variação angular. 


\subsubsection{Sistema de Espectrometria}

Antes da realização das medições dos espectros nos feixes de raios $X$, o espectrômetro precisou ser calibrado com a fonte de ${ }^{241} \mathrm{Am}$. Foi utilizado o pico de 59,537 keV como referência para ajustar os canais no software Maestro.

Para a medição dos espectros, o espectrômetro foi posicionado a 2,5 $\mathrm{m}$ do ponto focal do aparelho de raios X. Esse posicionamento distante foi escolhido pela alta sensibilidade do espectrômetro que apresentava um tempo morto alto quando utilizado mais próximo do ponto focal. Pelo mesmo motivo de sensibilidade, foram escolhidas no painel do aparelho de raios $X$ as correntes mais baixas para a aquisição dos dados: 0,2 $\mathrm{mA}$ para os espectros referentes a determinação das tensões de pico e 0,1 mA para o restante dos espectros.

Inicialmente, as medições foram efetuadas com o colimador de $1 \mathrm{~mm}$ de diâmetro posicionado próximo a janela de incidência de radiação do espectrômetro, no entanto devido a resultados indesejados (presença do efeito de borda K), esse colimador foi substituído pelo de $0,1 \mathrm{~mm}$ de diâmetro e as medições foram refeitas.

$\mathrm{Na}$ primeira etapa, foram adquiridos os espectros sem filtração adicional nas tensões nominais de 25, 50, 70, 100, 120 e 150 kV. Cada aquisição durou cerca de 8 minutos.

Em seguida foram efetuados os espectros referentes às Qualidades de Radiação X para Radiodiagnóstico (RQR) com cada espectro sendo adquirido por volta de 10 minutos.

Por último, foram realizados os espectros com o objetivo de determinar a tensão de pico (kVp). As tensões nominais selecionadas no painel do aparelho de raios $X$ foram: $25,28,30,35,40,50,60,70,80,90,100,110,120,130,140$ e 150 kV. Para cada tensão selecionada, foram testadas várias espessuras de filtrações visando diminuir o empilhamento de pulsos e melhorar os espectros para a determinação da tensão de pico. A TAB. 3 mostra os materiais utilizados para a aquisição final desses espectros e suas respectivas espessuras.

Em todos os espectros gerados, foram calculadas as energias médias por fóton de raios $X$ visando analisar o comportamento do feixe de raios $X$ com 0 aumento da filtração adicional. A energia média por fóton foi calculada integrando a curva de cada espectro e dividindo o valor pelo número total de contagens. 
TABELA 3 - Materiais e espessuras das filtrações adicionais utilizadas para a geração dos espectros referentes à determinação das tensões de pico $(k \bigvee p)$.

\begin{tabular}{clc}
\hline Tensão & \multicolumn{2}{c}{ Filtração Adicional } \\
\cline { 2 - 3 } Nominal $(\mathrm{kV})$ & Material & Espessura $(\mathrm{mm})$ \\
\hline 25 & Alumínio & 2 \\
28 & Alumínio & 2 \\
30 & Alumínio & 3 \\
35 & Alumínio & 3 \\
40 & Alumínio & 10 \\
50 & Alumínio & 10 \\
60 & Alumínio & 16 \\
70 & Alumínio & 21 \\
80 & Cobre & 2,5 \\
90 & Cobre & 2,5 \\
100 & Cobre & 3,5 \\
110 & Cobre & 5,5 \\
120 & Cobre & 6 \\
130 & Cobre & 6,5 \\
140 & Cobre & 7 \\
150 & Cobre & 8 \\
\hline
\end{tabular}

Como as espessuras das filtrações adicionais foram bem superiores às das Qualidades em Radiodiagnóstico, o intervalo de tempo para cada medição foi aumentado para cerca de 50 minutos, assim como a corrente elétrica foi aumentada de $0,1 \mathrm{~mA}$ para $0,2 \mathrm{~mA}$.

\subsection{Incertezas}

As incertezas finais presentes nos resultados dessa dissertação para os detetores câmara de ionização tipo dedal e medidor não invasivo Diavolt foram determinadas partindo da equação da incerteza combinada (11), onde foram combinadas as incertezas de tipo A e de tipo B (TAB. 4 e 5) e por final determinada pela equação da incerteza expandida (13), onde foi escolhido o valor de 2,26 para o fator de abrangência, ou seja, um nível de confiança de $95 \%$. 
TABELA 4 - Fontes de incertezas utilizadas para a determinação das incertezas da câmara de ionização.

\begin{tabular}{ccc}
\hline Fonte de incerteza & Tipo & Incerteza \\
\hline Desvio Padrão & $\mathrm{A}$ & $s=\sqrt{\frac{1}{n-1} \sum_{i=1}^{n}\left(x_{i}-\bar{x}\right)^{2}}$ \\
Câmara de ionização (Calibração) & $\mathrm{B}$ & $\pm 2 \%$ \\
Eletrômetro (Resolução) & $\mathrm{B}$ & $\pm 0,5 \%$ \\
Eletrômetro (Calibração) & $\mathrm{B}$ & $\pm 0,5 \%$ \\
Régua de aço (Resolução) & $\mathrm{B}$ & $\pm 0,05 \mathrm{~cm}$ \\
Termômetro (Resolução) & $\mathrm{B}$ & $\pm 0,0025^{\circ} \mathrm{C}$ \\
Barômetro (Resolução) & $\mathrm{B}$ & $0,01 \%$ \\
Barômetro (Calibração) & $\mathrm{B}$ & $0,01 \%$ \\
Cronômetro (Resolução) & $\mathrm{B}$ & $\pm 0,001 \mathrm{~s}$ \\
Espessura das Filtraçães (micrômetro) & $\mathrm{B}$ & $\pm 0,01 \mathrm{~mm}$ \\
\hline
\end{tabular}

TABELA 5 - Fontes de incertezas utilizadas para a determinação das incertezas do medidor Diavolt.

\begin{tabular}{ccc}
\hline Fonte de incerteza & Tipo & Incerteza \\
\hline Desvio Padrão & $\mathrm{A}$ & $s=\sqrt{\frac{1}{n-1} \sum_{i=1}^{n}\left(x_{i}-\bar{x}\right)^{2}}$ \\
Diavolt (Resolução - Tempo) & $\mathrm{B}$ & $\pm 0,3 \mathrm{~ms}$ \\
Diavolt (Resolução - kerma no ar) & $\mathrm{B}$ & $\pm 2 \%$ \\
Diavolt (Resolução - kVp e PPV) & $\mathrm{B}$ & $\pm 1 \%$ \\
Diavolt (Calibração - kVp e PPV) & $\mathrm{B}$ & $\pm 2 \%$ \\
Diavolt (Calibração - kerma no ar) & $\mathrm{B}$ & $\pm 1,5 \%$ \\
Régua de aço (Resolução) & $\mathrm{B}$ & $\pm 0,05 \mathrm{~cm}$ \\
Termômetro (Resolução) & $\mathrm{B}$ & $\pm 0,0025{ }^{\circ} \mathrm{C}$ \\
Barômetro (Resolução) & $\mathrm{B}$ & $0,01 \%$ \\
Barômetro (Calibração) & $\mathrm{B}$ & $0,01 \%$ \\
Espessura das Filtrações (micrômetro) & $\mathrm{B}$ & $\pm 0,01 \mathrm{~mm}$ \\
\hline
\end{tabular}


As incertezas presentes na determinação das tensões de pico através dos espectros gerados pelo espectrômetro foram calculadas pelo software Origin $^{2}$ que ao fazer um ajuste linear no fim da curva do espectro pelo método dos mínimos quadrados forneceu uma incerteza desse ajuste referente à dispersão dos valores medidos em relação à reta ajustada. Como a resolução do espectrômetro fornecido pelo fabricante é $\leq \pm 0,03 \%$ e a calibração do aparelho pela fonte de ${ }^{241} \mathrm{Am}$ forneceu incertezas abaixo de $0,12 \%$, as fontes de incerteza do tipo B não contribuem de maneira significativa, em relação a incerteza de tipo $A$, para a determinação da incerteza final das medições. Logo, foram utilizadas somente as incertezas devido aos ajustes lineares realizados para a determinação da tensão de pico.

No cálculo das energias médias por fóton de raios $X$ não foram propagadas as incertezas, já que a análise estabelecida no trabalho foi meramente qualitativa visando observar apenas as tendências das energias médias por fóton com 0 aumento da filtração adicional.

\subsection{Critérios Para o Uso da Grandeza PPV (Norma IEC 61676, 2002)}

A norma IEC 61676 descreve alguns critérios para o uso da grandeza PPV e para os erros intrínsecos das medições efetuadas por um detetor não invasivo, em relação às tensões nominais configuradas em um aparelho de raios $X$, além de fornecer o algoritmo para a determinação da grandeza, como também pode ser visto na seção 2.6.5. Os máximos erros intrínsecos relativos (I) e absolutos (E) são dados pelas equações 14 e 15, respectivamente, onde a equação 14 se refere às tensões nominais acima de $50 \mathrm{kV}$ e a equação 15 às tensões nominais abaixo de $50 \mathrm{kV}$.

$$
\begin{gathered}
\||=| \frac{U_{\text {meas }}-U_{\text {true }}}{U_{\text {true }}} \mid \leq 0,02 \\
|E|=\left|U_{\text {meas }}-U_{\text {true }}\right| \leq 1 \mathrm{kV}
\end{gathered}
$$

\footnotetext{
${ }^{2}$ OriginPro 8 SRO - Copyright $\odot 1991$ - 2007 OriginLab Corporation
} 
Onde $U_{\text {meas }}$ é a grandeza PPV medida e $U_{\text {true }}$, a grandeza PPV verdadeira que pode ser substituída pelas tensões nominais selecionadas no aparelho de raios $X$.

Como não há uma norma equivalente para a grandeza tensão de pico, nesse trabalho foi utilizado o máximo erro intrínseco da norma IEC 61676 para a análise das tensões de pico determinadas por espectrometria e pelo medidor não invasivo Diavolt. No entanto, como os valores da tensão de pico prático são sempre inferiores ou, no máximo, iguais aos valores da tensão de pico, a margem de erro intrínseco recomendada pela norma IEC 61676 deve ser mais flexível para a grandeza tensão de pico, no caso em que os valores das duas grandezas se encontrem acima das tensões nominais. 


\section{RESULTADOS E DISCUSSÕES}

\subsection{Homogeneidade do Campo de Radiação X}

\subsubsection{Testes de Estabilidade da Câmara de Ionização}

Antes, durante e depois da realização dos testes para a verificação da uniformidade do campo de radiação $X$, foram realizados os devidos controles na câmara de ionização. Nos testes de repetibilidade e de estabilidade a longo prazo, os desvios padrões percentuais das medições não excederam 0,43\% e 0,45\%, respectivamente. Segundo a norma IEC 60731 (1997), a recomendação é que esses desvios padrões percentuais não devem exceder $0,5 \%$.

No teste de fuga de corrente, durante o tempo em que a câmara esteve exposta somente ao BG, este valor não excedeu a 0,48\% da leitura final (quando a câmara estava exposta a fonte de referência), sendo que a norma IEC 60731 (1997) recomenda que essa relação percentual não exceda 0,5\%.

Portanto, os testes de repetibilidade, de estabilidade a longo prazo e de fuga, realizados pela câmara do tipo dedal, atenderam as recomendações da norma vigente.

\subsubsection{Teste de Homogeneidade do Campo de Radiação}

Com os testes de controle mostrando resultados satisfatórios, o teste de homogeneidade do campo de radiação foi realizado. Os gráficos das FIG. 36 e 37 mostram as intensidades relativas dos feixes de radiação $X$ em posições distintas, visando varrer os campos de radiação nas direções verticais e horizontais. 


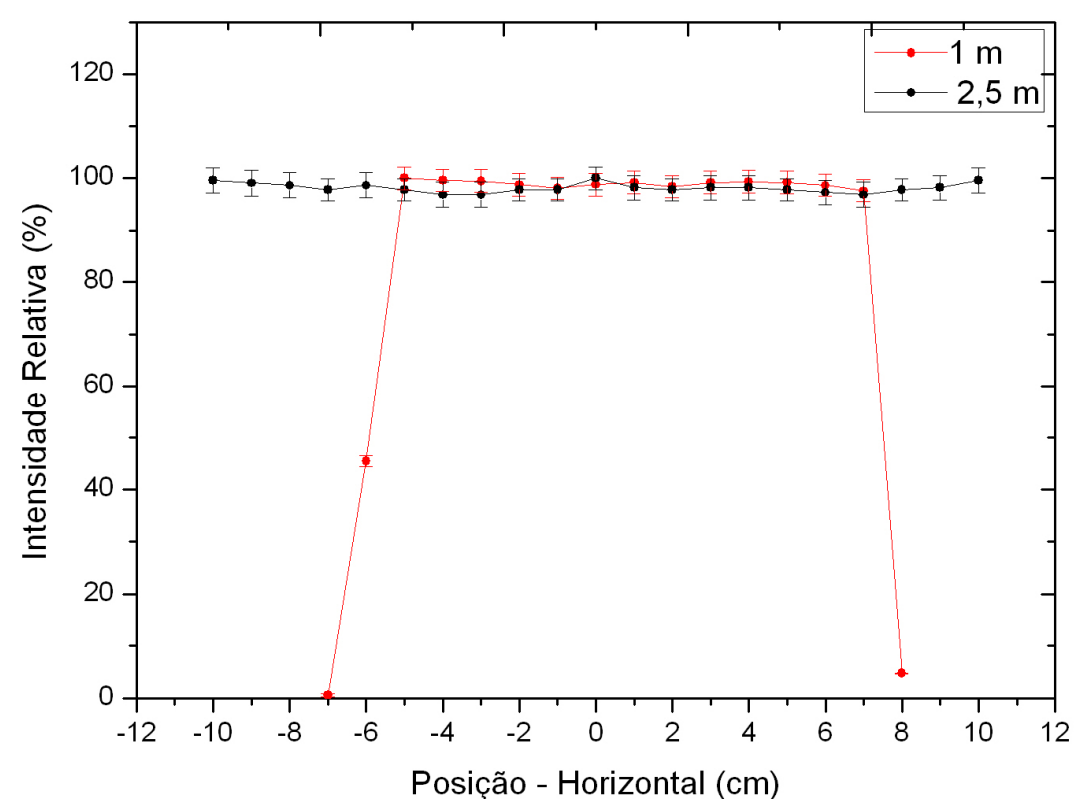

FIGURA 36 - Homogeneidade do campo de radiação $X$ na direção horizontal a 1 e 2,5 m de distância com colimadores de 50,8 e 70,5 mm de diâmetro, respectivamente.

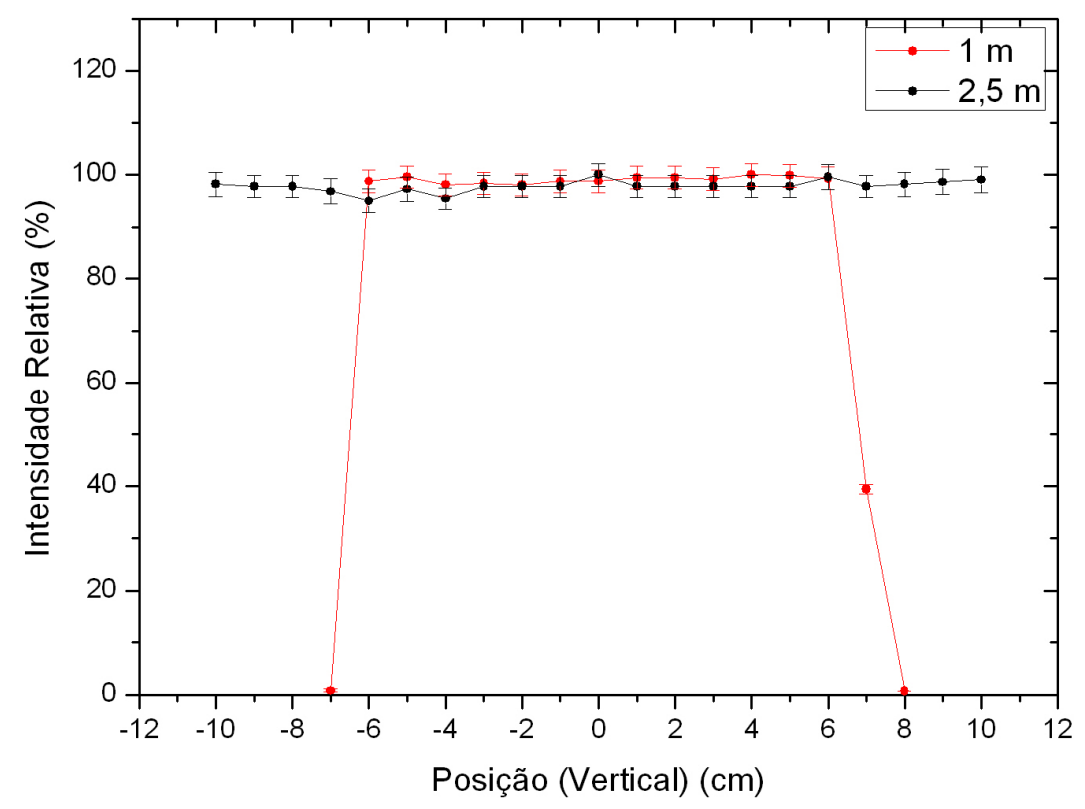

FIGURA 37 - Homogeneidade do campo de radiação $X$ na direção vertical a $1 \mathrm{e}$ 2,5 m de distância com colimadores de 50,8 e 70,5 mm de diâmetro, respectivamente.

Observando os gráficos das FIG. 36 e 37, nota-se que os pontos referentes às medições das intensidades relativas da radiação $X$ nas distâncias 1 e 2,5 m respeitam, aproximadamente, uma simetria ao redor da posição $0 \mathrm{~cm}$. Essa 
simetria aproximada indica uma homogeneidade no campo de radiação $X$, ou seja, o efeito anódico não é verificado. Essa homogeneidade também é comprovada pelo fato das leituras da intensidade relativa apresentarem valores superiores a 95\% (porcentagem referente à leitura na posição zero), de acordo com os Requisitos para Operação de Laboratórios de Calibração de Instrumentos de Medição para Radiação Ionizante Usados em Radioproteção (2004). Esse fenômeno foi corrigido em estudo anterior (Maia, 2005), mas como recentemente o aparelho de raios $X$ foi removido de lugar por motivo de manutenção corretiva, sentiu-se a necessidade de uma nova verificação da uniformidade do campo e como constatado, o tubo de raios $X$ não sofreu nenhum deslocamento dentro do alojamento do tubo.

As medições efetuadas a $1 \mathrm{~m}$ de distância do ponto focal do aparelho de raios $X$ varreram o campo de radiação em um diâmetro de $15 \mathrm{~cm}$, onde a partir daí, a câmara passou a não registrar mais a presença do feixe de raios $X$. Portanto, o colimador de 50,8 mm delimitou o feixe deixando-o com um diâmetro de $15 \mathrm{~cm}$ na distância de $1 \mathrm{~m}$, ou seja, um medidor posicionado a essa distância deve ter um volume sensível tal que suas dimensões superficiais não ultrapassem os limites estabelecidos pela colimação do feixe. Já a 2,5 m de distância, o campo foi varrido em um diâmetro de $20 \mathrm{~cm}$, sendo que em nenhum momento o feixe foi atenuado consideravelmente. Portanto, não foi possível identificar experimentalmente o diâmetro do campo de radiação nessa distância, o que não é um grande problema, já que todos os detetores utilizados no laboratório possuem dimensões inferiores ao diâmetro do campo de radiação varrido e seus volumes sensíveis são completamente irradiados pelo feixe de radiação. No entanto, o diâmetro do campo nesta distância pôde ser calculado por geometria elementar (semelhança de triângulos) por meio do conhecimento do diâmetro do colimador presente na distância de $36,3 \mathrm{~cm}(70,5 \mathrm{~mm})$, onde o valor encontrado foi de aproximadamente $48,5 \mathrm{~cm}$.

Por último, verifica-se, a $1 \mathrm{~m}$ de distância, que o campo está deslocado a 0,5 cm para direita e para cima, em relação ao sistema de raios laser utilizados como referência. Esse deslocamento é constatado quando observado que os eixos de simetria dos campos não estão na posição 0 e $\operatorname{sim}$ na posição $0,5 \mathrm{~cm}$. A correção desse deslocamento deve ser efetuada ajustando o sistema de referência através de calibração por profissionais da área. 


\subsection{Medidor não invasivo Diavolt}

O primeiro teste com o aparelho Diavolt forneceu informações da dependência dos valores do kerma no ar, da tensão de pico e da tensão de pico prático com a variação da corrente elétrica, único parâmetro variável durante cada conjunto de medições (70 e 120 kV). Nas TAB. 6 e 7, observa-se os resultados obtidos com suas respectivas incertezas.

TABELA 6 - Valores das medições efetuadas, pelo Diavolt, no teste de dependência da corrente elétrica para a tensão nominal de $70 \mathrm{kV}$.

\begin{tabular}{cccc}
\hline \multirow{2}{*}{$\begin{array}{c}\text { Corrente } \\
(\mathrm{mA})\end{array}$} & $\begin{array}{c}\text { Kerma no } \\
\text { ar (mGy) }\end{array}$ & $\begin{array}{c}\text { Tensão de } \\
\text { Pico }(\mathrm{kV})\end{array}$ & $\begin{array}{c}\text { PPV } \\
(\mathrm{kV})\end{array}$ \\
\hline 3 & $11,33 \pm 0,42$ & $73,05 \pm 2,16$ & $71,60 \pm 2,12$ \\
5 & $18,81 \pm 0,70$ & $72,72 \pm 2,15$ & $71,60 \pm 2,12$ \\
8 & $30,01 \pm 1,12$ & $72,50 \pm 2,14$ & $71,62 \pm 2,12$ \\
10 & $37,48 \pm 1,39$ & $72,40 \pm 2,14$ & $71,64 \pm 2,12$ \\
15 & $56,09 \pm 2,09$ & $72,27 \pm 2,14$ & $71,70 \pm 2,12$ \\
20 & $74,70 \pm 2,78$ & $72,22 \pm 2,13$ & $71,70 \pm 2,12$ \\
25 & $93,31 \pm 3,47$ & $72,20 \pm 2,13$ & $71,80 \pm 2,12$ \\
\hline
\end{tabular}

TABELA 7 - Valores das medições efetuadas, pelo Diavolt, no teste de dependência da corrente elétrica para a tensão nominal de 120 kV.

\begin{tabular}{cccc}
\hline \multirow{2}{*}{$\begin{array}{c}\text { Corrente } \\
(\mathrm{mA})\end{array}$} & $\begin{array}{c}\text { Kerma } \\
\text { no ar (mGy) }\end{array}$ & $\begin{array}{c}\text { Tensão de } \\
\text { Pico }(\mathrm{kV})\end{array}$ & $\begin{array}{c}\text { PPV } \\
(\mathrm{kV})\end{array}$ \\
\hline 3 & $27,26 \pm 1,01$ & $124,08 \pm 3,65$ & $121,99 \pm 3,59$ \\
5 & $45,30 \pm 1,70$ & $123,72 \pm 3,64$ & $122,01 \pm 3,59$ \\
8 & $72,22 \pm 2,69$ & $123,51 \pm 3,63$ & $122,20 \pm 3,60$ \\
10 & $90,37 \pm 3,37$ & $123,48 \pm 3,63$ & $122,30 \pm 3,60$ \\
15 & $135,24 \pm 5,02$ & $123,39 \pm 3,63$ & $122,40 \pm 3,60$ \\
20 & $180,14 \pm 6,68$ & $123,21 \pm 3,63$ & $122,45 \pm 3,60$ \\
25 & $224,93 \pm 8,34$ & $123,20 \pm 3,62$ & $122,50 \pm 3,60$ \\
\hline
\end{tabular}


As incertezas variaram de 2,9 a 3,7\% para os testes realizados na tensão nominal de $70 \mathrm{kV}$, onde a mesma variação foi observada na tensão de $120 \mathrm{kV}$, o que mostra que a precisão do aparelho Diavolt independe da tensão nominal selecionada. Em todos os valores de tensão de pico e tensão de pico prático, os erros intrínsecos relativos estão abaixo de 1,5\%, ou seja, a norma IEC 61676 (2002) é obedecida e todas as configurações podem ser utilizadas no laboratório.

Para uma melhor representação dos valores dos testes de dependência com a corrente elétrica, foram plotados os gráficos das FIG. 38, 39 e 40 destacando cada uma das grandezas estudadas em cada gráfico e os devidos ajustes (todos as funções ajustadas de todos os testes com o Diavolt são mostradas com maior detalhe no ANEXO C ).

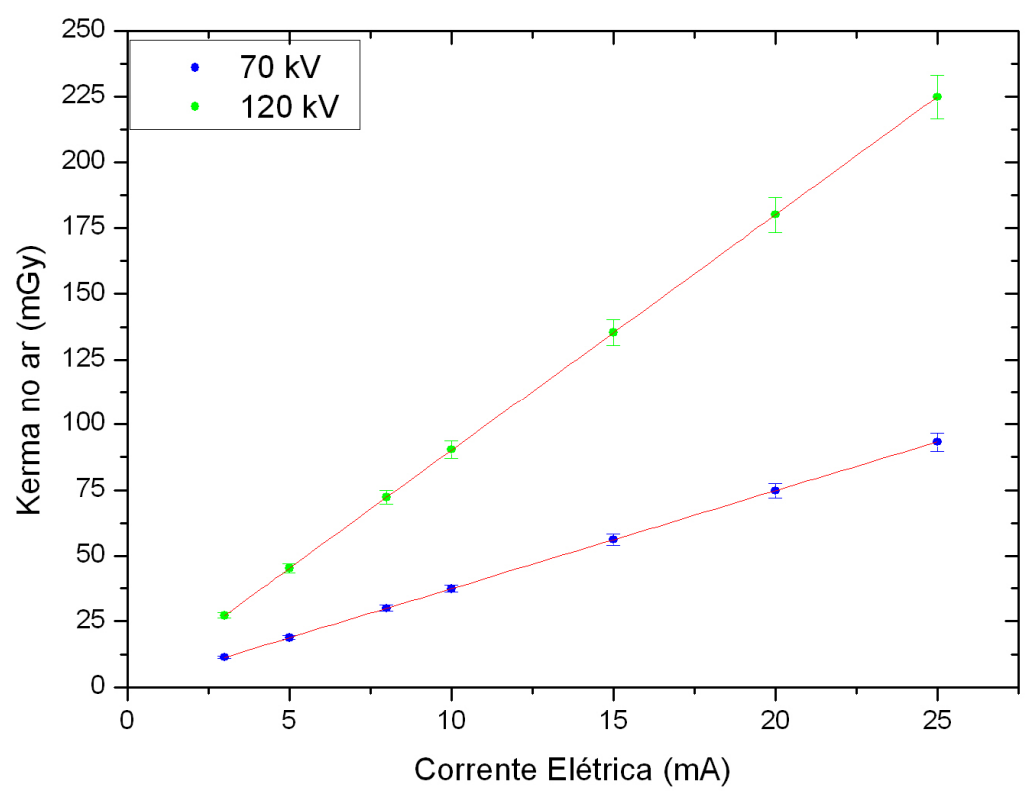

FIGURA 38 - Respostas da grandeza kerma no ar com a variação da corrente elétrica nas tensões nominais de 70 e $120 \mathrm{kV}$.

O kerma no ar é uma grandeza é linearmente proporcional a corrente elétrica e observando o gráfico da FIG. 38, nota-se que essa proporção é respeitada nas duas tensões nominais, já que as retas ajustadas nos dois casos passam entre as barras de incerteza de todos os pontos. Portanto, esses resultados indicam que não há, no laboratório, nenhuma fonte externa interferindo no feixe de raios $X$, assim como nenhum objeto provocando um retroespalhamento significativo e interferindo nas medições do detetor. 


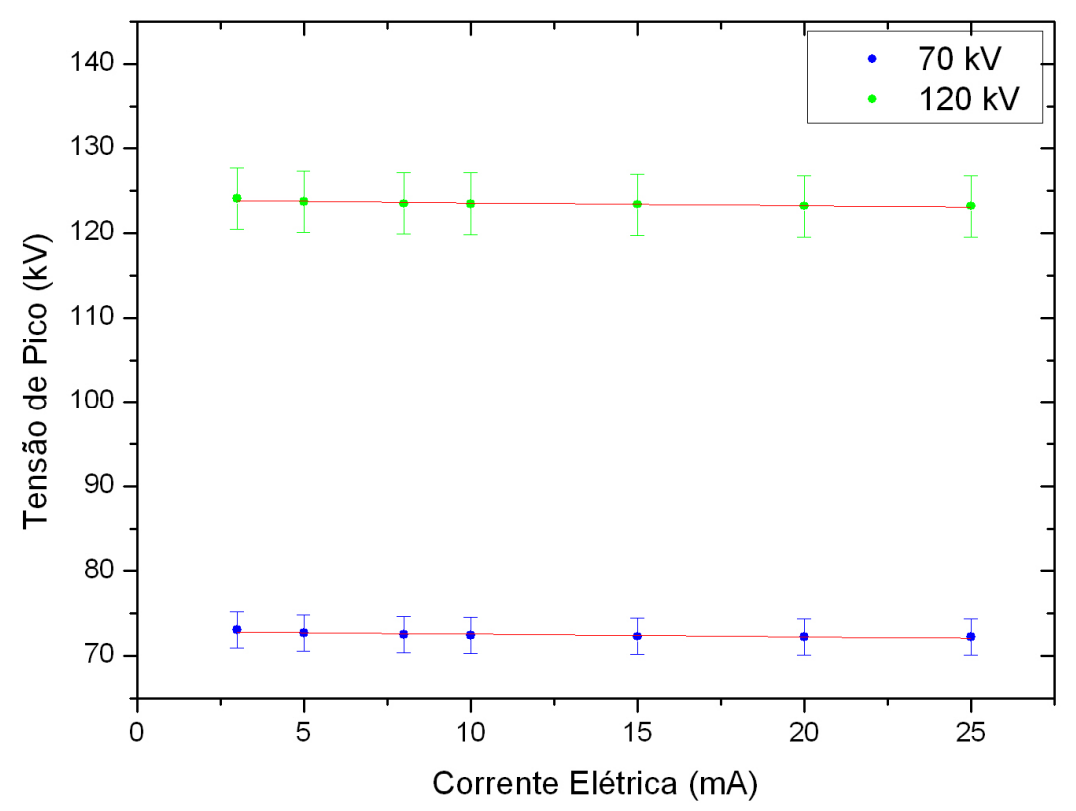

FIGURA 39 - Respostas da grandeza tensão de pico com a variação da corrente elétrica nas tensões nominais de 70 e $120 \mathrm{kV}$.

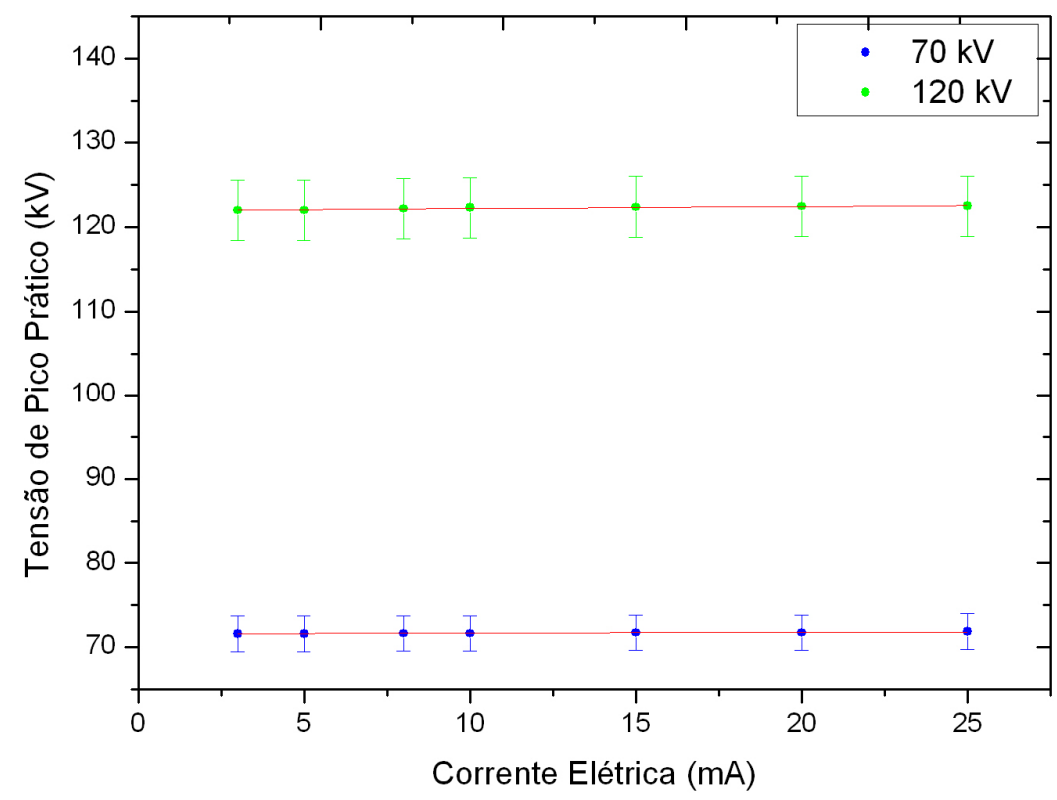

FIGURA 40 - Respostas da grandeza tensão de pico prático com a variação da corrente elétrica nas tensões nominais de 70 e $120 \mathrm{kV}$.

Já os gráficos das tensões de pico e de pico prático (FIG. 39 e 40) não indicam nenhuma tendência dessas grandezas com relação a variação da corrente elétrica. A variação das tensões é muito baixa e as duas retas praticamente horizontais plotadas em 70 e $120 \mathrm{kV}$ passam por entre as barras de 
incerteza, mostrando que em qualquer configuração de corrente escolhida, o Diavolt fornece valores muito próximos entre si.

No teste de variação das Qualidades de Radiação para Radiodiagnóstico, o medidor Diavolt não conseguiu efetuar as medições na tensão nominal de $150 \mathrm{kV}$, pois o aparelho limita-se, nessas Qualidades, a medir tensões nos intervalos entre 40 e $150 \mathrm{kV}$ para as tensões de pico e de pico prático. Como todos os valores medidos apresentaram tensões acima dos valores nominais, as tensões de pico e de pico prático referentes a tensão nominal de $150 \mathrm{kV}$ não puderam ser medidas. Quando isso ocorre, o aparelho também não fornece o valor do kerma no ar. A TAB. 8 apresenta os valores medidos e suas respectivas incertezas de todas as Qualidades de Radiação X para Radiodiagnóstico, exceto para RQR 10.

TABELA 8 - Valores das medições efetuadas, pelo Diavolt, no teste de dependência das Qualidades de Radiação para Radiodiagnóstico.

\begin{tabular}{cccc}
\hline $\begin{array}{c}\text { Qualidade } \\
\text { De Radiação }\end{array}$ & $\begin{array}{c}\text { Kerma no } \\
\text { ar (mGy) }\end{array}$ & $\begin{array}{c}\text { Tensão de } \\
\text { Pico }(\mathrm{kV})\end{array}$ & $\begin{array}{c}\text { PPV } \\
(\mathrm{kV})\end{array}$ \\
\hline RQR 2 & $31,35 \pm 1,17$ & $43,96 \pm 1,31$ & $42,73 \pm 1,27$ \\
RQR 3 & $52,69 \pm 1,97$ & $52,48 \pm 1,56$ & $51,67 \pm 1,53$ \\
RQR 4 & $70,88 \pm 2,64$ & $62,30 \pm 1,84$ & $61,80 \pm 1,83$ \\
RQR 5 & $93,94 \pm 3,50$ & $72,40 \pm 2,14$ & $71,97 \pm 2,13$ \\
RQR 6 & $114,99 \pm 4,28$ & $82,93 \pm 2,45$ & $82,35 \pm 2,43$ \\
RQR 7 & $141,54 \pm 5,26$ & $92,73 \pm 2,74$ & $92,04 \pm 2,72$ \\
RQR 8 & $169,77 \pm 6,31$ & $102,90 \pm 3,03$ & $102,28 \pm 3,01$ \\
RQR 9 & $222,61 \pm 8,26$ & $123,13 \pm 3,62$ & $122,39 \pm 3,60$ \\
RQR 10 & - & - & - \\
\hline
\end{tabular}

Assim como no teste da dependência com a corrente elétrica, as incertezas do teste para as diferentes Qualidades variaram entre 2,9 e 3,7\%. Nos valores de tensão de pico e tensão de pico prático, os erros intrínsecos relativos respeitam o recomendado pela norma IEC 61676 (2002), com exceção das tensões de pico e de pico prático na RQR2 (40 kV) que apresentaram os erros intrínsecos relativos acima de $3,6 \%$ (diferença maior que $1 \mathrm{kV}$ entre as tensões medidas e a nominal).

Os resultados da TAB. 8 estão representados nos gráficos das FIG. 41, 42 e 43. 


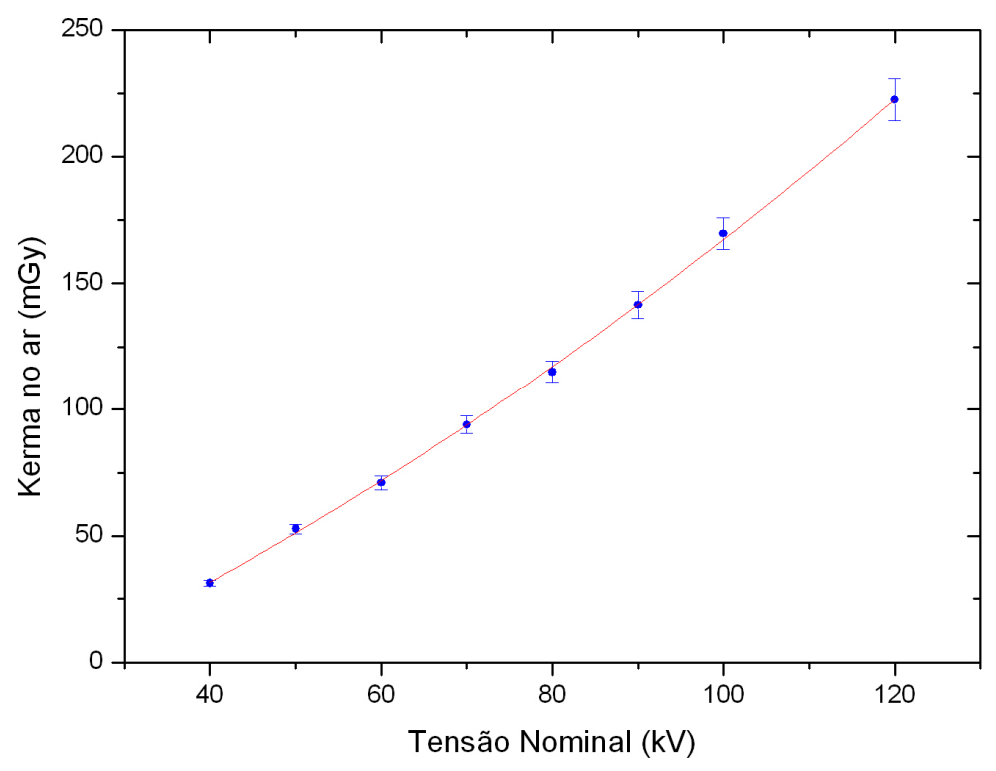

FIGURA 41 - Valores da grandeza kerma no ar obtidas para as diferentes Qualidades de Radiação em Radiodiagnóstico.

O gráfico da FIG. 41 mostra como a grandeza kerma no ar se comporta para as diferentes Qualidades em Radiodiagnóstico. Os pontos foram ajustados por um polinômio de grau 2 (curva vermelha) que passa entre as barras de incerteza de todos os pontos mostrando uma correspondência entre os dados experimentais e o esperado pela literatura. Esse resultado também confirma que a determinação das Qualidades em Radiodiagnóstico (Franciscatto, 2009) foi realizada de maneira satisfatória.

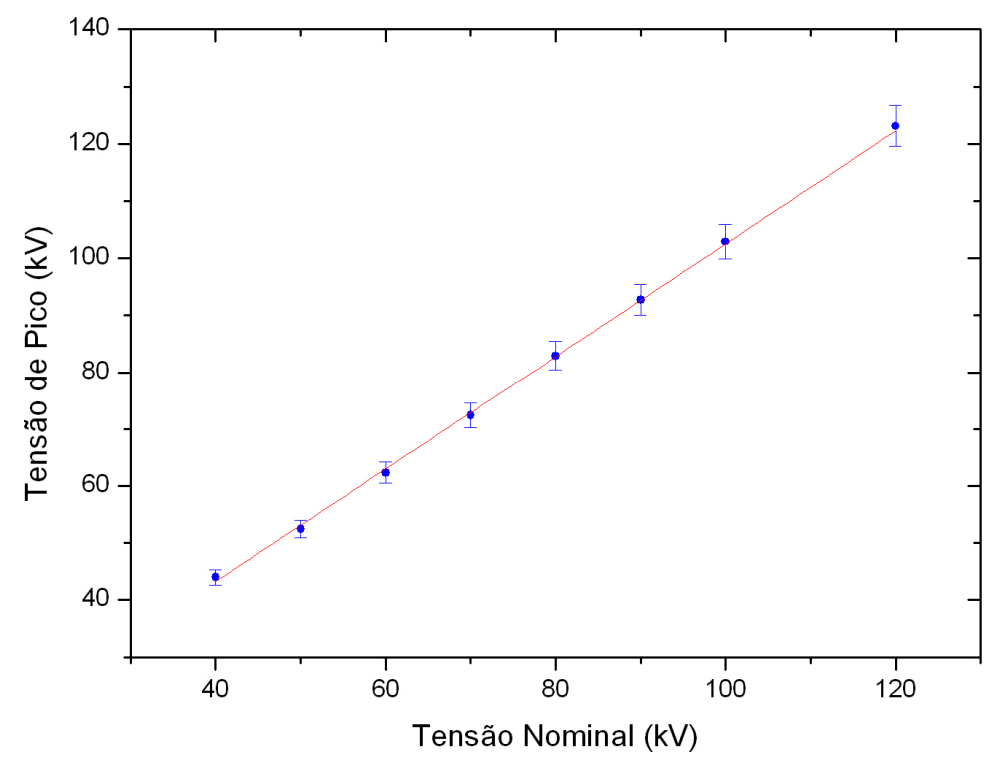

FIGURA 42 - Valores da grandeza tensão de pico obtidas para as diferentes Qualidades de Radiação em Radiodiagnóstico. 


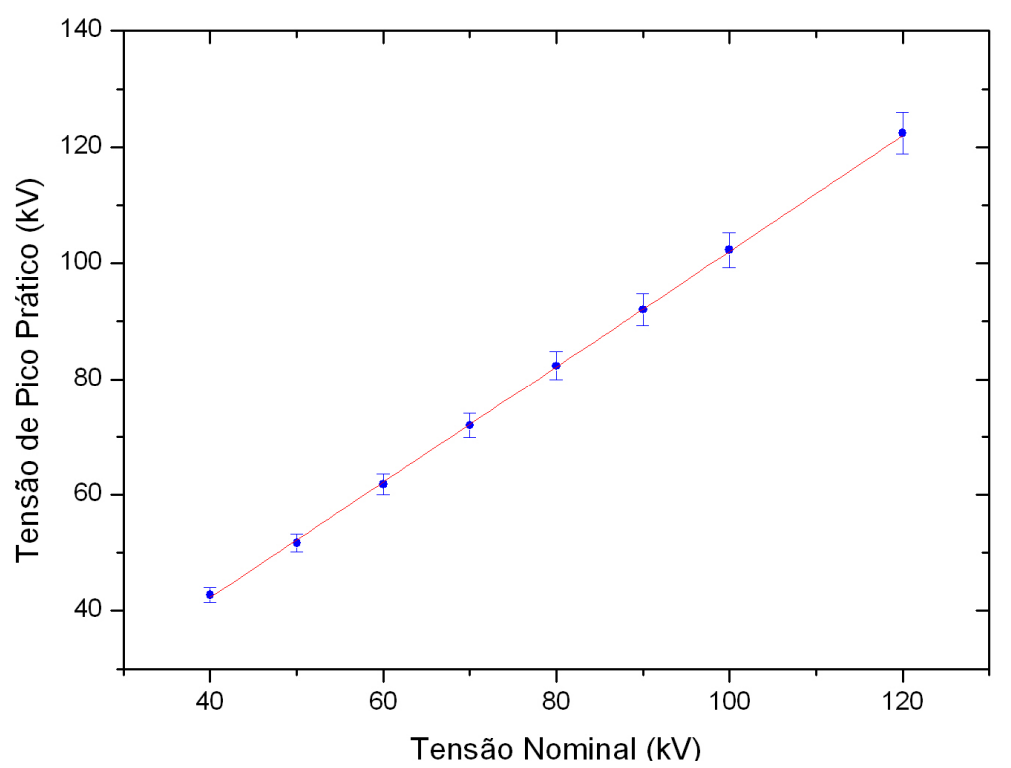

FIGURA 43 - Valores da grandeza tensão de pico prático obtidas para as diferentes Qualidades de Radiação em Radiodiagnóstico.

Os dados de tensão de pico e de pico prático apresentaram tendências semelhantes, como pode ser observado nas FIG. 42 e 43. Em ambos os casos, foram ajustados polinômios de grau $1 \mathrm{e}$ as retas passaram entre as barras de incerteza de todos os pontos mostrando que os ajustes são consistentes com o esperado, já que se tratam de grandezas linearmente proporcionais (tensão nominal em relação às tensão de pico e de pico prático).

Os valores medidos dos testes de dependência da distância, entre o medidor e o ponto focal do aparelho de raios $X$, em função das grandezas kerma no ar, tensão de pico e tensão de pico prático são mostrados nas TAB. $9 \mathrm{E} 10$, para as tensões nominais de 70 e $120 \mathrm{kV}$, respectivamente. 
TABELA 9 - Valores das medições efetuadas, pelo Diavolt, no teste de dependência da distância para a tensão nominal de 70 kV.

\begin{tabular}{cccc}
\hline \multirow{2}{*}{$\begin{array}{c}\text { Distância } \\
(\mathrm{m})\end{array}$} & $\begin{array}{c}\text { Kerma no } \\
\text { ar (mGy) }\end{array}$ & $\begin{array}{c}\mathrm{kVp} \\
(\mathrm{kV})\end{array}$ & $\begin{array}{c}\text { PPV } \\
(\mathrm{kV})\end{array}$ \\
\hline 0,5 & $301,44 \pm 11,21$ & $72,00 \pm 2,13$ & $71,76 \pm 2,12$ \\
1 & $74,70 \pm 2,78$ & $72,22 \pm 2,13$ & $71,70 \pm 2,12$ \\
1,5 & $32,98 \pm 1,23$ & $72,51 \pm 2,14$ & $71,70 \pm 2,12$ \\
2 & $18,07 \pm 0,67$ & $72,88 \pm 2,15$ & $71,76 \pm 2,12$ \\
2,5 & $11,32 \pm 0,42$ & $73,21 \pm 2,16$ & $71,80 \pm 2,12$ \\
3 & $7,74 \pm 0,29$ & $74,10 \pm 2,19$ & $71,30 \pm 2,11$ \\
\hline
\end{tabular}

TABELA 10 - Valores das medições efetuadas, pelo Diavolt, no teste de dependência da distância para a tensão nominal de 120 kV.

\begin{tabular}{rccc}
\hline \multirow{2}{*}{\begin{tabular}{c} 
Distância $(\mathrm{m})$ \\
\cline { 2 - 4 }
\end{tabular}} & $\begin{array}{c}\text { Kerma no } \\
\text { ar }(\mathrm{mGy})\end{array}$ & $\begin{array}{l}\mathrm{kVp} \\
(\mathrm{kV})\end{array}$ & $\begin{array}{c}\text { PPV } \\
(\mathrm{kV})\end{array}$ \\
\hline 0,5 & $736,84 \pm 27,34$ & $122,78 \pm 3,61$ & $122,09 \pm 3,59$ \\
1 & $180,14 \pm 6,68$ & $123,21 \pm 3,63$ & $122,45 \pm 3,60$ \\
1,5 & $78,70 \pm 2,92$ & $123,80 \pm 3,64$ & $122,51 \pm 3,60$ \\
2 & $44,46 \pm 1,65$ & $124,28 \pm 3,66$ & $122,50 \pm 3,60$ \\
2,5 & $27,95 \pm 1,04$ & $124,90 \pm 3,67$ & $122,80 \pm 3,61$ \\
3 & $19,22 \pm 0,71$ & $125,42 \pm 3,69$ & $122,87 \pm 3,62$ \\
\hline
\end{tabular}

Nos dois testes de dependência com a distância, as incertezas relativas estiveram entre 2,9 e 3,7\%, como em todos os outros testes realizados até aqui com o medidor Diavolt. Os erros intrínsecos relativos corresponderam, em sua maioria, à norma IEC 61676 (2002). A exceção foi para o valor de $(74,10 \pm 2,19)$ $\mathrm{kV}$ referente à tensão de pico na distância de 3 metros, cujo erro intrínseco relativo mínimo foi de $2,7 \%$. Portanto, não é aconselhável efetuar medições de tensão de pico a uma distância maior que $2,5 \mathrm{~m}$ com o medidor Diavolt no aparelho de raios $X$ utilizado para os testes. No entanto, as incertezas dos valores da tensão de pico prático cobriram, em todos os casos, a tensão nominal 
selecionada no aparelho de raios $X$, o que demonstra que para a medição das tensões de pico prático, qualquer distância pode ser utilizada para a aquisição de dados coerentes.

Os gráficos das FIG. 44, 45 e 46, mostram as tendências das grandezas kerma no ar, tensão de pico e tensão de pico prático com o aumento da distância entre o medidor e o ponto focal do aparelho de raios $\mathrm{X}$.

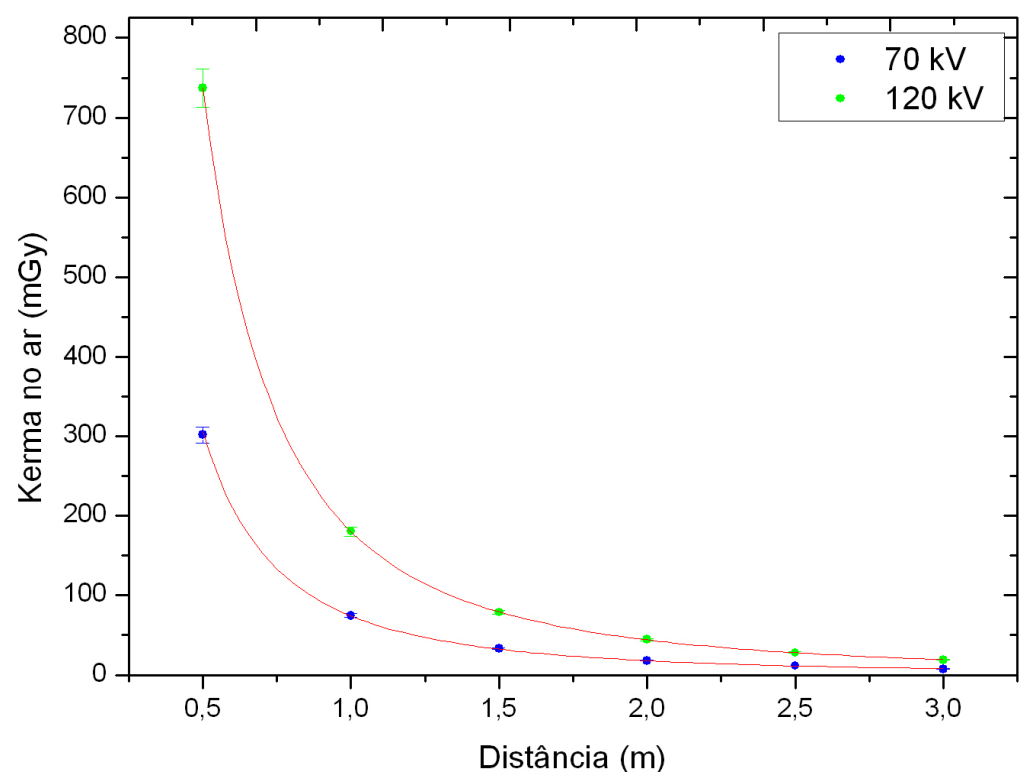

FIGURA 44 - Variação da grandeza kerma no ar com a distância nas tensões nominais de 70 e $120 \mathrm{kV}$.

Observa-se, no gráfico da FIG. 44, que o kerma no ar diminui acentuadamente com o aumento da distância. Em princípio, o comportamento esperado é que o kerma no ar diminua com o inverso do quadrado da distância. No entanto, a coluna de ar que fica mais espessa com o aumento da distância também ajuda na atenuação da radiação. Portanto, foram ajustadas nos pontos do gráfico duas curvas referentes à função alométrica $y=A x^{b}$ para as tensões 70 e $120 \mathrm{kV}$, onde espera-se que o coeficiente b seja ligeiramente menor do que -2, devido a lei do inverso do quadrado da distância influenciada pela variação da coluna de ar que fica mais espessa com o aumento da distância. As funções que melhor se ajustaram aos dados das tensões nominais 70 e 120 kV são mostradas nas equações 16 e 17, onde o valor de b para a tensão de $70 \mathrm{kV}$ é igual a (-2,043 $\pm 0,099)$ e o valor de b para a tensão de $120 \mathrm{kV}$ é igual a $(-2,032 \pm 0,039)$. A partir desses dois valores, com suas respectivas incertezas, é fácil notar que os parâmetros b calculados são ligeiramente menores que -2 e que suas incertezas 
também cobrem exatamente esse valor. Dessa maneira, verifica-se que esse comportamento experimental está de acordo com o esperado.

$$
\begin{aligned}
& y=74,068 x^{-2,043} \\
& y=180,100 x^{-2,032}
\end{aligned}
$$

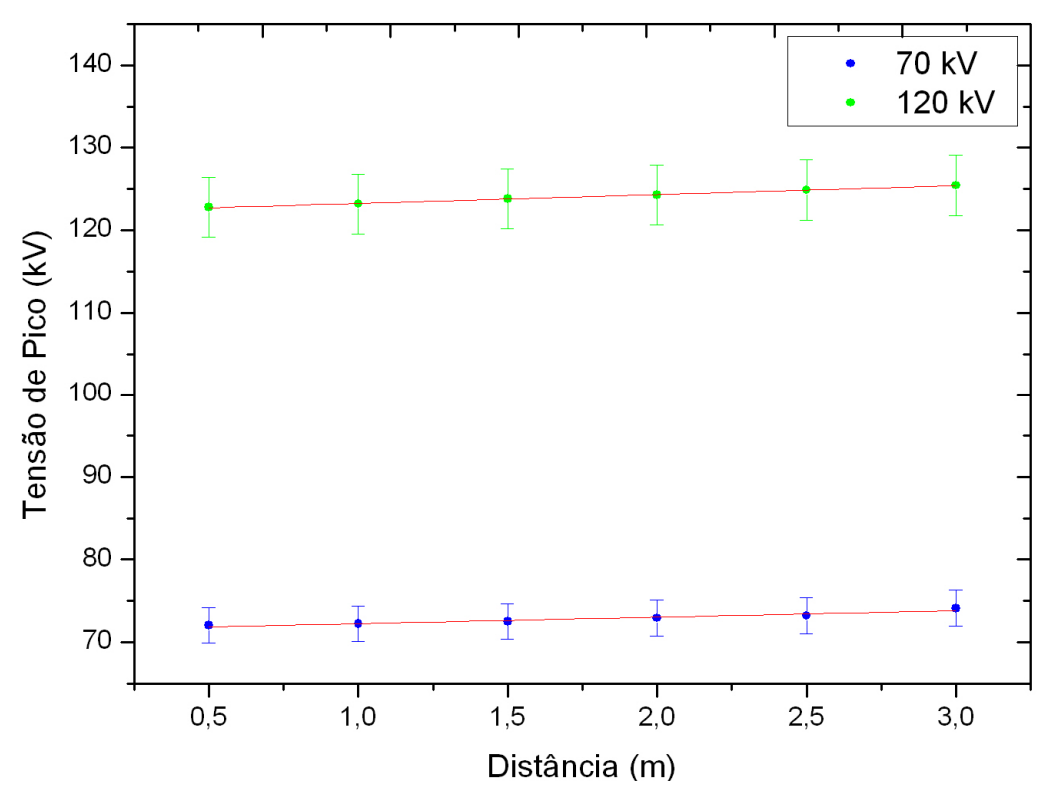

FIGURA 45 - Variação da grandeza tensão de pico com a distância nas tensões nominais de 70 e $120 \mathrm{kV}$.

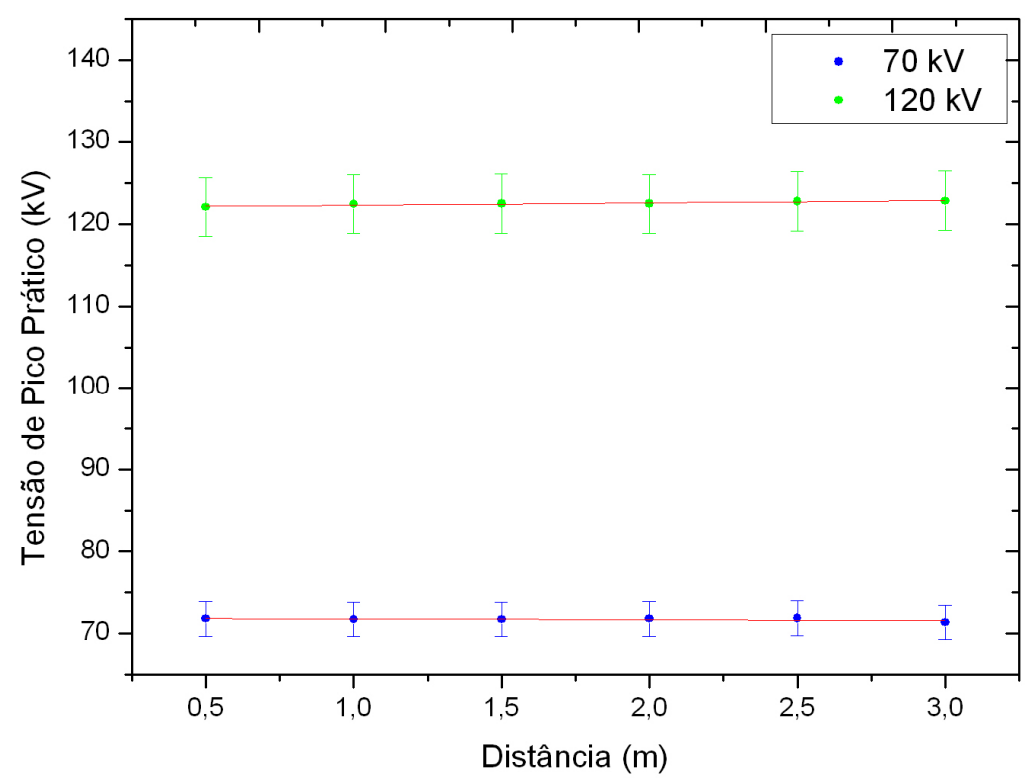

FIGURA 46 - Variação da grandeza tensão de pico prático com a distância nas tensões nominais de 70 e $120 \mathrm{kV}$. 
Observando os gráficos da FIG. 45, nota-se que a tensão de pico tem uma leve tendência a aumentar quando a distância aumenta, tanto na tensão nominal de $70 \mathrm{kV}$, como na de $120 \mathrm{kV}$, o que provoca o afastamento dos dados medidos em relação à tensão nominal a medida em que a distância aumenta (vide os ajustes lineares na FIG. 45). Essa tendência não é observada nas tensões de pico prático, cujos valores se mantém estáveis, como pode ser visto pelo ajuste quase horizontal realizado nas tensões de 70 e 120 kV dos gráficos da FIG. 46. Portanto, quando o interesse do operador for medir a grandeza tensão de pico, ele deve posicionar o medidor o mais próximo possível do ponto focal do aparelho de raios $X$ visando obter medições mais satisfatórias. Caso o interesse seja medir a tensão de pico prático, os resultados apontam que, em qualquer posição, o medidor efetuará medições satisfatórias.

O teste de dependência angular foi realizado nas tensões nominais de 70 e 100 kV. A segunda tensão nominal utilizada não foi de $120 \mathrm{kV}$, pois em seu uso, o medidor acusou sobretensão em vários ângulos medidos e o número de pontos realmente medidos eram muito poucos para fazer uma análise. No teste de 100 kV, não foi possível fazer a medição em um dos ângulos $\left(-60^{\circ}\right)$ pelo mesmo motivo. Os valores medidos de kerma no ar, tensão de pico e de pico prático podem ser observados nas TAB. 11 e 12. 
TABELA 11 - Valores das medições efetuadas, pelo Diavolt, no teste de dependência angular para a tensão nominal de 70 kV.

\begin{tabular}{cccc}
\hline $\begin{array}{c}\text { Ângulo } \\
\left(^{\circ}\right)\end{array}$ & $\begin{array}{c}\text { Kerma } \\
\text { no ar }(\mathrm{mGy})\end{array}$ & $\begin{array}{c}\mathrm{kVp} \\
(\mathrm{kV})\end{array}$ & $\begin{array}{c}\mathrm{PPV} \\
(\mathrm{kV})\end{array}$ \\
\hline-60 & $0,60 \pm 0,02$ & $125,59 \pm 3,72$ & $111,50 \pm 3,30$ \\
-48 & $14,46 \pm 0,61$ & $76,23 \pm 2,26$ & $74,33 \pm 2,21$ \\
-36 & $27,71 \pm 1,04$ & $67,37 \pm 2,76$ & $66,20 \pm 2,78$ \\
-24 & $35,89 \pm 1,34$ & $68,99 \pm 2,54$ & $68,09 \pm 2,58$ \\
-15 & $36,74 \pm 1,37$ & $71,40 \pm 2,11$ & $70,60 \pm 2,09$ \\
-9 & $36,99 \pm 1,38$ & $72,01 \pm 2,13$ & $71,22 \pm 2,11$ \\
-6 & $36,99 \pm 1,38$ & $72,20 \pm 2,13$ & $71,43 \pm 2,11$ \\
-3 & $37,18 \pm 1,39$ & $72,30 \pm 2,14$ & $71,50 \pm 2,11$ \\
0 & $37,13 \pm 1,38$ & $72,40 \pm 2,14$ & $71,60 \pm 2,12$ \\
3 & $37,09 \pm 1,38$ & $72,39 \pm 2,14$ & $71,60 \pm 2,12$ \\
6 & $37,15 \pm 1,38$ & $72,26 \pm 2,14$ & $71,47 \pm 2,11$ \\
9 & $37,20 \pm 1,38$ & $72,11 \pm 2,13$ & $71,34 \pm 2,11$ \\
15 & $37,00 \pm 1,40$ & $71,27 \pm 2,11$ & $70,48 \pm 2,08$ \\
24 & $35,83 \pm 1,33$ & $69,75 \pm 2,06$ & $69,00 \pm 2,04$ \\
36 & $31,28 \pm 1,17$ & $68,70 \pm 2,03$ & $67,81 \pm 2,00$ \\
48 & $15,84 \pm 0,59$ & $70,78 \pm 2,09$ & $69,51 \pm 2,05$ \\
60 & $9,04 \pm 0,36$ & $97,26 \pm 3,05$ & $91,49 \pm 2,80$ \\
\hline
\end{tabular}


TABELA 12 - Valores das medições efetuadas, pelo Diavolt, no teste de dependência angular para a tensão nominal de 100 kV.

\begin{tabular}{|c|c|c|c|}
\hline \multirow[b]{2}{*}{$\begin{array}{c}\text { Ângulo } \\
\left({ }^{\circ}\right)\end{array}$} & \multicolumn{3}{|c|}{$100 \mathrm{kV}$} \\
\hline & $\begin{array}{c}\text { Kerma } \\
\text { no } \operatorname{ar}(m G y)\end{array}$ & $\begin{array}{l}k \bigvee p \\
(k V)\end{array}$ & $\begin{array}{l}\text { PPV } \\
\text { (kV) }\end{array}$ \\
\hline-60 & & & \\
\hline-48 & $29,30 \pm 1,15$ & $103,89 \pm 3,08$ & $101,93 \pm 3,02$ \\
\hline-36 & $9,54 \pm 2$, & $127,50 \pm 4,13$ & $124,97 \pm 4,01$ \\
\hline-24 & $65,50 \pm 2$ & $110,15 \pm 5,45$ & $108,72 \pm 5,35$ \\
\hline-15 & $67,77 \pm 2$ & $105,78 \pm 3,38$ & $104,55 \pm 3,32$ \\
\hline-9 & $68,36 \pm 2$ & $103,03 \pm 3,04$ & $101,91 \pm 3,01$ \\
\hline-6 & $68,40 \pm 2$ & $102,96 \pm 3,05$ & $101,83 \pm 3,01$ \\
\hline-3 & $68,53 \pm 2$ & $102,95 \pm 3,05$ & $101,84 \pm 3,02$ \\
\hline 0 & $68,53 \pm 2,5$ & $103,03 \pm 3,07$ & $101,92 \pm 3,03$ \\
\hline 3 & $68,05 \pm 2,5$ & $103,12 \pm 3,07$ & $101,99 \pm 3,04$ \\
\hline 6 & $67,66 \pm 2$ & $102,63 \pm 3$ & $101,55 \pm 3,00$ \\
\hline 9 & $67,63 \pm 2,5$ & $102,56 \pm 3,03$ & $101,44 \pm 2,99$ \\
\hline 15 & $67,00 \pm 2,4$ & $102,39 \pm 3,25$ & $101,45 \pm 3,18$ \\
\hline 24 & $65,19 \pm 2,43$ & $100,10 \pm 4,65$ & $99,37 \pm 4,65$ \\
\hline 36 & $56,34 \pm 2,17$ & $93,70 \pm 2,76$ & $92,70 \pm 2,73$ \\
\hline 48 & $30,70 \pm 1,14$ & $95,50 \pm 2,82$ & $94,15 \pm 2,77$ \\
\hline 60 & $12,47 \pm 0,49$ & $121,64 \pm 3,58$ & $118,46 \pm 3,49$ \\
\hline
\end{tabular}

A variação angular provocou uma instabilidade nas medições efetuadas do medidor Diavolt. As incertezas relativas variaram de 2,9 a 4,2\% para a tensão nominal de $70 \mathrm{kV}$ e de 2,9 a 4,6\% para a tensão de $100 \mathrm{kV}$. No entanto, o maior problema encontrado foram nos erros intrínsecos relativos, onde esses erros chegaram a $75 \%$ na tensão de $70 \mathrm{kV}$ e $26 \%$ na tensão de $100 \mathrm{kV}$ (esse erro poderia ser maior, caso a leitura em $-60^{\circ}$ tivesse sido efetuada). Esses grandes erros ocorrem devido ao distanciamento dos valores medidos em relação ao nominal com o aumento, em módulo, da angulação. Porém, no intervalo de $-9^{\circ}$ a $15^{\circ}$, os máximos erros intrínsecos relativos não ultrapassam $2 \%$ em todos os casos estudados, ou seja, esses erros diminuem quando o ângulo se aproxima de $0^{\circ}$.

Os valores das TAB. 11 e 12 foram representados nos gráficos das FIG. 47, 48 e 49 para uma melhor visualização das medições efetuadas. 


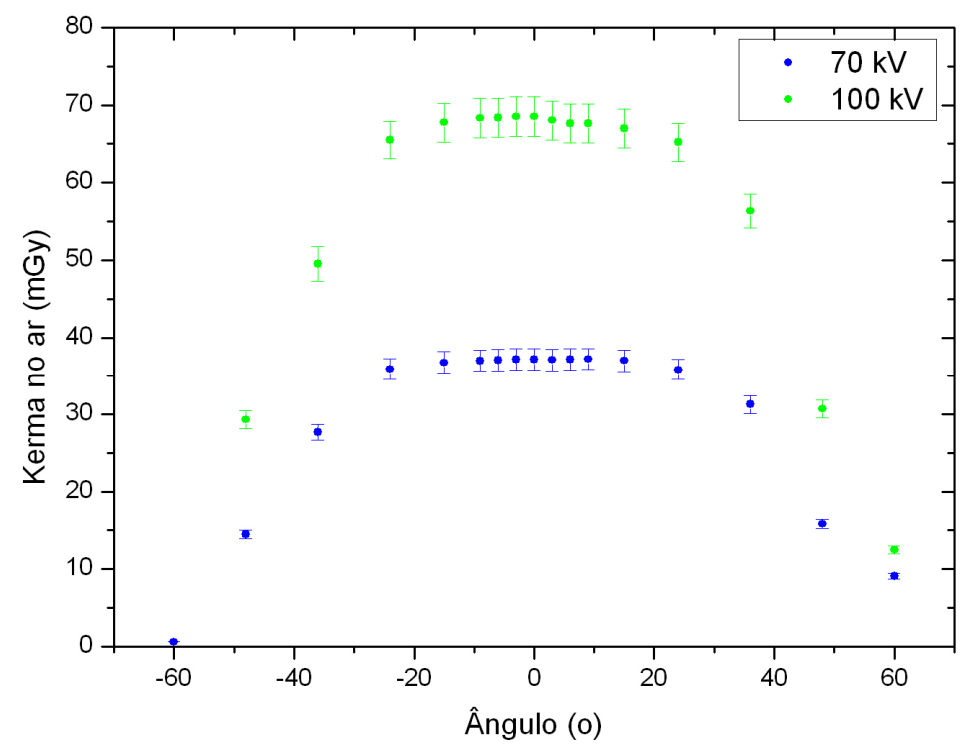

FIGURA 47 - Variação da grandeza kerma no ar com o ângulo nas tensões nominais de 70 e $100 \mathrm{kV}$.

Pelo gráfico da FIG. 47, observa-se que a grandeza kerma no ar possui um intervalo estável, onde os valores estão muito próximos uns dos outros, mas que tem uma tendência de se tornar instável com o aumento, em módulo, da angulação do medidor e os valores medidos tendem a diminuir, como era de se esperar, já que com a inclinação do volume sensível, o fluxo de radiação diminui, ou seja, o kerma no ar deve diminuir. O intervalo mais estável constatado se encontra entre $-15^{\circ}$ e $15^{\circ}$.

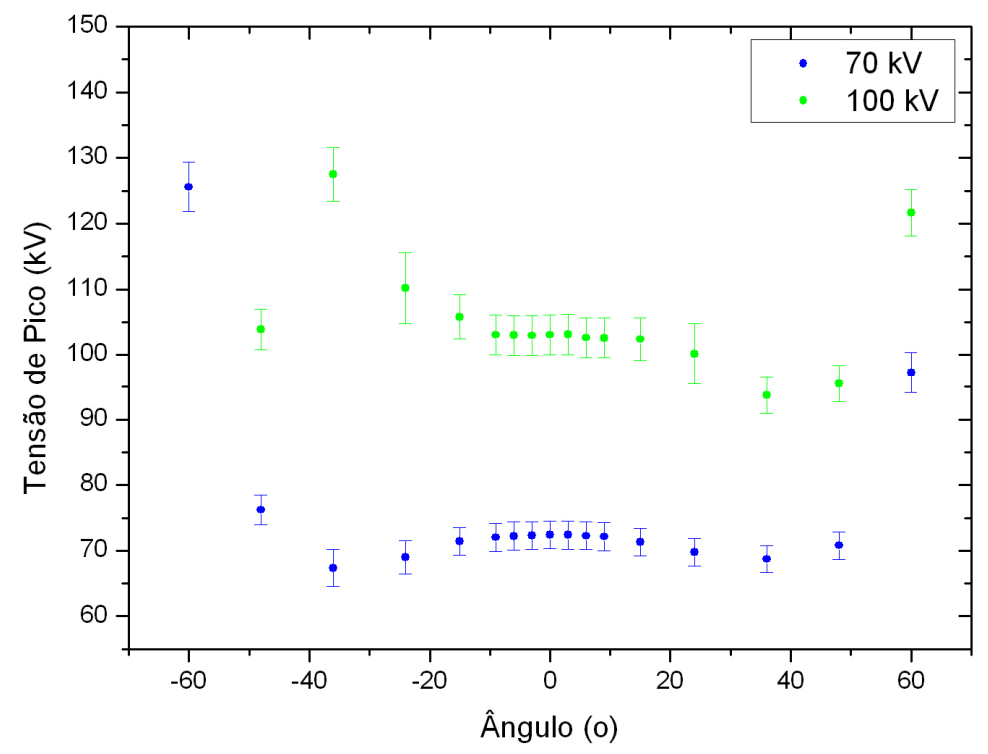

FIGURA 48 - Variação da grandeza tensão de pico com o ângulo nas tensões nominais de 70 e $100 \mathrm{kV}$. 


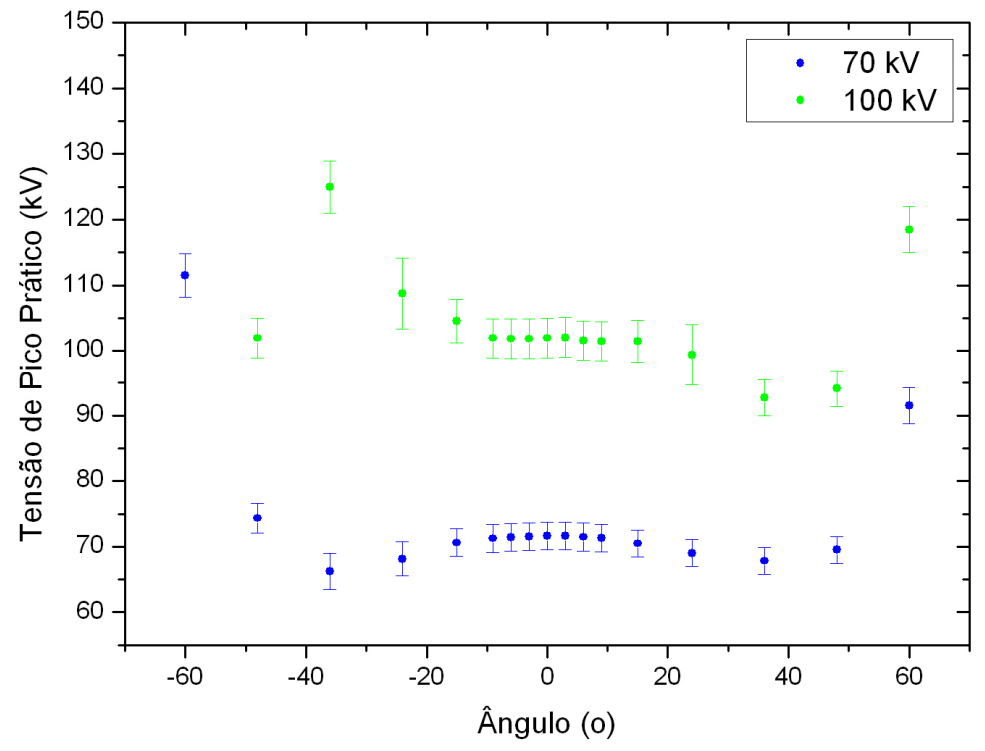

FIGURA 49 - Variação da grandeza tensão de pico prático com o ângulo nas tensões nominais de 70 e $100 \mathrm{kV}$.

Assim como na grandeza kerma no ar, observa-se nos gráficos das tensões de pico e de pico prático (FIG. 48 e 49), uma região estável, próxima ao ângulo $0^{\circ}$, e com o aumento, em módulo, da angulação, nota-se uma dispersão dos valores, com medições excedendo em até $44 \%$ a tensão nominal. A região estável mencionada se encontra entre $9^{\circ}$ e $-9^{\circ}$, onde dentro desse intervalo, a norma IEC 61676 (2002) é obedecida, em termos dos erros intrínsecos relativos.

Os testes de dependência angular mostraram, de uma maneira geral, que o medidor Diavolt pode ser posicionado inclinado entre os ângulos de $-9^{\circ}$ e $9^{\circ} \mathrm{e}$ mesmo assim realizar medições satisfatórias. No entanto, é aconselhável que o operador do medidor tente posicioná-lo o mais próximo possível do ângulo $0^{\circ}$, pois nessas condições o aparelho se encontrará mais distante da região angular instável proporcionando uma segurança maior nas medições.

\subsection{Sistema de espectrometria}

Todos os resultados dos espectros de raios $\mathrm{X}$ foram inicialmente obtidos com o colimador de chumbo de $1 \mathrm{~mm}$ de diâmetro e $8 \mathrm{~mm}$ de espessura. No entanto, foram observadas descontinuidades nas curvas dos espectros referentes às tensões nominais acima de $90 \mathrm{kV}$ (FIG. 48). Essas descontinuidades apareceram sempre entre as energias 87 e $89 \mathrm{keV}$, independente do espectro. 
Analisando na literatura as propriedades físicas do chumbo e simulando os

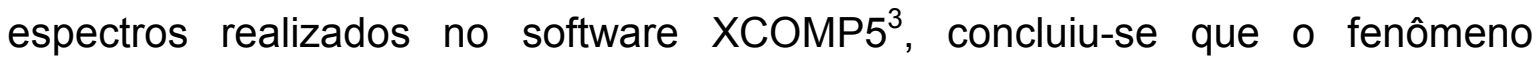
observado era decorrente do efeito de borda $\mathrm{K}$, consequência da pequena espessura do colimador. O efeito ocorreu justamente no intervalo de energia que abrange a energia de ligação do elétron da camada $\mathrm{K}$ do chumbo. Logo os espectros precisaram ser gerados novamente com outro colimador para evitar a "contaminação" dos espectros pelo efeito de borda K.

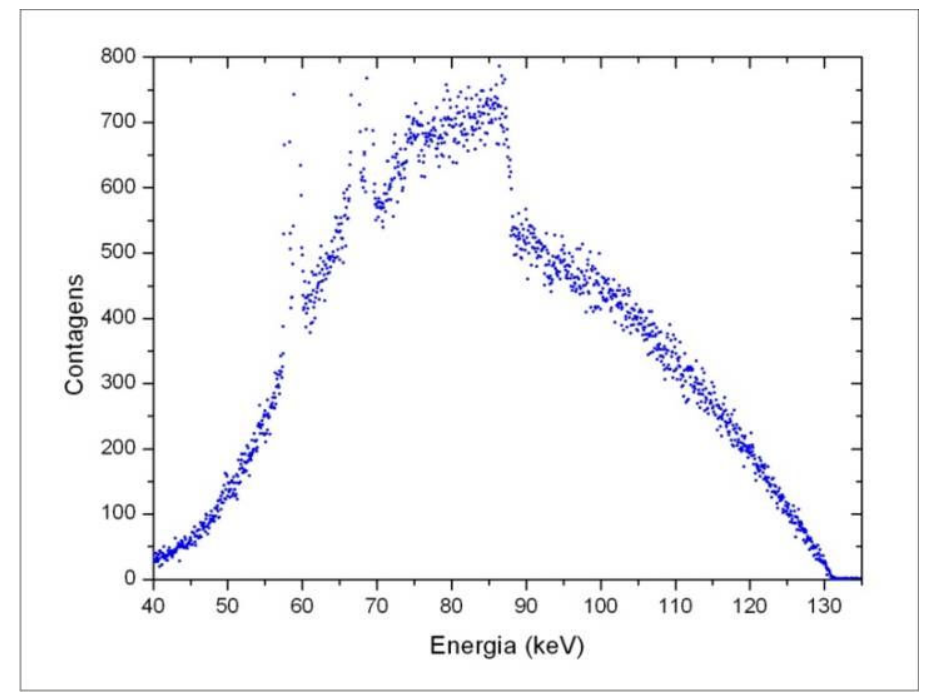

FIGURA 50 - Descontinuidade observada a aproximadamente $90 \mathrm{keV}$ no espectro de raios X na tensão nominal de 130 kV e filtração de 61 mm (Al).

Com o colimador de $0,1 \mathrm{~mm}$ de diâmetro não foram observados os efeitos de borda $\mathrm{K}$ e, portanto, com esse colimador, foram gerados e utilizados nesse trabalho os espectros sem filtração, referentes às Qualidades da Radiação X para Radiodiagnóstico e referentes às determinações das tensões de pico.

Ao não utilizar filtração adicional, o feixe de raios $X$ gerado não sofre nenhuma alteração após sair pela janela do tubo de raios $\mathrm{X}$ e chegar ao volume sensível do detetor. Nos espectros gerados sem filtração adicional é observado um número maior de contagens nas energias baixas, assim como picos característicos referentes ao alvo de tungstênio (FIG. 51, 52 e 53).

\footnotetext{
${ }^{3}$ Instituto für Biomed Technik, University of Viena, Austria (1985). Autores: NOWOTNY, R. e HOFER, A.
} 

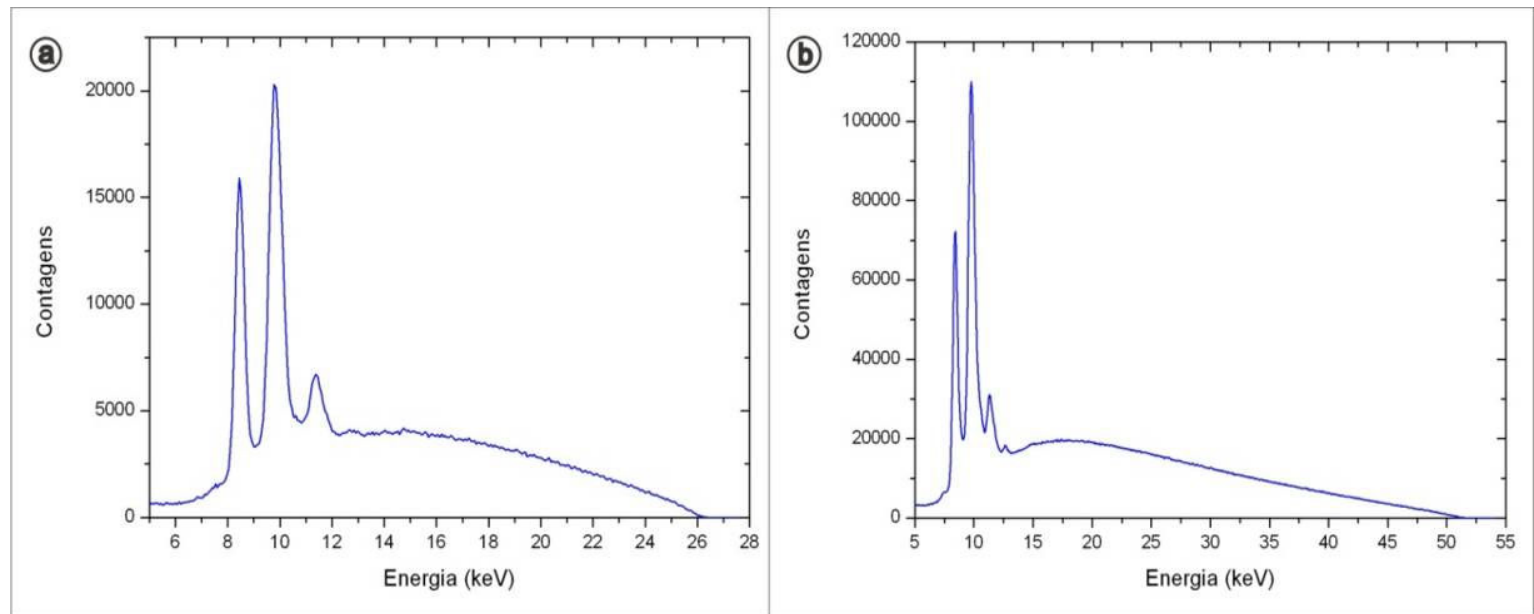

FIGURA 51 - Espectros de a) $25 \mathrm{kV}$ e b) $50 \mathrm{kV}$ sem filtrações adicionais.
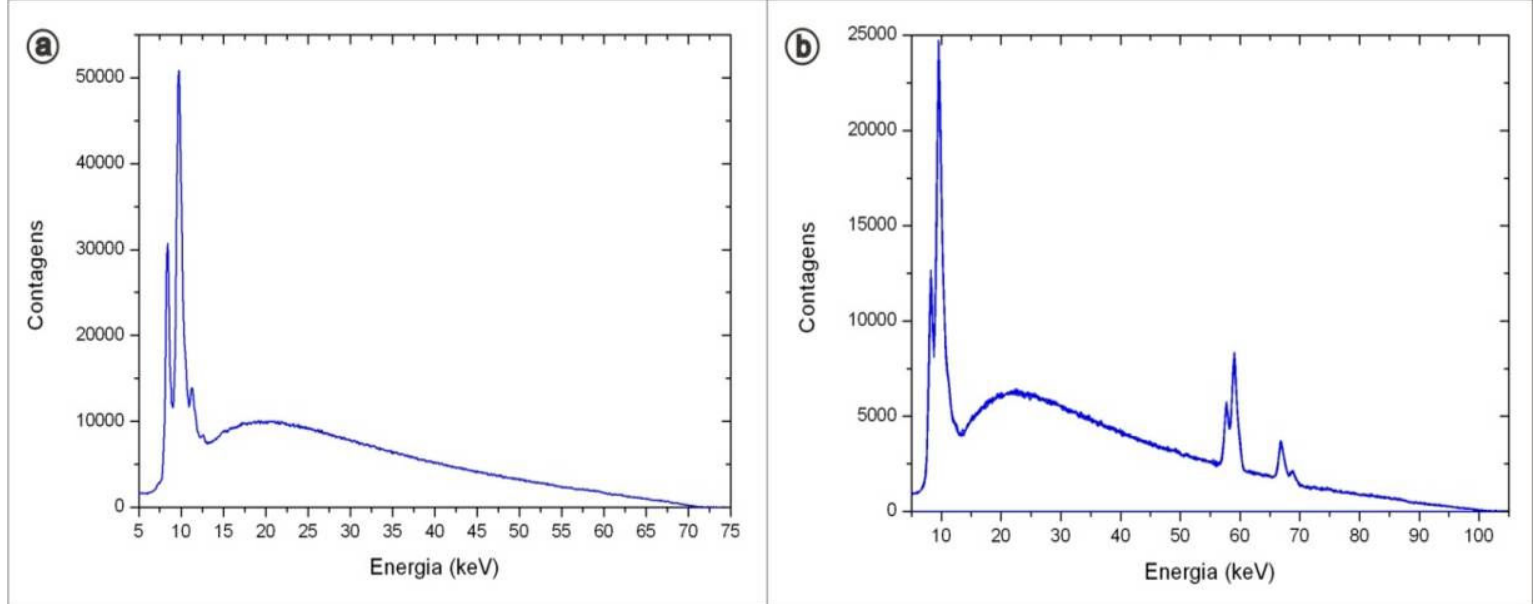

FIGURA 52 - Espectros de a) 70 kV e b) 100 kV sem filtrações adicionais.
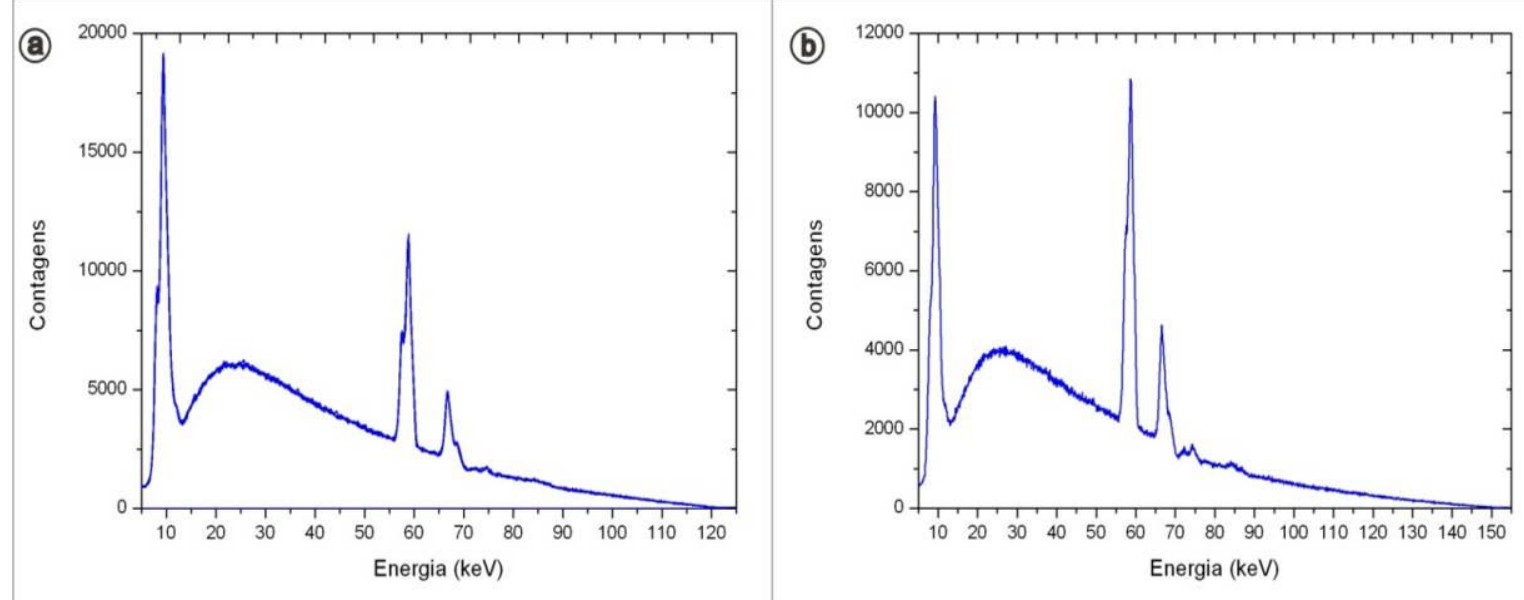

FIGURA 53 - Espectros de a) 120 kV e b) 150 kV sem filtrações adicionais. 
Nos espectros das FIG. 51 e 52a são observados três picos característicos do alvo tungstênio em cada espectro. Esses picos influenciam para que a energia média por fóton de raios $X$ seja pequena, já que os picos se encontram nas baixas energias e possuem grande contribuição para o cálculo da energia média por possuírem altas contagens.

Acima de 70 kV começam a aparecer, nos espectros, os picos característi$\cos k_{\alpha}$ e $k_{\beta}$ do alvo de tungstênio juntamente com os picos de baixa energia. Esses picos podem ser observados nos espectros das FIG. 52b e 53.

As energias médias por fóton de raios $X$ dos espectros sem filtração são mostradas na TAB. 13. As energias médias tendem a ser pequenas, já que não há filtração dos fótons de baixa energia.

TABELA 13 - Energias médias por fóton dos espectros sem filtração.

\begin{tabular}{cc}
\hline $\begin{array}{c}\text { Tensão } \\
\text { Nominal (kV) }\end{array}$ & $\begin{array}{c}\text { Energia média } \\
\text { por fóton (keV) }\end{array}$ \\
\hline 25 & 13,54 \\
50 & 20,60 \\
70 & 26,09 \\
100 & 34,77 \\
120 & 39,73 \\
150 & 45,97 \\
\hline
\end{tabular}

Os espectros referentes às Qualidades de Radiação X para Radiodiagnóstico são mostrados nas FIG. de 54 à 58 , onde são observadas diferenças nas formas dos espectros em relação aos espectros sem filtração, justamente pela presença das filtrações de alumínio nas Qualidades. 

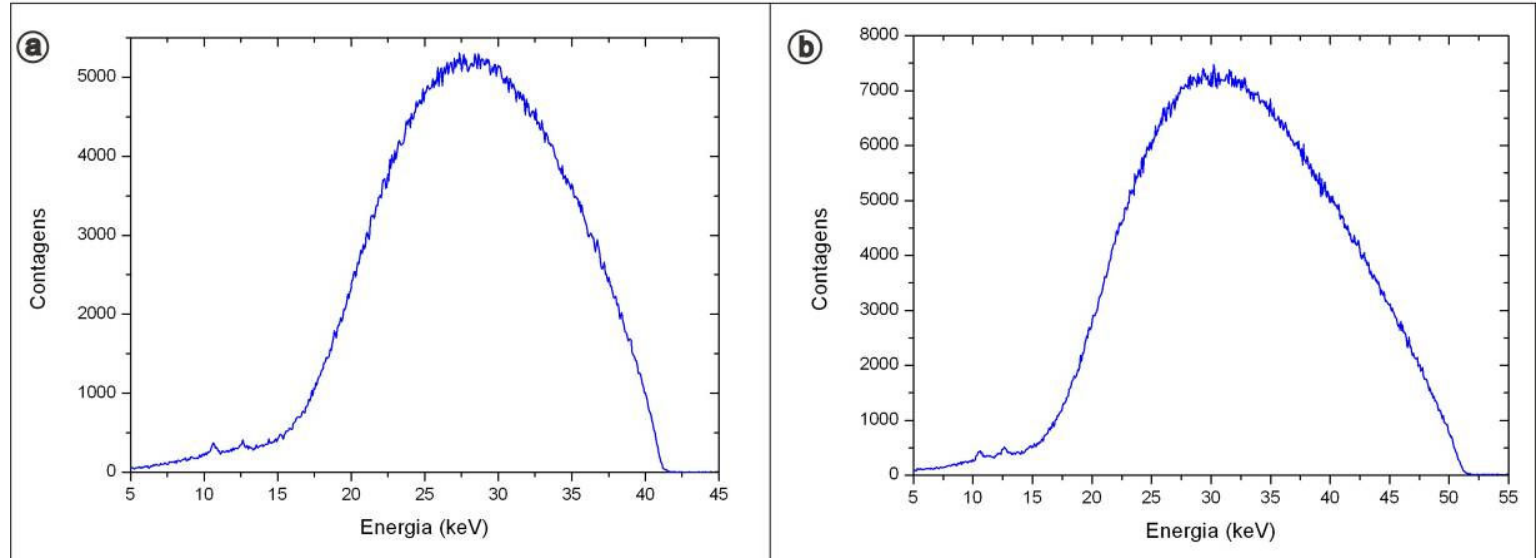

FIGURA 54 - Espectros de a) 40kV com filtração de 2,3 mmAl (RQR2) e b) 50kV com filtração de 2,4 mmAl (RQR3).
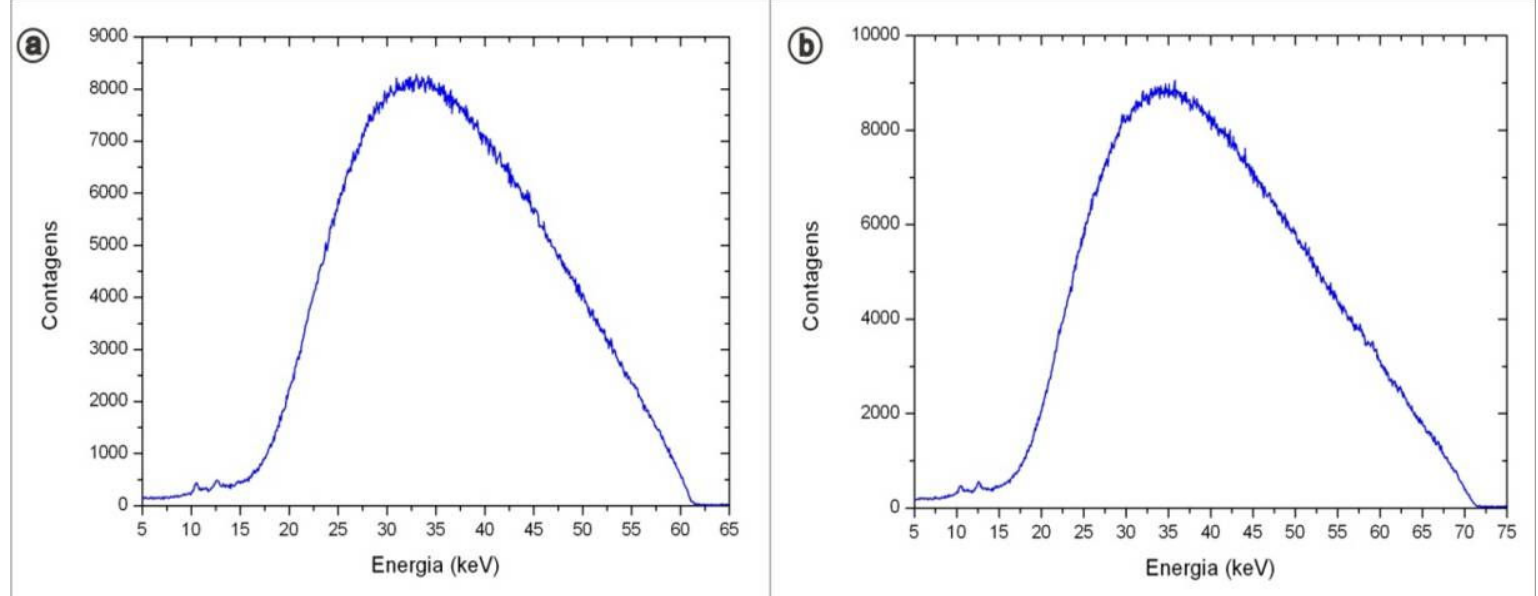

FIGURA 55 - Espectros de a) 60kV com filtração de 2,7 mmAl (RQR4) e b) 70kV com filtração de 2,8 mmAl (RQR5).

Nos espectros das FIG. 54 e 55, nota-se que, diferentemente dos espectros sem filtrações adicionais, os três picos característicos do alvo tungstênio nas baixas energias não aparecem com grande amplitude. Isso ocorre pela filtração dos mesmos pelo alumínio. O mesmo ocorre com os demais fótons de baixa energia presentes nos espectros ocasionados por produção de raios $X$ por freamento. 

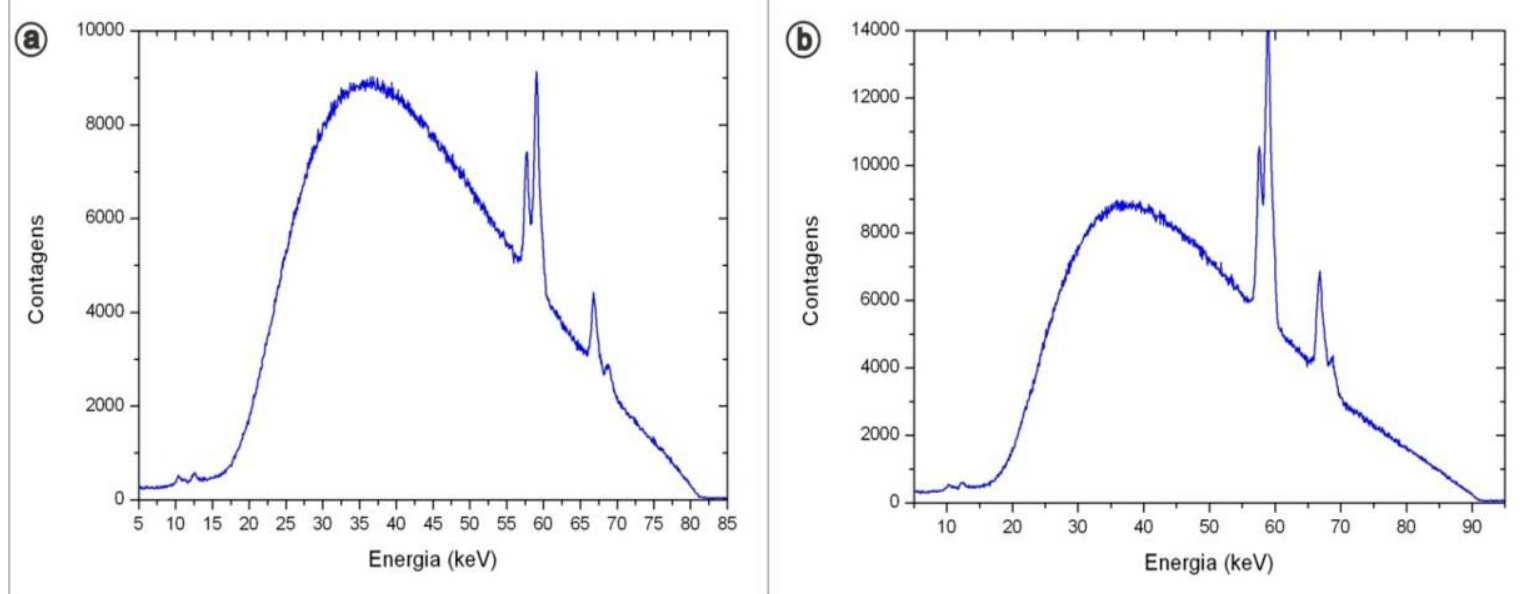

FIGURA 56 - Espectros de a) 80kV com filtração de 3,0 mmAl (RQR6) e b) 90kV com filtração de 3,1 mmAl (RQR7).
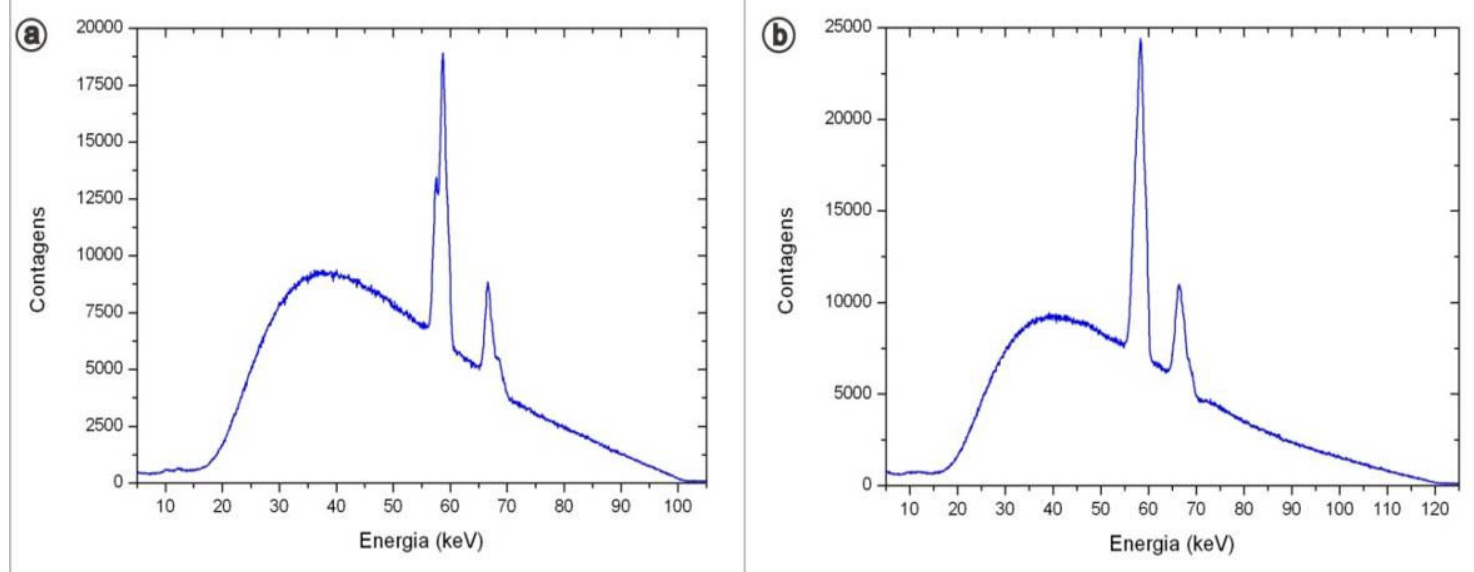

FIGURA 57 - Espectros de a) 100kV com filtração de 3,2 mmAl (RQR8) e b) de $120 \mathrm{kV}$ com filtração de 3,5 mmAl (RQR9).

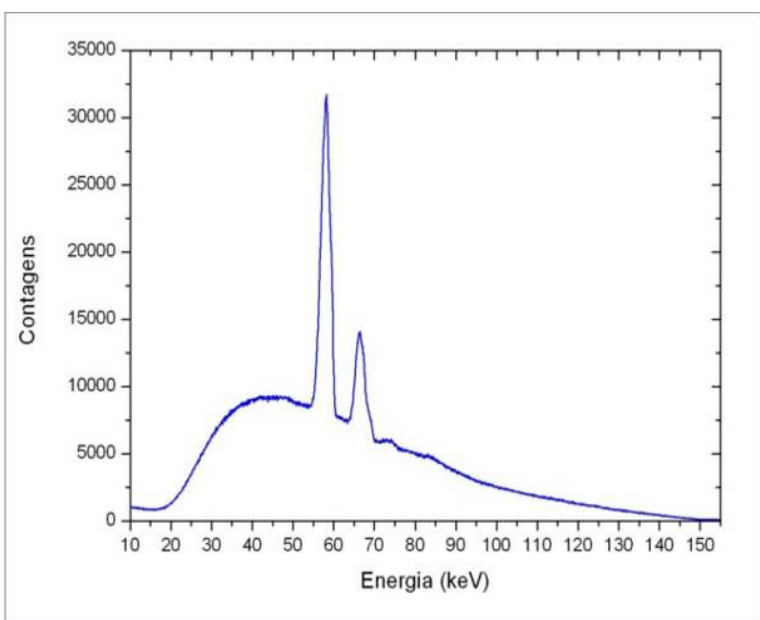

FIGURA 58 - Espectro de 150kV com filtração de 4,2 mmAl (RQR10). 
Nas FIG. 56, 57 e 58, observa-se a presença dos picos $k_{\alpha}$ e $k_{\beta}$ do alvo de tungstênio que não são absorvidos pela filtração de alumínio que absorveu apenas os fótons de baixa energia. Isso faz com que o feixe de raios $X$ seja mais energético com a presença da filtração, onde as energias médias por fóton aumentam com o aumento da filtração.

$\mathrm{Na}$ TAB. 14 é possível notar o aumento da energia média por fóton de raios $\mathrm{X}$ dos espectros das Qualidades em Radiodiagnóstico em relação aos espectros sem filtração.

TABELA 14 - Energias médias por fóton dos espectros referentes às Qualidade em Radiodiagnóstico.

\begin{tabular}{cccc}
\hline $\begin{array}{c}\text { Qualidade } \\
\text { De Radiação }\end{array}$ & $\begin{array}{c}\text { Tensão } \\
\text { Nominal (kV) }\end{array}$ & $\begin{array}{c}\text { Filtração } \\
(\mathrm{mmAl})\end{array}$ & $\begin{array}{c}\text { Energia média } \\
\text { por fóton (keV) }\end{array}$ \\
\hline RQR2 & 40 & 2,3 & 28,15 \\
RQR3 & 50 & 2,4 & 32,21 \\
RQR4 & 60 & 2,7 & 36,52 \\
RQR5 & 70 & 2,8 & 40,08 \\
RQR6 & 80 & 3,0 & 43,83 \\
RQR7 & 90 & 3,1 & 47,27 \\
RQR8 & 100 & 3,2 & 49,95 \\
RQR9 & 120 & 3,5 & 54,95 \\
RQR10 & 150 & 4,2 & 61,39 \\
\hline
\end{tabular}

A determinação das tensões de pico foi baseada nos espectros das FIG. 59 à 66. As filtrações utilizadas para a realização desses espectros foram bem superiores às dos espectros das Qualidades em Radiodiagnóstico, o que fez com que houvesse uma diminuição considerável do empilhamento de pulsos no detetor e consequentemente uma queda acentuada das curvas no final dos espectros (energias altas) facilitando a determinação das tensões de pico através de ajustes lineares. 

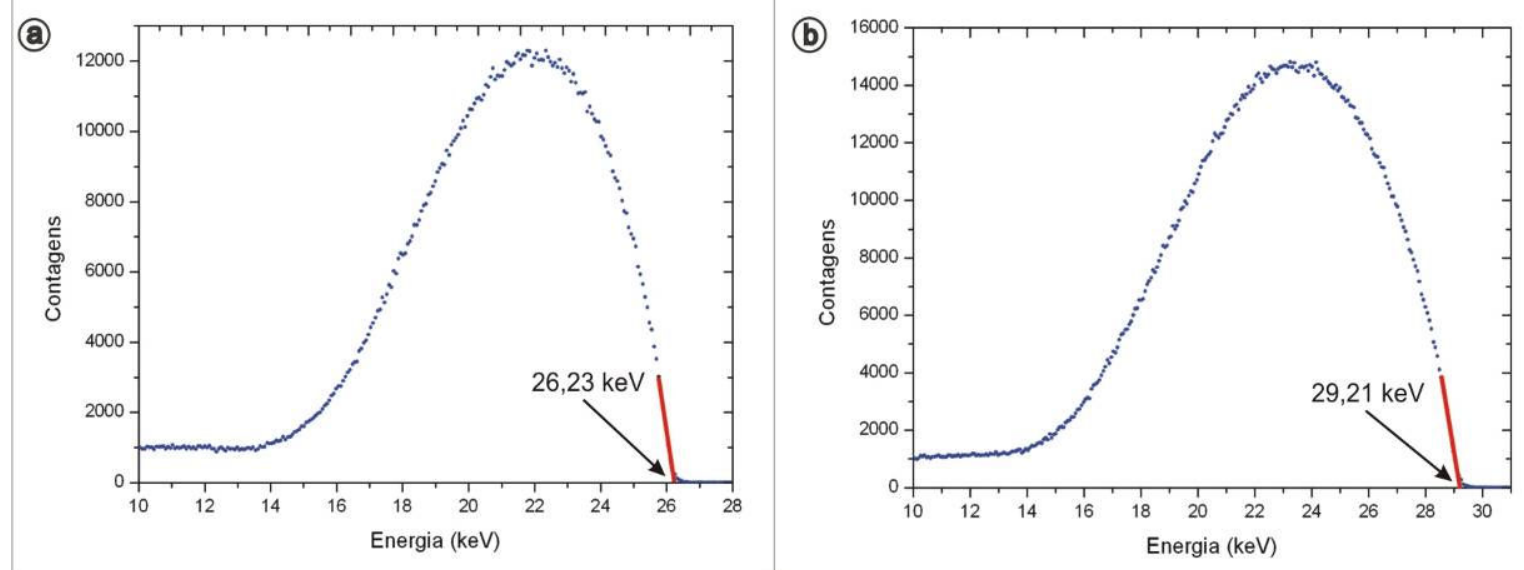

FIGURA 59 - Espectros de a) $25 \mathrm{kV}$ e b) $28 \mathrm{kV}$ com $2 \mathrm{mmAl}$.
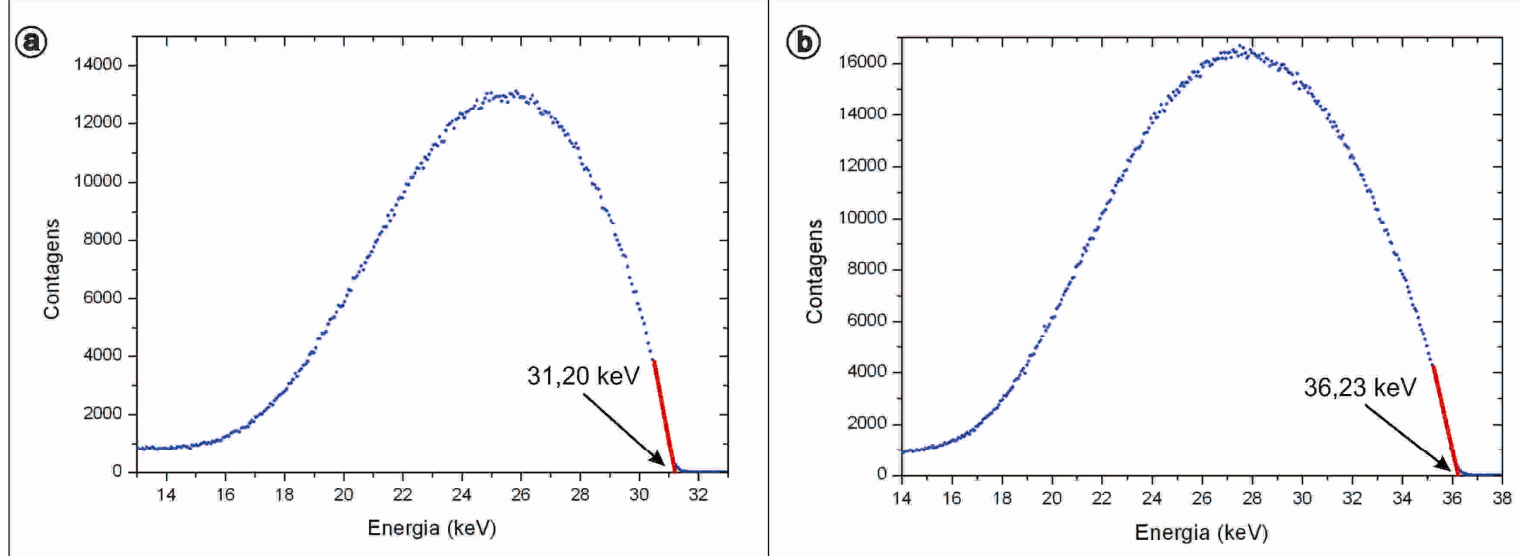

FIGURA 60 - Espectros de a) $30 \mathrm{kV}$ e b) $35 \mathrm{kV}$ com $3 \mathrm{mmAl}$.
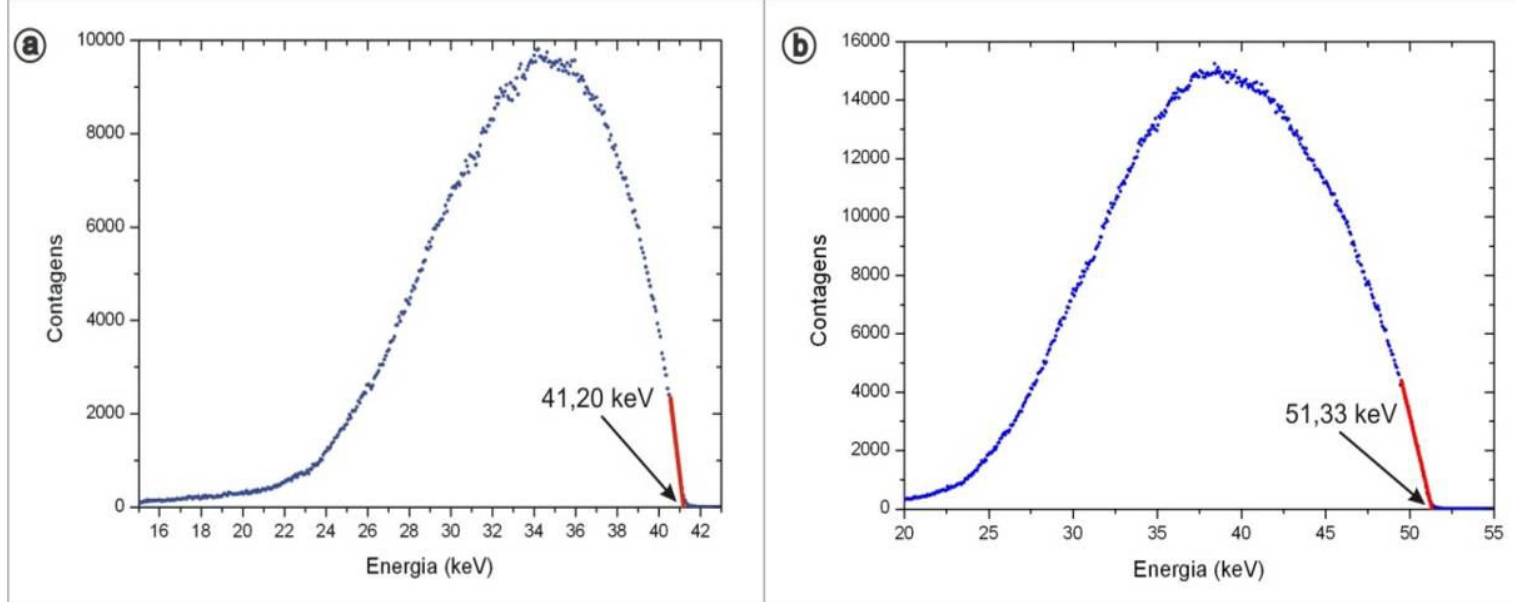

FIGURA 61 - Espectros de a) $40 \mathrm{kV}$ e b) $50 \mathrm{kV}$ com $10 \mathrm{mmAl}$. 

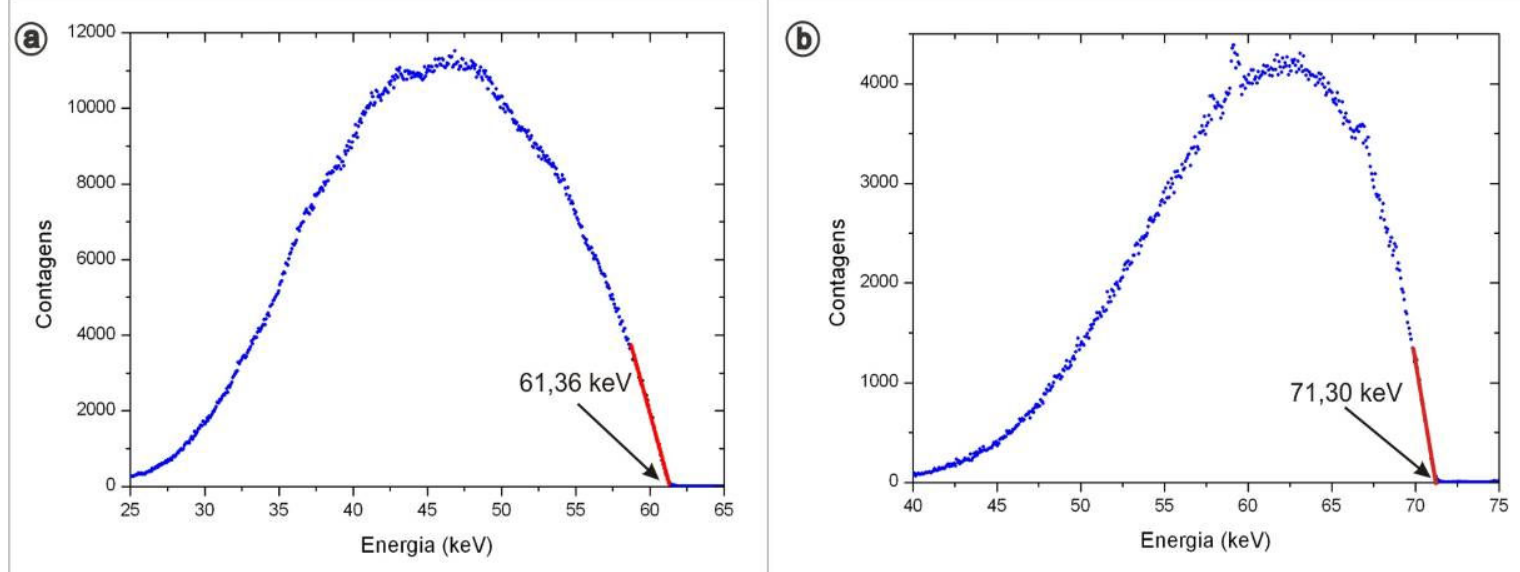

FIGURA 62 - Espectros de a) $60 \mathrm{kV}$ com $16 \mathrm{mmAl}$ e b) $70 \mathrm{kV}$ com $21 \mathrm{mmAl}$.
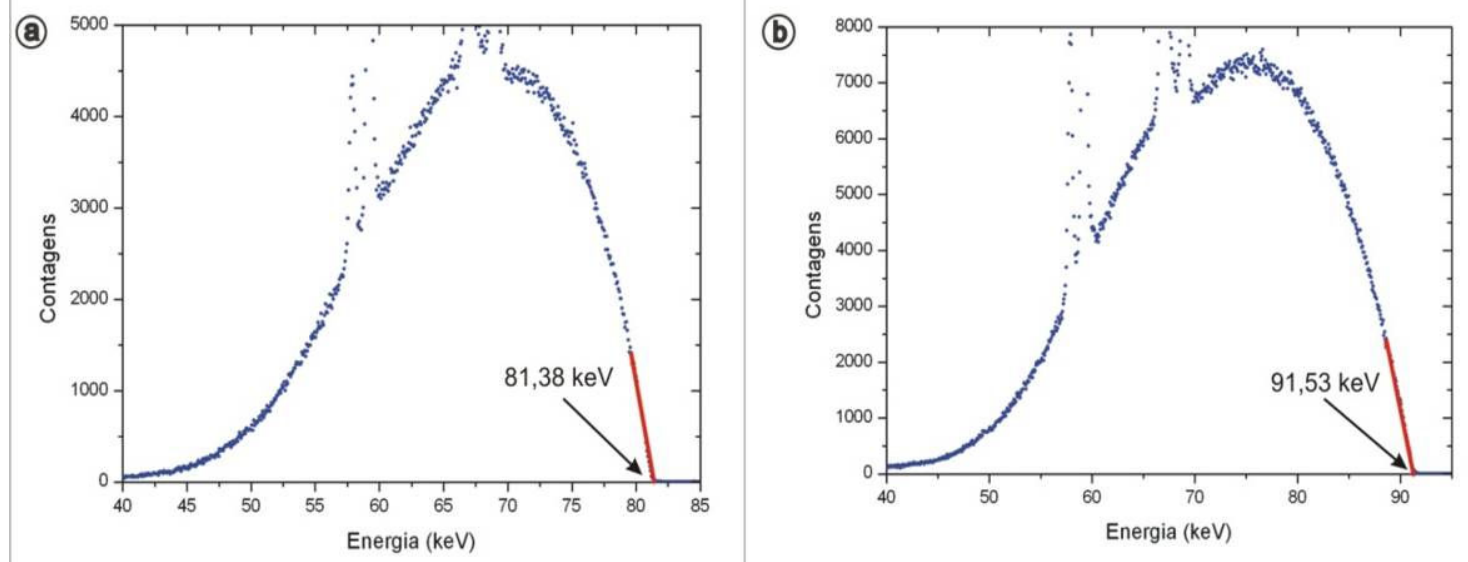

FIGURA 63 - Espectros de a) $80 \mathrm{kV}$ e b) $90 \mathrm{kV}$ com 2,5 mmCu.
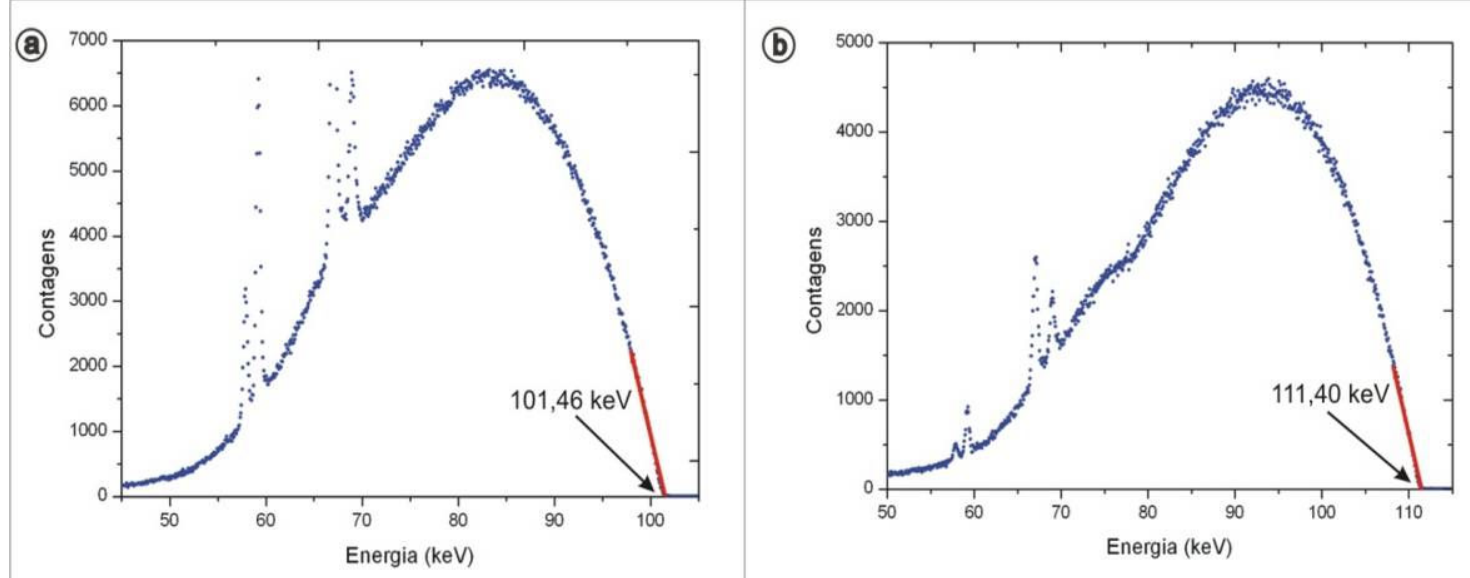

FIGURA 64 - Espectros de a) $100 \mathrm{kV}$ com 3,5 mmCu e b) $110 \mathrm{kV}$ com 5,5 mmCu. 

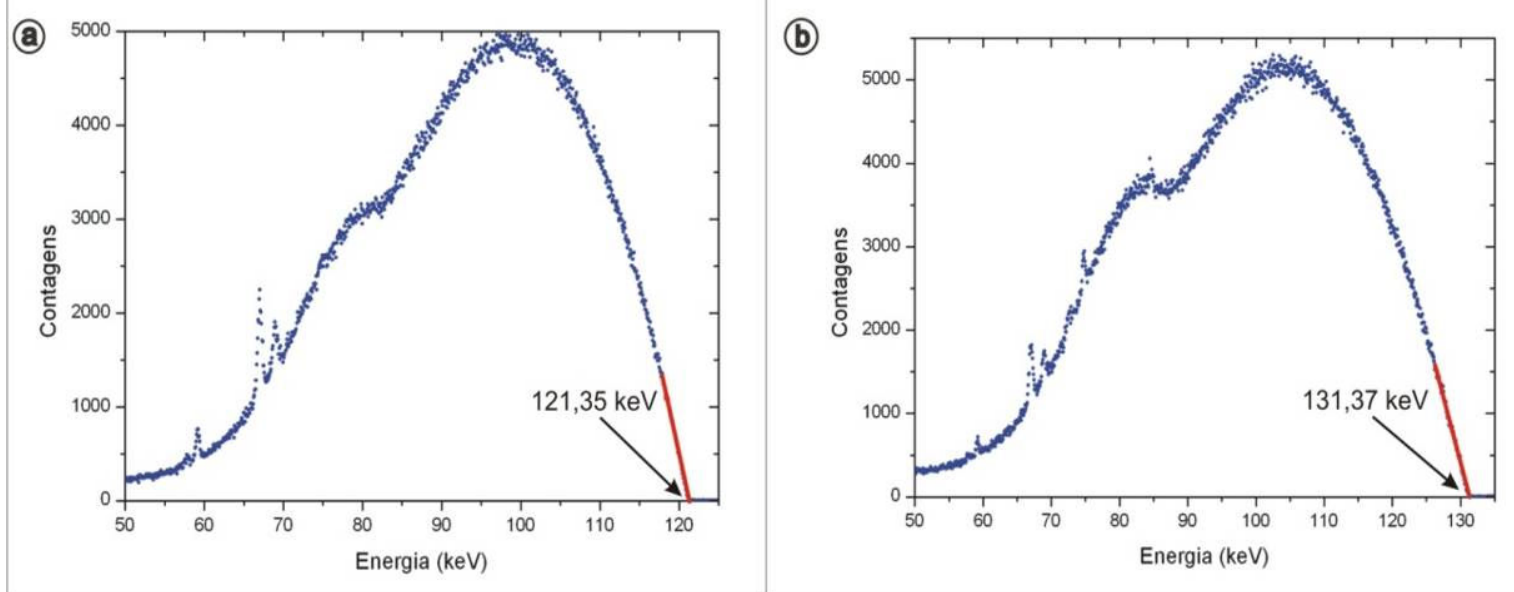

FIGURA 65 - Espectros de a) $120 \mathrm{kV}$ com 6 mmCu e b) $130 \mathrm{kV}$ com 6,5 mmCu.
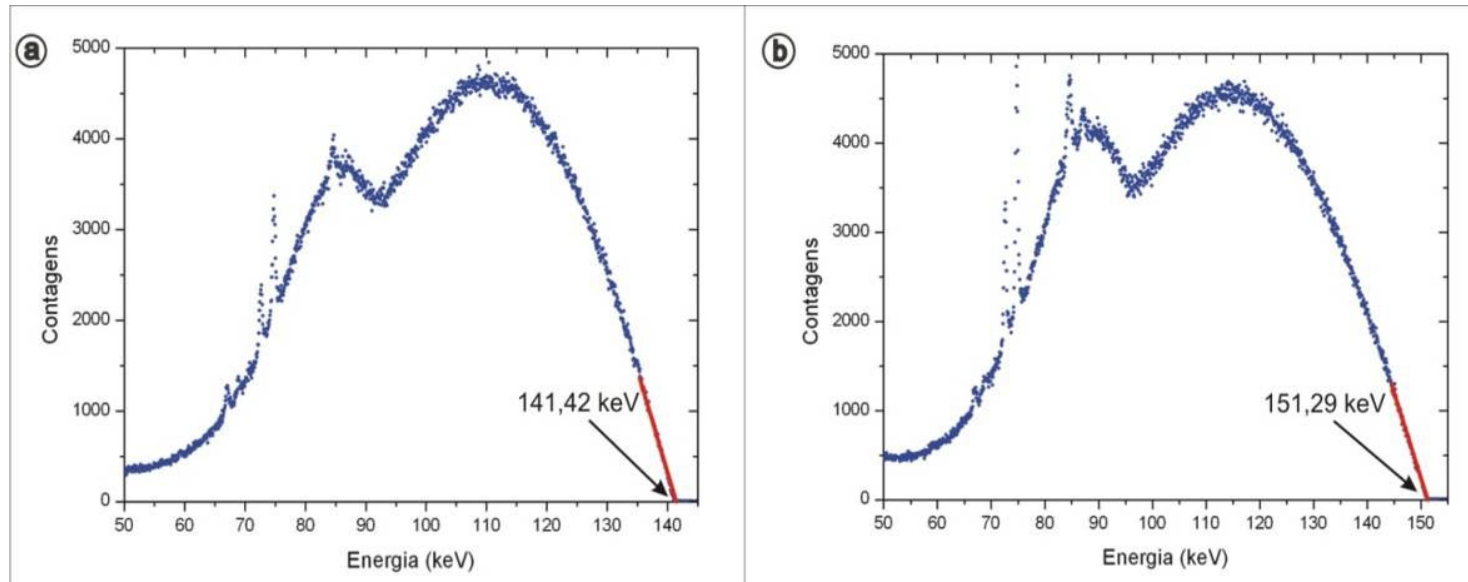

FIGURA 66 - Espectros de a) $140 \mathrm{kV}$ com 7 mmCu e b) $150 \mathrm{kV}$ com $8 \mathrm{mmCu}$.

As retas vermelhas presentes nos espectros referentes às determinações das tensões de pico foram plotadas pelo software Origin e representam ajustes lineares efetuados nos últimos pontos das curvas dos espectros. Essas retas, ao cruzarem o eixo $\mathrm{x}$, fornecem, indiretamente, os valores das tensões de pico em todos os espectros (o valor numérico da energia determinada equivale ao valor da tensão de pico em kV). Como os últimos pontos não estão alinhados com as retas vermelhas, há dispersões dos pontos em relação a essas retas que gerarão incertezas em todos as tensões de pico determinadas. Na TAB. 15 são mostrados os valores das tensões de pico e suas respectivas incertezas. Os pontos para os ajustes das retas foram escolhidos empiricamente através de uma sequência de ajustes em um mesmo espectro, onde para cada ajuste era aumentado o número de pontos escolhidos. Os ajustes escolhidos foram os anteriores aqueles cujas as 
incertezas começaram a aumentar devido à curvatura acentuada no final do espectro.

TABELA 15 - Tensões de pico determinadas por espectrometria e energia médias por fóton de cada espectro.

\begin{tabular}{cccc}
\hline $\begin{array}{c}\text { Tensão } \\
\text { Nominal }(\mathrm{kV})\end{array}$ & $\begin{array}{c}\text { Filtração } \\
(\mathrm{mm})\end{array}$ & $\begin{array}{c}\text { Tensão de } \\
\text { Pico }(\mathrm{kV})\end{array}$ & $\begin{array}{c}\text { Energia média } \\
\text { por fóton }(\mathrm{keV})\end{array}$ \\
\hline 25 & $2(\mathrm{Al})$ & $26,23 \pm 1,41$ & 20,41 \\
28 & $2(\mathrm{Al})$ & $29,21 \pm 0,97$ & 22,02 \\
30 & $3(\mathrm{Al})$ & $31,20 \pm 0,49$ & 24,08 \\
35 & $3(\mathrm{Al})$ & $36,23 \pm 0,72$ & 26,66 \\
40 & $10(\mathrm{Al})$ & $41,20 \pm 0,89$ & 33,15 \\
50 & $10(\mathrm{Al})$ & $51,33 \pm 0,86$ & 38,18 \\
60 & $16(\mathrm{Al})$ & $61,36 \pm 1,02$ & 45,16 \\
70 & $21(\mathrm{Al})$ & $71,30 \pm 1,14$ & 58,72 \\
80 & $2,5(\mathrm{Cu})$ & $81,38 \pm 1,46$ & 64,55 \\
90 & $2,5(\mathrm{Cu})$ & $91,53 \pm 1,17$ & 68,52 \\
100 & $3,5(\mathrm{Cu})$ & $101,46 \pm 1,10$ & 74,56 \\
110 & $5,5(\mathrm{Cu})$ & $111,40 \pm 1,22$ & 80,97 \\
120 & $6(\mathrm{Cu})$ & $121,35 \pm 1,09$ & 84,25 \\
130 & $6,5(\mathrm{Cu})$ & $131,37 \pm 1,06$ & 87,10 \\
140 & $7(\mathrm{Cu})$ & $141,42 \pm 0,92$ & 89,79 \\
150 & $8(\mathrm{Cu})$ & $151,29 \pm 1,06$ & 91,69 \\
\hline
\end{tabular}

As tensões de pico determinadas foram comparadas com a norma IEC 61676 (2002), onde foi constatado que os erros intrínsecos relativos apresentam valores menores que $1 \%$, ou seja, os resultados obedecem ao critério exigido pela norma. As incertezas relativas estimadas representam menos que $2,5 \%$ dos valores das tensões de pico, mostrando que esse método de espectrometria com ajuste linear é um método preciso por fornecer resultados com pequenos intervalos de incertezas.

Observando cuidadosamente todos os valores das tensões de pico, notase que eles apresentam um deslocamento de 1,20 a 1,46 kV acima das tensões nominais. Como os valores são próximos, isso pode significar que o aparelho de raios $X$ esteja apresentando um erro sistemático e caso haja uma tendência de 
aumento nesses valores com o decorrer do tempo, futuramente eles deverão ser corrigidos por meio da diminuição dos valores de tensão nominal no painel de controle e verificação da resposta da tensão de pico por meio do sistema de espectrometria.

Pela TAB. 15, nota-se ainda, que com o aumento considerável das filtrações, em relação às Qualidades em Radiodiagnóstico, as energias médias por fóton aumentam também consideravelmente, assim como devido às trocas dos filtros de alumínio pelos de cobre nas energias acima de $70 \mathrm{kV}$, já que o cobre apresenta uma densidade maior e barra com maior eficiência os fótons de baixa energia.

É importante salientar que com o aumento da filtração ou da troca do material da filtração por um material mais denso, os filtros passam a absorver fótons mais energéticos. Todas as vezes que foram mencionados os fótons de baixa energia nesse trabalho, 0 intuito foi denominar os fótons que se encontravam no início das curvas dos espectros. Portanto, com o aumento da tensão nominal, as energias desses fótons se deslocaram para a direita tornando os fótons mais energéticos, onde uma filtração mais espessa ou mais densa mostrou-se necessária para poder barrá-los.

Nas três configurações para a geração dos espectros nesse trabalho, o estudo das energias médias por fóton em cada caso foi de importância significativa, pois ele mostrou que o uso de filtrações nos aparelhos de raios $X$ contribui de forma significativa na energia média do feixe de raios $X$, já que uma mesma dose recebida por um paciente ou registrada por um detetor possui energias médias distintas com o uso de filtrações com materiais e espessuras diferentes. Logo, essas energias podem ser manipuladas indiretamente de acordo com o interesse do operador do aparelho de raios $X$.

\subsection{Comparação entre os Valores Obtidos para a Tensão de Pico (Diavolt e Espectrômetro)}

Os valores de tensão de pico obtidos pelo medidor Diavolt e pelo sistema de espectrometria são mostrados na TAB. 16. 
TABELA 16 - Valores de Tensão de Pico obtidos pelo espectrômetro e pelo medidor Diavolt.

\begin{tabular}{ccccc}
\hline \multirow{2}{*}{$\begin{array}{c}\text { Tensão } \\
\text { Nominal }(\mathrm{kV})\end{array}$} & $\begin{array}{c}\text { Filtração } \\
(\mathrm{mm})\end{array}$ & $\begin{array}{c}\text { Tensão de } \\
\text { Pico }(\mathrm{kV})\end{array}$ & $\begin{array}{c}\text { Filtração } \\
(\mathrm{mm})\end{array}$ & $\begin{array}{c}\text { Tensão de } \\
\text { Pico }(\mathrm{kV})\end{array}$ \\
\hline 25 & $2(\mathrm{Al})$ & $26,23 \pm 1,41$ & - & - \\
28 & $2(\mathrm{Al})$ & $29,21 \pm 0,97$ & - & - \\
30 & $3(\mathrm{Al})$ & $31,20 \pm 0,49$ & - & - \\
35 & $3(\mathrm{Al})$ & $36,23 \pm 0,72$ & - & - \\
40 & $10(\mathrm{Al})$ & $41,20 \pm 0,89$ & 2,3 & $43,96 \pm 1,13$ \\
50 & $10(\mathrm{Al})$ & $51,33 \pm 0,86$ & 2,4 & $52,48 \pm 1,35$ \\
60 & $16(\mathrm{Al})$ & $61,36 \pm 1,02$ & 2,7 & $62,30 \pm 1,60$ \\
70 & $21(\mathrm{Al})$ & $71,30 \pm 1,14$ & 2,8 & $72,40 \pm 1,86$ \\
80 & $2,5(\mathrm{Cu})$ & $81,38 \pm 1,46$ & 3,0 & $82,93 \pm 2,12$ \\
90 & $2,5(\mathrm{Cu})$ & $91,53 \pm 1,17$ & 3,1 & $92,73 \pm 2,37$ \\
100 & $3,5(\mathrm{Cu})$ & $101,46 \pm 1,10$ & 3,2 & $102,90 \pm 2,63$ \\
110 & $5,5(\mathrm{Cu})$ & $111,40 \pm 1,22$ & - & - \\
120 & $6(\mathrm{Cu})$ & $121,35 \pm 1,09$ & 3,5 & $123,13 \pm 3,14$ \\
130 & $6,5(\mathrm{Cu})$ & $131,37 \pm 1,06$ & - & - \\
140 & $7(\mathrm{Cu})$ & $141,42 \pm 0,92$ & - & - \\
150 & $8(\mathrm{Cu})$ & $151,29 \pm 1,06$ & 4,2 & - \\
\hline
\end{tabular}

$\mathrm{Na}$ análise efetuada das determinações das tensões de pico foi verificado que os valores encontrados respeitam os erros intrínsecos relativos recomendados pela norma IEC 61676 (2002), com exceção da medição na tensão nominal de $50 \mathrm{kV}$ do medidor Diavolt que apresentou um valor ligeiramente acima do recomendado. Os valores finais derivados do medidor Diavolt apresentaram grandes intervalos nas incertezas, o que fez com que a norma fosse respeitada na maioria dos casos. No entanto, essas grandes incertezas impossibilitam fazer um estudo detalhado da determinação das tensões de pico, devido à baixa precisão resultante da análise dos dados. Já os valores derivados da espectrometria apresentaram os menores erros intrínsecos relativos e também as menores incertezas. Essas baixas incertezas mostraram que o método empregado para a determinação das tensões de pico por ajuste linear nas curvas dos espectros é mais preciso, possibilitando um estudo mais detalhado desses 
valores. Por essa análise, conclui-se que o medidor Diavolt pode ser usado para a determinação dos valores da grandeza tensão de pico rotineiramente, pois sua vantagem é a praticidade e rapidez na realização das medições. O sistema de espectrometria não possui essas últimas vantagens, porém pode ser utilizado para um estudo mais detalhado da grandeza tensão de pico devido a sua precisão e confiabilidade. 


\section{CONCLUSÕES}

O controle de qualidade realizado nesse trabalho foi de grande importância para um melhor entendimento do comportamento dos instrumentos envolvidos durante os processos de aquisição de dados, bem como suas limitações técnicas e limitações presentes nos arranjos experimentais. Além dessas verificações, os testes possibilitaram constatar as melhores condições para as realizações das medições das três grandezas estudadas, assim como a necessidade de ajustes na logística empregada.

O teste de homogeneidade mostrou que o campo de radiação se apresenta de maneira uniforme em uma mesma distância e que não há necessidade de alterar a posição do tubo, já que não foi constatado o efeito anódico. Além disso, foi possível varrer os campos em intervalos suficientes para assegurar que qualquer detetor posicionado nas duas distâncias tenha o seu volume sensivel exposto completamente à radiação incidente. Foi constatado, ainda, que o sistema laser de referência para o posicionamento dos detetores em relação ao sistema de radiação $X$ está deslocado nos eixos $x$ e y e necessita ser ajustado para que qualquer detetor seja posicionado de maneira mais precisa no campo de radiação.

Nos testes realizados com o medidor não invasivo Diavolt, verificou-se que as incertezas presentes nos valores medidos são altos devido, principalmente, as limitações técnicas do aparelho juntamente com o alto erro cedido pela calibração do medidor. No entanto, os valores medidos pelo Diavolt atenderam a norma IEC 61676 na maioria das vezes, mostrando ser um aparelho confiável, mesmo não sendo tão preciso. Nos testes de dependência angular, de corrente, de tensão e de distância, os resultados apresentados estiveram de acordo com as tendências esperadas na literatura, onde essas tendências representadas por funções polinomiais ou alométricas foram confirmadas por serem abrangidas pelas barras de incertezas dos valores medidos. Portanto, foi constatado que não há nenhuma fonte de ruído interna ou externa ao processo de aquisição de dados interferindo de modo significativo nas medições efetuadas, assim como problemas técnicos no sistema de radiação e no medidor Diavolt. A única exceção é feita na análise 
da tensão de pico em função da distância, onde foi constatado que, diferentemente do esperado, a medida da tensão de pico apresenta uma leve tendência de aumento com o aumento da distância, o que permitiu concluir que para efetuar medições mais satisfatórias, o medidor deve ser posicionado o mais próximo possível do ponto focal do aparelho de raios $X$. Já no teste de dependência angular, foi mostrado que o medidor Diavolt mantém-se estável mesmo quando rotacionado até $9^{\circ}$ no sentido horário ou anti-horário. A partir dessa angulação, as medições ficam mais instáveis, pois os desvios padrões aumentam significativamente e os valores medidos se afastam, cada vez mais, dos valores esperados.

A análise dos espectros realizados com configurações distintas mostrou que com a utilização de filtração, ou aumento da mesma, os fótons de menor energia são filtrados e a energia média do feixe de raios $X$ aumenta, o mesmo ocorrendo quando adicionado filtrações com elementos mais densos. Isso possibilita ao operador do aparelho de raios $X$ ajustar a energia média do feixe sem precisar alterar a tensão nominal no aparelho. Devido, também, a essa alteração na filtração foi visto que as formas dos espectros mudaram e alguns dos picos característicos (menos energéticos) são filtrados, como era esperado. Dessa forma, os espectros referentes às Qualidades em Radiodiagnóstico foram gerados possibilitando o conhecimento da distribuição energética dos fótons em função de suas contagens. Por último, foram determinadas as tensões de pico por ajuste linear, que mostrou ser um método mais preciso e confiável, em relação as medições do Diavolt, já que as margens de incerteza foram bem menores que as do Diavolt, assim como os erros intrínsecos relativos que estiveram sempre abaixo de 2\%, obedecendo a norma IEC 61676 (2002) adaptada para a grandeza tensão de pico.

Os testes de qualidades efetuados nesse trabalho podem ser empregados em outros sistemas de radiação $X$, bem como melhorados e complementados. Além disso, recomenda-se que os testes sejam feitos regularmente para que seja possível acompanhar modificações no decorrer do tempo no funcionamento do sistema de radiação $X$ e dos detetores empregados durante os testes. As rotinas desses testes são sugeridas no ANEXO D dessa dissertação, assim como os procedimentos básicos para efetuá-las de maneira satisfatória. 


\section{REFERÊNCIAS BIBLIOGRÁFICAS}

1. BETTI, F. Desenvolvimento e implementação de um programa de controle e aquisição de dados na calibração de instrumentos em radiodiagnóstico. São Paulo: 2007. Dissertação (Mestrado) - Instituto de Pesquisas Energéticas e Nucleares - USP.

2. BIRCH, R.; MARSHALL, M. Catalougue of spectral data for diagnostic X-rays. The Hospital Physicists` Association. London, 1979.

3. BOAG, J.W. Ionization chambers. In: KASE, K.R., BJÄRNGARD, B.E., ATTIX, F.H. The dosimetry of ionizing radiation. Orlando, FL: Academic Press Inc., 1987. V.2. p. 169-243.

4. BUSHONG, S.G., Radiologic Science for Technologists - Physics, Biology, and Radiation Protection. $6^{\text {th }}$ edition, Missouri: Mosby Company, 1997.

5. Center for Devices and Radiological Health, Initiative to Reduce Unnecessary Radiation Exposure from Medical Imaging. CDRH, U.S. Food and Drug Administration, 2010.

6. CORREA, E.L., LUCENA, R.F., VIVOLO, V., POTIENS, M.P.A. Comparação de Espectros de Raios x Gerados por um Alvo de W e Filtração Adicional de Mo e Al para Aplicações em Metrologia na Mamografia. XIV Congresso Brasileiro de Física Médica. São Paulo, 2009.

7. COSTA, A. M. da.; CALDAS, L. V. E. A special ionization chamber for quality control of diagnostic and mammography X-ray equipment. Radiat. Prot. Dosim., v.104, n. 1, p. 41-45, 2003.

8. CURRY III, T.S., DOWDEY, J.E., MURRY JR., R.C. Christensen's physics of diagnostic radiology. $4^{\text {th }}$ Ed. Media, PA: Williams \& Wilkins, 1990.

9. EISBERG, R., RESNICK, R. Física Quântica - Átomos, Moléculas, Sólidos, Núcleos e Partículas. Rio de Janeiro: Elsevier, 1979.

10.FRANCISCATTO, P. C. Caracterização das Qualidades de Radiação X Seguindo as Recomendações da Norma IEC 61267 no Laboratório de 
Calibração do IPEN. 2009. São Paulo. Dissertação (Mestrado) - Instituto de Pesquisas Energéticas e Nucleares, Universidade de São Paulo.

11.GIARRATANO, J.C., WAGGENER, R.G., HEVEZI, J.M., SHALEK, R.J. Comparison of Voltage - Divider, Modified Ardran - Crooks Cassete, and $\mathrm{Ge}(\mathrm{Li})$ Spectrometer Methods to determine the Peak kilovoltage $(\mathbf{k V p )}$ of Diagnostic X-Ray Units. Medical Physics, V. 3, N.3, 1976.

12. HENDEE, R. W., RITENOUR, E. R. Medical Imaging Physics. $4^{\text {th }}$ edition, Wiley-Liss. New York, 2002.

13.INSTITUTO NACIONAL DE METROLOGIA, NORMALIZAÇÃO E QUALIDADE INDUSTRIAL (INMETRO), Guia para a expressão da incerteza de medição. Rio de Janeiro, 2003.

14.INTERNATIONAL ATOMIC ENERGY AGENCY. Calibration of dose meters used in radiotherapy. IAEA, Vienna, 1979 (Technical Reports Series No. 185).

15.INTERNATIONAL ATOMIC ENERGY AGENCY. Absorbed dose determination in photon and electron beams. Na international code of practice. IAEA, Vienna, 1987 (Technical Reports Series No. 277).

16.INTERNATIONAL ATOMIC ENERGY AGENCY. Review of data and methods recommended in the international code of practice: IAEA Technical Reports Series No. 277 - Absorbed dose determination in photon and electron beams. Proceed. Consultants Meeting IAEA, Vienna, 8-11 Dec. 1992 (TEC-DOC 897).

17.INTERNATIONAL ATOMIC ENERGY AGENCY. Calibration of dosimeters used in radiotherapy. IAEA, Vienna, 1994 (Technical Reports Series No. 374).

18. INTERNATIONAL ATOMIC ENERGY AGENCY. Dosimetry in Diagnostic Radiology: An International Code of Practice. IAEA, Vienna, 2007 (Technical Reports Series No 457).

19. INTERNATIONAL ATOMIC ENERGY AGENCY. The use of plane parallel ionization chambers in high energy electron and photon beams - An international code of practice for dosimetry. IAEA, Vienna, 1997 (Technical Reports Series No. 381). 
20.INTERNATIONAL COMMISSION ON RADIOLOGICAL PROTECTION. Recommendations of the ICRP. Publication No 26. ICRP, 1987.

21.INTERNATIONAL COMMISSION ON RADIOLOGICAL PROTECTION. Recommendations of the ICRP. Publication No 60. ICRP, 1991.

22.INTERNATIONAL ELECTROTECHNICAL COMISSION, Medical Diagnostic Equipment - Radiation Conditions for use in the Determination of Characteristics, Geneva, 1994. (IEC 61267).

23. INTERNATIONAL ELECTROTECHNICAL COMISSION, Dosemeters with Ionization Chambers as Used in Radiotherapy, Geneva, 2005. 2nd (IEC $60731 \mathrm{Ed} .2)$.

24. INTERNATIONAL ELECTROTECHNICAL COMISSION, Medical Electrical Equipment - Dosimetric Instruments Used for Non-Invasive Measurement of X-Ray Tube Voltage in Diagnostic Radiology, Geneva, 2002. (IEC 61676).

25. INTERNATIONAL ORGANIZATION FOR STANDARDIZATION. $\mathbf{X}$ and gamma reference radiations for calibrating dosemeters and dose ratemeters and for determining their response as a function of photon energy. PART 1: Characteristics of the radiation and their methods of production [Revision of first edition (ISO 4037:1979)]. Aug. 1997 (Final Draft International Standard ISO/DIS 4037 - 1).

26.JOHNS, H.E. The Physics of radiology. 3a ed. Charles C Thomas Publisher, Springfield, Ilinois, USA, 1974.

27.KHAN, F.M. The physics of radiation therapy. 2. Ed. Baltimore, MD. Willians, 1994.

28.KODAK. Elementos de Radiografia. Publicação Kodak M1-18. Eastman Kodak Company, USA, 1980.

29.KRAMER, H.M.; SELBACH, H.J.; ILES, W.J. The Practical Peak Voltage of Diagnostic X-Ray Generators. Brit. J. Radiol., v.71, p. 200-209. 1998.

30.LABORATÓRIO NACIONAL DE METROLOGIA DAS RADIAÇÕES IONIZANTES. Requisitos para operação de laboratórios de calibração de instrumentos de medição para radiação ionizante usados em radioproteção. IRD/CNEN. CRIOLAB06.DOC - revisão 2004. 
31.MAIA, A. F. Padronização de feixes e metodologia dosimétrica em tomografia computadorizada. 2005. São Paulo. Tese (Doutorado) Instituto de Pesquisas Energéticas e Nucleares, Universidade de São Paulo.

32. MARSHALL, B.; ARDRAN, G.M. Catalogue of Spectral data for diagnostic X-rays. Scientific Report Series. The Hospital Physicists` Association. London, 1979.

33. MINISTÉRIO DA SAÚDE. ANVISA. Portaria Federal 453. Diretrizes básicas de Proteção Radiológica em Radiodiagnóstico Médico e Odontológico. Brasília: Diário Oficial da União. Julho de 1998.

34. OLIVEIRA, M. L.; CALDAS, L. V. E. A special mini-extrapolation chamber for calibration of ${ }^{90} \mathrm{Sr}+{ }^{90} \mathrm{Y}$ sources. Phys. Med. Biol., v.50, p. 2929-2936, 2005.

35. OLIVEIRA, P.M.C. Análise de parâmetros característicos de feixes de raios X diagnóstico para calibração de dosímetros. 2008. Dissertação (Mestrado) - Universidade Federal de Minas Gerais (UFMG).

36.POTIENS, M. P. A. Metodologia dosimétrica e sistema de referência para radiação-X nível diagnóstico. São Paulo: 1999. Tese (Doutorado) Instituto de Pesquisas Energéticas e Nucleares - USP.

37.RAMOS, M. M. O. Padronização de grandeza kerma no ar para radiodiagnóstico e proposta de requisitos para laboratórios de calibração. Rio de Janeiro: 2009. Tese (Doutorado) - Universidade Federal do Rio de Janeiro.

38.ROS, R. A. Metodologia de controle de qualidade de equipamentos de raios $X$ (nível diagnóstico) utilizados em calibração de equipamentos. São Paulo: 2000. Dissertação (Mestrado) - Instituto de Pesquisas Energéticas e Nucleares - USP.

39.SPRAWLS, P. Principles of radiography for technologists. Maryland: An Aspen Publication, 1990. 
40.TSOULFANIDIS, N. Measurement and Detection of Radiation. 2a ed. Missouri: Taylor \& Francis, 1995.

41.VIVOLO, V. Desenvolvimento de um sistema de referência para determinação do equivalente de dose pessoal e da constância de feixes de radiação-X. São Paulo: 2006. Tese (Doutorado) - Instituto de Pesquisas Energéticas e Nucleares - USP.

42.WOLBARST, A.B. Physics of radiology. Norwalk: Appleton \& Lange, 1993. 


\section{ANEXO A \\ Certificado de Calibração \\ do aparelho Diavolt \\ (2007)}


KALIBRIERSCHEIN NR.

Calibration Certificate No. 0713503

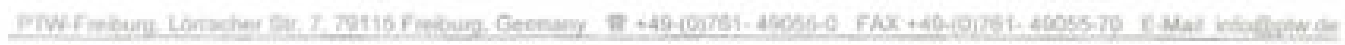

\section{Kalibriergegenstand / Calibration Object}

Nicht-imasives KV-Messgerat und Dosimeter / Non-invasive KV-Meter and Doaimeter

DIAVOLT UNIVERSAL

Hersteller I Manufacturer

Auftraggeber 1 Customer

Auftragsnummer 1 Order No Auftragsdatum / Order Date
T43014-01153

PrW-Freiburg

CNEN - Comissao Nacional de Energia Nuclear

Avenida Prof. Lineu Prestes, 2.242

Cidade Universitaria

05508-000 Sao Paulo - SP - Brasil

Ergobnis dor Kalibrierung / Calibration Results

\begin{tabular}{|c|c|c|}
\hline $\begin{array}{l}\text { Messgrobe I } \\
\text { Measiting Quantity }\end{array}$ & $\begin{array}{l}\text { PPV } \\
\text { a practical peak wotage / IEC } 61676\end{array}$ & Kar (Luftiema / Air Kerm \\
\hline $\begin{array}{l}\text { Messergebnis in I } \\
\text { Measurement result in }\end{array}$ & kV & Gy \\
\hline $\begin{array}{l}\text { Kalibrierfaktor I } \\
\text { Calbration Factor }\end{array}$ & $N_{m v}=1,00$ & $N_{k}=1,00$ \\
\hline $\begin{array}{l}\text { Unsicherhet der Kalibrierung } t \\
\text { Uncertainty of caiburation }\end{array}$ & $\begin{array}{l}\varepsilon=2 \% \\
(\epsilon \leq 1 \mathrm{KV} \text { for } f \text { af } \mathrm{PFV}<40 \mathrm{KV})\end{array}$ & $t=2 \%$ \\
\hline $\begin{array}{l}\text { Kalbrierdatum } f \\
\text { Calibration Date }\end{array}$ & 28.09 .2007 & \\
\hline $\begin{array}{l}\text { Emplohlenes Rekalbrierinterval I } \\
\text { Recommended rocalibration interval }\end{array}$ & 2 Jahre 12 yoars & \\
\hline $\begin{array}{l}\text { Messbereiche und Strahlenqualitaten / } \\
\text { Moasuwing range and racfiation qualities }\end{array}$ & \multicolumn{2}{|c|}{$\begin{array}{l}\text { konventionel / conventional. }[40,150] \mathrm{kV} \text {. [ROR2, RQR 10] } \\
\text { MAM / MAM : [22. } 40] \mathrm{KV} \text {. [RQR-M 1. RQR -M 4] }\end{array}$} \\
\hline & W-Anode $[40,150] \mathrm{kV}$ & Mo-Anode $[22.40] \mathrm{kV}$ \\
\hline Anodemwinkel / Anode Angle & $12^{*}$ & $20^{\circ}$ \\
\hline HV Wellenform / HV Waveform & CP (constant potential) & HF (high frequency) \\
\hline Feldgroce I Fieid Size & $12 \mathrm{~cm} \times 12 \mathrm{~cm}$ & $16 \mathrm{~cm} \times 16 \mathrm{~cm}$ \\
\hline Fokusabstand / Focal Distance & $50 \mathrm{~cm}$ & $60 \mathrm{~cm}$ \\
\hline Belichtungszeit / trradiation Time & $0,4 \mathrm{~s}$ & $0.4 \mathrm{~s}$ \\
\hline
\end{tabular}

PTW-Freburg

Freiburg, den 28.09 .2007

Physikalisch-Technische

Werkstattep Dr. Pychlau GmbH

Seite $1 / 2$, page $1 / 2$

(Unterschph / Signature) 


\section{Kalibrierbedingungen und Aufbau / Calibration Conditions and Set-up}

$\begin{array}{lllll}\text { Klimatische Bedingungen / } & \text { Temperaturbereich / Temperature Range } & {[18 \ldots 24]^{\circ} \mathrm{C}} \\ \text { Climatic Conditions } & \text { Luftdruck } & \text { I Air Pressure Range } & {[950 \ldots 1050] \mathrm{hPa}} \\ & \text { Relative Lufteuchte I Relative Humidity Range } & {[40 \ldots 60] \%}\end{array}$

Anordnung im Strahlenfeld / Die Oberseite des Gerats zeigte zur Strahlenquelle /

Arrangement in radiation field The top side of the instrument faced towards the radiation source

Bezugsort am Gerat I

siehe Gebrauchsanweisung / refer to user manual

Reference point of device

Strahiungsqualitaten /

RQR und RQR-M Qualitaten gemaß IEC 61267

Beam Qualities $R Q R$ und $R Q R-M$ qualities according to IEC 61267

Invasive kV-Referenz I Invasive $k V$-reference

DYNALYZER III A HVU

(SN 73-05-1-1523, Cert. No. 14327) for $/$ for $[40 \ldots 150] \mathrm{kV}$

DYNALYZER II HVU

for $/$ for $[22 \ldots 40] \mathrm{kV}$

(SN 61-06-8-0124, Cert

Dosis und Dosisleistung /

$[4.0 \ldots 55] \cdot 10^{3} \mathrm{~Gy}$

Dose and Dose Rate

$[0.3 \ldots 8.0]$ Gy/min

Bemerkungen / Remarks

1. Die angegebene Unsicherheit entspricht der 2 -fachen Standardabweichung $(k=2)$. Die Unsicherheit der Kalibrierung wurde entsprechend ISO GUM aus den Teilunsicherheiten der Normale, des Kalibrierverfahrens, der Umgebungsbedingungen und des Kurzzeitverhaltens des Gerats berechnet. Die Gesamtunsicherheit einer Messung setzt sich zusammen aus der Unsicherheit der Kalibrierung und allen Unsicherheiten, die durch ein Abweichen von den Referenzbedingungen bedingt sind. Ein Anteil fur die Langzeitinstablitat des Proflings ist nicht enthalten. I

The uncertainty stated corresponds to the double standard deviation $(\mathrm{k}=2)$. The uncertainty of the calibration was calculated according to ISO GUM from the partial uncertainties arising from the standards used, the calibration procedure, the environmental conditions and short time effocts of the object of measurement. The overali uncertainy of a measurement is composed of the uncertainty of the calibration as well as uncertainty contributions that are causod by deviations from the reference conditions. A share for the long term instability of the object under calibration is not included.

2. Die Kalibrierung ist rûckfuhrbar auf Normale der Physikalisch Technischen Bundesanstalt (PTB), Braunschweig und des National institute of Standards and Tochnology, USA (NIST). Unvollstandige oder auszugsweise Wiedergabe dieses Kalibrierscheins bedarf der Genehmigung des ausstellenden Labors Dieser Kalibrierschein gilt nur im Zusammenhang mit dem unverletzten Aunkleber mit der

Kalibrierscheinnummer. Die Kalibrierung von Geraten, die zur Reparatur geoffnet wurden, sind mit fruheren Kalibrierungen nicht vergleichbar. Kalibrierscheine ohne Unterschrift sind ungoltig. I

The calibration of all kV-reference components is traceable to national standards of the German Nationat Laboratory, PTB, Braunschweig and to the National Institute of Standarcs and Technology, USA (NIST). This calibration certificate may not be reproduced other than in full except with the permission of the issuing laboratory. This certificate is valid only with the instrument showing the intact sticker with the certificate number. The calibration of instruments having been opened for repair are not comparable fo previous calibrations. Calibration cortificates without signature are not valid. 


\section{ANEXO B \\ Certificado de Calibração Do Medidor \\ Diavolt Para a Grandeza \\ Kerma no ar \\ (2010)}


Data da Calibração: 13/04/2010

Cliente

Nome: Instituto de Pesquisas Energéticas e Nucleares.

CNPJ: 00.402.552/0005-50

Endereço: Av. Prof. Lineu Prestes, 2242.

Cidade: São Paulo

UF: SP

\section{Identificação do Instrumento}

Tipo do detector : Medidor de Radiação X Diagnóstico Fabricante: PTW

Modelo: Diavolt Universal

Série: $\quad$ 43014-01153

Patrimônio: --

Tipo da sonda: Interna Fabricante:

Modelo:

Série:

Patrimônio:

\section{Procedimento/Método utillizado}

O método utilizado foi o de substituição, sendo que o centro geométrico do detector foi tomado como ponto de referência para a calibração. Os valores medidos foram comparados com os valores de referência, ou valor verdadeiro convencional (VVC) obtidos com o instrumento padrão do LCl, conforme procedimento PO-LCl-0904.

A radiação- $X$ foi proveniente de uma máquina de radiação, marca Pantak/Seifert, modelo Isovolt HS, tubo Comet ( $160 \mathrm{kV})$, e as qualidades utilizadas são aquelas recomendadas pela norma IEC 61267.

As incertezas padrão expandidas declaradas foram calculadas de acordo com as recomendações da Edição Brasileira da ISO GUM, para um fator de abrangência k=2 e nível de confiança de $95,45 \%$.

\section{Ajuste no Instrumento}

Não foi realizado.

\section{Condições Ambientais durante a Calibração}

Temperatura: $18,4^{\circ} \mathrm{C}$

Pressão: $\quad 93,2 \mathrm{kPa}$

Umidade Relativa do Ar: $\quad 55 \%$

Data Emissão do Certificado: 13/04/2010

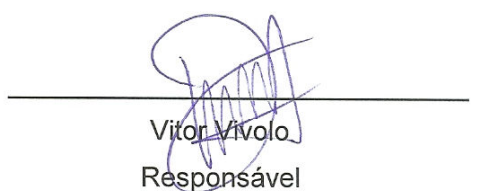

Estes resultados referem-se exclusivamente ao instrumento submetido à calibração, nas condiçöes especificadas no texto desto Certificado, não sendo extensivo a quaisquer outros instrumentos. Sua reproduçấo só poderá ser completa. A reprodução parcial dependerá da autorização formal do gerente do laboratório. 
05. Rastreabilidade

Sistema Padrão Secundário constituído por uma câmara de ionização da Radcal, modelo RC 6, série 16675, e por um eletrômetro Keithley, modelo 6517A, série 0989665, este sistema padrão foi calibrado pelo PTB que é o Laboratório Primário de Radiações lonizantes da Alemanha.

\section{Informações Adicionais}

$\bigotimes \quad$ A grandeza exposição é expressa, no Sistema Internacional (SI), em C/kg e $1 \mathrm{R}=2,58 \times 10^{-4} \mathrm{C} / \mathrm{kg}$.

Os valores de taxa de dose e de dose equivalente ambiental foram encontrados a partir da multiplicação dos valores de kerma no ar pelos fatores em Sv/Gy, conforme Safety Reports Series no.16 (IAEA)

Para as câmaras de ionização não seladas, as leituras devem ser corrigidas pelo fator de correção para a temperatura e pressão ambientais.

07. Resultados:

\begin{tabular}{|c|c|c|c|c|c|c|}
\hline Qualidade & Tensão & $\begin{array}{c}\text { Energia } \\
\text { Efetiva } \\
(\mathbf{k e V})\end{array}$ & $\begin{array}{c}\text { Camada } \\
\text { Semi-Redutora } \\
\text { (m) }\end{array}$ & $\begin{array}{c}\text { Valor } \\
\text { Verdadeiro } \\
\text { Convencional } \\
(\mathbf{m G y / m i n})\end{array}$ & $\begin{array}{c}\text { Indicação } \\
\text { no Instrumento } \\
(\mathbf{G y})\end{array}$ & Incerteza \\
\hline RQR 3 & 50 & 27 & 1,78 & 22,3 & 1,96 & $(\%)$ \\
RQR 5 & 70 & 30 & 2,58 & 38,8 & 3,22 & 1,5 \\
RQR 8 & 100 & 34 & 3,97 & 69,1 & 5,85 & \\
\hline
\end{tabular}

* tempo de medida = 600seg.; filtração selecionada: W/2,5 Al (RQR3), W/3,0 Al (RQR5) e W/3,0 Al (RQR8)

respectivamente para cada qualidade de radiação, corrente $20 \mathrm{~mA}$, distância $50 \mathrm{~cm}$.

Calibração realizada por: Vitor Vivolo

\section{Observações}

Devido às características do instrumento, recomenda-se que seja recalibrado periodicamente, ou no caso de ocorrência de quaisquer danos ou alterações que possam modificar a resposta do instrumento.

Recomenda-se guardar o instrumento em ambiente de baixa umidade sempre que não estiver em uso.

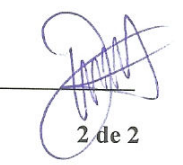


ANEXO C

Funções Ajustadas nos

Testes com o Diavolt 
TABELA C.1 - Parâmetros ajustados no teste de dependência com a variação da Corrente elétrica.

\begin{tabular}{ccccc}
\hline Grandeza & $\begin{array}{c}\text { Tensão } \\
(\mathbf{k V})\end{array}$ & $\begin{array}{c}\text { Função } \\
\text { Ajustada }\end{array}$ & \multicolumn{2}{c}{$\begin{array}{c}\text { Parâmetros } \\
\text { Ajustados }\end{array}$} \\
\hline Kerma no & 70 & $y=a+b x$ & $a=0,147 \pm 0,011$ & $b=3,730 \pm 0,002$ \\
\cline { 2 - 5 } $\operatorname{Ar}(m G y)$ & 120 & $y=a+b x$ & $a=0,285 \pm 0,033$ & $b=8,995 \pm 0,005$ \\
\hline $\begin{array}{c}\text { Tensão de Pico } \\
(k V)\end{array}$ & 70 & $y=a+b x$ & $a=72,888 \pm 0,122$ & $b=-0,033 \pm 0,008$ \\
\cline { 2 - 5 } & 120 & $y=a+b x$ & $a=123,930 \pm 0,111$ & $b=-0,034 \pm 0,008$ \\
\hline $\begin{array}{c}\text { Tensão de Pico } \\
\text { Prático (kV) }\end{array}$ & 70 & $y=a+b x$ & $a=71,559 \pm 0,015$ & $b=0,009 \pm 0,001$ \\
\hline
\end{tabular}

TABELA C.2 - Parâmetros ajustados no teste de dependência com a variação das Qualidades em Radiodiagnóstico.

\begin{tabular}{|c|c|c|c|c|}
\hline Grandeza & $\begin{array}{l}\text { Função } \\
\text { Ajustada }\end{array}$ & & $\begin{array}{l}\text { Parâmetros } \\
\text { Ajustados }\end{array}$ & \\
\hline $\begin{array}{l}\text { Kerma no } \\
\operatorname{Ar}(m G y)\end{array}$ & $y=a+b x+c x^{2}$ & $a=-33,814 \pm 4,628$ & $b=1,385 \pm 0,153$ & $c=0,006 \pm 0,001$ \\
\hline $\begin{array}{c}\text { Tensão de Pico } \\
(\mathrm{kV})\end{array}$ & $y=a+b x$ & $a=3,741 \pm 0,751$ & $b=0,988 \pm 0,011$ & \\
\hline $\begin{array}{c}\text { Tensão de Pico } \\
\text { Prático }(\mathrm{kV})\end{array}$ & $y=a+b x$ & $a=2,417 \pm 0,505$ & $b=0,996 \pm 0,008$ & \\
\hline
\end{tabular}


TABELA C.3 - Parâmetros ajustados no teste de dependência com a variação da Distância.

\begin{tabular}{ccccc}
\hline Grandeza & $\begin{array}{c}\text { Tensão } \\
(k V)\end{array}$ & $\begin{array}{c}\text { Função } \\
\text { Ajustada }\end{array}$ & \multicolumn{2}{c}{$\begin{array}{c}\text { Parâmetros } \\
\text { Ajustados }\end{array}$} \\
\hline Kerma no & 70 & $y=a x^{b}$ & $a=74,068 \pm 0,538$ & $b=-2,043 \pm 0,099$ \\
\cline { 2 - 5 } $\operatorname{Ar}(m G y)$ & 120 & $y=a x^{b}$ & $a=180,159 \pm 0,511$ & $b=-2,032 \pm 0,039$ \\
\hline \multirow{2}{*}{ Tensão de Pico $(k V)$} & 70 & $y=a+b x$ & $a=71,442 \pm 0,198$ & $b=-0,787 \pm 0,103$ \\
\cline { 2 - 5 } & 120 & $y=a+b x$ & $a=122,191 \pm 0,046$ & $b=1,071 \pm 0,023$ \\
\hline Tensão de Pico & 70 & $y=a+b x$ & $a=71,865 \pm 0,160$ & $b=-0,111 \pm 0,082$ \\
\hline Prático $(k V)$ & 120 & $y=a+b x$ & $a=122,042 \pm 0,094$ & $b=-0,282 \pm 0,048$ \\
\hline
\end{tabular}


ANEXO D

Procedimentos de Rotina

Sugeridos 


\section{PROCEDIMENTOS PARA O TESTE DE HOMOGENEIDADE COM A CÂMARA DE IONIZAÇÃO}

Objetivo: Verificar a uniformidade do campo de radiação (se está de acordo com a norma vigente) e o alinhamento dos feixes de laser do sistema de referência do aparelho de raios $X$.

Frequência Mínima: Anualmente ou quando o sistema de radiação $X$ for removido de lugar.

\section{Instrumental}

(1) Câmara de ionização cilíndrica do tipo dedal com volume sensível igual ou inferior a $0,125 \mathrm{~cm}^{3}$.

(2) Sistema de referência para o posicionamento da câmara na linha vertical e horizontal (perpendiculares ao feixe de radiação).

(3) Colimadores na saída do feixe de raios $X$ com as dimensões utilizadas de acordo com as calibrações efetuadas no laboratório

(4) Trena ou régua de aço para a medição do raio do campo de radiação $X$.

(5) Instrumentações para o controle das condições ambientais.

\section{Metodologia}

(1) Posicionar a câmara de ionização em duas distâncias distintas, em relação ao ponto focal do aparelho de raios $X$ (utilização preferencial das distâncias de calibração adotadas no laboratório).

(2) Fazer a varredura do campo nas direções horizontal e vertical com intervalos de $1 \mathrm{~cm}$ partindo-se do centro do campo de radiação (fornecido pelo sistema de referência). Deve-se efetuar 20 medições simétricas na horizontal e na vertical ou quando a intensidade da radiação diminuir próximo a zero devido à delimitação do feixe pelos colimadores. 
(3) Efetuar 10 medições de 60 segundos para cada posicionamento da câmara.

(4) Fazer as devidas correções nas medições da câmara quando observado qualquer variação nas condições ambientais no laboratório.

\section{Resultados}

(1) Plotar os gráficos da intensidade relativa em função das distâncias horizontais e verticais, onde o centro do campo de radiação será considerado a posição zero com $100 \%$ de intensidade relativa.

\section{Interpretação dos Resultados}

(1) Constatar se todas as leituras apresentam intensidade relativa superior a 95\%, de acordo com os Requisitos para Operação de Laboratórios de Calibração de Instrumentos de Medição para Radiação Ionizante Usados em Radioproteção.

(2) Verificar se as intensidades relativas apresentam uma simetria em torno da posição zero, ou seja, se é observado efeito anódico.

(3) Observar se a posição zero do sistema de referência está de acordo com o ponto de simetria dos gráficos. 


\section{PROCEDIMENTOS PARA OS TESTES DE DEPENDÊNCIA COM O MEDIDOR NÃO INVASIVO DIAVOLT}

Objetivo: Verificar se os testes de dependência de corrente elétrica, das Qualidades de Radiação X em Radiodiagnóstico, de distância e angular em função das grandezas kerma no ar, tensão de pico e tensão de pico prático estão de acordo com os resultados esperados pela literatura e se obedecem as devidas normas vigentes.

Frequência Mínima: A cada dois anos ou quando o medidor for calibrado.

\section{Instrumental}

(1) Medidor não invasivo Diavolt Universal.

(2) Filtros adicionais de Alumínio e Cobre com pureza maior que 99,9\%.

(3) Trena ou régua de aço para a medição do raio do campo de radiação $X$.

(4) Transferidor para a medição da angulação do medidor.

(5) Instrumentações para o controle das condições ambientais.

\section{Metodologia}

(1) Configurar 0 aparelho de raios $X$ visando, em cada teste, variar os parâmetros corrente elétrica, Qualidades em Radiodiagnóstico, distância do medidor em relação ao ponto focal do aparelho de raios $X$ e ângulo, respeitando os limites técnicos característicos do medidor.

(2) Efetuar medições de 60 segundos, cada, repetindo-as 10 vezes.

(3) Controlar as condições ambientais de acordo com o manual do medidor.

(4) Adquirir as três grandezas fornecidas pelo medidor e aplicar os devidos fatores de correção. 


\section{Resultados}

(1) Construir tabelas e gráficos das três grandezas estudadas em função dos parâmetros variados estimando as incertezas expandidas de todos os valores partindo-se das incertezas de tipo $A$ e $B$.

(2) Ajustar pelo Método dos Mínimos Quadrados as devidas retas e curvas em todos os gráficos plotados.

\section{Interpretação dos Resultados}

(1) Verificar se o medidor apresenta uma constância em suas incertezas relativas estimadas no decorrer dos testes e se os erros intrínsecos relativos obedecem à norma IEC 61676 (erros intrínsecos relativos inferiores a $2 \%$ ).

(2) Observar se os testes efetuados apresentam tendências esperadas de acordo com a literatura e a partir de possíveis tendências observadas, determinar as melhores condições de uso do aparelho para se obter resultados satisfatórios.

(3) Caso os testes apresentem resultados distorcidos, em relação aos esperados, procurar possíveis fontes de ruídos ou de retro espalhamento presentes no laboratório que podem estar perturbando o campo de radiação. 


\section{PROCEDIMENTOS PARA A GERAÇÃO DE ESPECTROS E DETERMINAÇÃO DAS TENSÕES DE PICO}

Objetivo: Caracterizar os feixes de raios $X$ nas diversas condições de configuração do sistema de radiação $X$ e determinar as tensões de pico por ajuste linear comparando-as com as tensões nominais selecionadas a partir da norma vigente.

Frequência Mínima: Anualmente ou logo após a possíveis manutenções no sistema de radiação $X$ ou do detetor.

\section{Instrumental}

(1) Sistema de espectrometria compatível aos intervalos energéticos utilizados.

(2) Caso necessário, colimador para delimitar o feixe de raios $X$ na janela do espectrômetro.

(3) Filtros adicionais de Alumínio e Cobre com pureza maior que 99,9\%.

(4) Trena ou régua de aço para a medição do raio do campo de radiação $X$.

(5) Instrumentações para o controle das condições ambientais.

\section{Metodologia}

(1) Posicionar o espectrômetro, de preferência, nas posições de calibração.

(2) Inserir as devidas filtrações adicionais no aparelho de raios $X$ referentes à caracterização dos feixes de raios X nas Qualidades de Radiodiagnóstico ou em outras qualidades e às determinações das tensões de pico.

(3) Configurar o aparelho de raios $X$, quando possível, com os mesmos parâmetros utilizados nas calibrações.

(4) Adquirir os espectros com o tempo mínimo de 10 minutos para baixas ou sem filtrações e 50 minutos para altas filtrações (referentes aos espectros para a determinação das tensões de pico). 
(5) Fazer os ajustes lineares (regressão linear) nos finais das curvas dos espectros gerados para as determinações das tensões de pico.

\section{Resultados}

(1) Plotar os espectros em um software que possibilite a manipulação dos valores e que possua o recurso de ajuste pelo método dos mínimos quadrados.

(2) Determinar a energia média por fóton de raios $X$ de cada espectro.

\section{Interpretação dos Resultados}

(1) Verificar se os valores das tensões nominais determinadas obedecem à norma IEC 61676 (erros intrínsecos relativos inferiores a 2\%) e propagar suas incertezas para analisar a precisão do sistema de espectrometria.

(2) Analisar os espectros característicos aos feixes de raios $X$ observando a interferência dos diversos parâmetros (configurados no sistema de radiação $X$ ) nos espectros gerados, bem como na energia média por fóton de raios $X$. 